UNIVERSIDADE DE BRASÍLIA

FACULDADE DE TECNOLOGIA

DEPARTAMENTO DE ENGENHARIA ELÉTRICA

\title{
AVALIAÇÃO DO DESEMPENHO DE UMA PROTEÇÃO DIGITAL DE DISTÂNCIA FRENTE A ALGUNS ALGORITMOS
}

ISA HELENA CASTRO CARRAMASCHI

ORIENTADOR: FRANCISCO DAMASCENO FREITAS

MONOGRAFIA DE GRADUAÇÃO EM ENGENHARIA ELÉTRICA

\author{
PUBLICAÇÃO: ENE-01/2006 \\ BRASÍLIA/DF: MARÇO - 2006
}




\author{
UNIVERSIDADE DE BRASÍLIA \\ FACULDADE DE TECNOLOGIA \\ DEPARTAMENTO DE ENGENHARIA ELÉTRICA
}

\begin{abstract}
AVALIAÇÃO DO DESEMPENHO DE UMA PROTEÇÃO DIGITAL DE DISTÂNCIA FRENTE A ALGUNS ALGORITMOS
\end{abstract}

ISA HELENA CASTRO CARRAMASCHI

MONOGRAFIA SUBMETIDA AO DEPARTAMENTO DE ENGENHARIA ELÉTRICA DA FACULDADE DE TECNOLOGIA DA UNIVERSIDADE DE BRASÍLIA COMO PARTE DOS REQUISITOS NECESSÁRIOS PARA A OBTENÇÃO DO GRAU DE ENGENHEIRO ELETRICISTA

APROVADA POR:

Prof. Francisco Damasceno Freitas , Dr. (ENE-UnB) (Orientador)

Prof. Alcides Leandro da Silva , Mestre. (ENE-UnB)

(Examinador Interno)

Prof.

(Examinador Externo)

BRASÍLIA/DF, 27 DE MARÇO DE 2006 
FICHA CATALOGRÁFICA

CARRAMASCHI, ISA HELENA CASTRO

AVALIAÇÃO DO DESEMPENHO DE UMA PROTEÇÃO DIGITAL DE DISTÂNCIA FRENTE A ALGUNS ALGORITMOS [Distrito Federal] 2006.

x, 77. (ENE/FT/UnB, Engenheiro Eletricista, 2006). Monografia de Graduação Universidade de Brasília. Faculdade de Tecnologia. Departamento de Engenharia Elétrica.

1. Relé digital de distância,zona de atuação

I. ENE/FT/UnB

II. Título (série)

\section{REFERÊNCIA BIBLIOGRÁFICA}

Carramaschi, I. H. C. (2006). Avaliação do desempenho de uma Proteção Digital de

Distância frente a Alguns Algoritmos. Monografia de Graduação, Publicação ENE 02/2005, Departamento de Engenharia Elétrica, Universidade de Brasília, Brasília, DF, 67

\section{CESSÃO DE DIREITOS}

AUTOR: Isa Helena Castro Carramaschi.

TÍTULO: Avaliação do desempenho de uma Proteção Digital de Distância frente a Alguns Algoritmos.

GRAU: Engenheiro Eletricista

ANO: 2006

É concedida à Universidade de Brasília permissão para reproduzir cópias desta monografia de graduação e para emprestar ou vender tais cópias somente para propósitos acadêmicos e científicos. O autor reserva outros direitos de publicação e nenhuma parte dessa monografia de graduação pode ser reproduzida sem autorização por escrito do autor.

Isa Helena Castro Carramaschi SHIS QI 21, conjunto 11, casa 09.

71.655-310 Brasília - DF - Brasil. 
Ao meu pai. 


\section{RESUMO}

AVALIAÇÃO DO DESEMPENHO DE UMA PROTEÇÃO DIGITAL DE DISTÂNCIA FRENTE A ALGUNS ALGORITMOS.

Autor: Isa Helena Castro Carramaschi

Orientador: Francisco Damasceno Freitas

Palavras-chave: relé digital de distância, zona de atuação.

Brasília, 27 de março de 2006. 


\section{INDICE}

REFERÊNCIA BIBLIOGRÁFICA...........................................................................ii

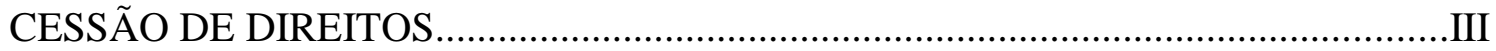

RESUMO .....................................................................................................................................

1- INTRODUÇÃO...................................................................................................................

1.1 - CONSIDERAÇÕES INICIAIS ...................................................................

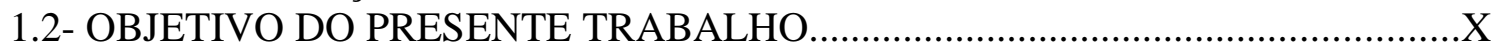

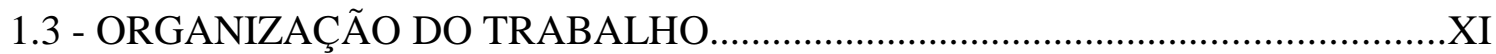

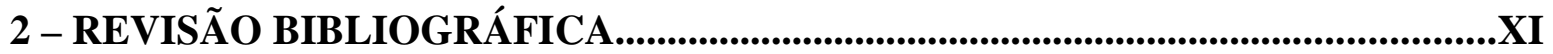

2.1- ESTUDO GERAL DA PROTEÇÃO.........................................................................

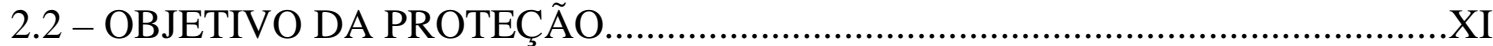

2.3 - TIPOS DE PROTEÇÃO...................................................................................

2.3.1 - Relé Diferencial de Corrente.....................................................................iii

2.3.2 - Relé de Sobrecorrente....................................................................................iv

2.3.3 - Relé direcional.......................................................................................

2.3.4 - Relé de Distância.......................................................................................

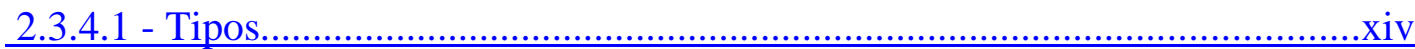

2.3.4.2. - Zonas de Atuação.....................................................................................

2.4 - PROTEÇÃO DE DISTÂNCIA........................................................................

2.4.1. Relés Eletromecânicos................................................................................

2.4.2. - Relés Estáticos, ou de Estado Sólido............................................................ viii

2.4.3. - Relés Digitais......................................................................................

2.5 - CONDICIONAMENTO DE SINAIS...............................................................X

2.5.1 - Compensação de Tensões de Linha na Presença de curtos-circuitos entre

Fases [10], [14] .....................................................................................

2.5.2 - Compensação de Tensões de Fase na Presença de faltas para a Terra [10],

[14].....................................................................................................

3 - ESTUDO DA PROTEÇÃO DIGITAL DE DISTÂNCIA.......................................XXIII

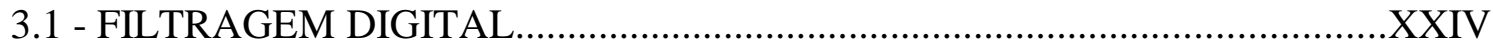

3.1.1 - Transformação Bilinear..............................................................................

3.2 -TÉCNICAS BASEADAS NOS CÁLCULOS DE PARÂMETROS DO MODELO

RL-SÉRIE DA LINHA DE TRANSMISSÃO .......................................................XXVI

3.3 - ALGORTIMOS DE PROTEÇÃO DIGITAL DE DISTÂNCIA........................XXVII

3.3.1 - Algoritmos Filtrantes Passa-Baixa..............................................................xxvii

3.3.2 - Algoritmo Seletivo................................................................................xxviii

3.4 - AJUSTE DA UNIDADE DE DISPARO DO RELÉ.........................................XXX

3.5 - CÁLCULO DA DISTÂNCIA ATÉ A FALTA..................................................XXX

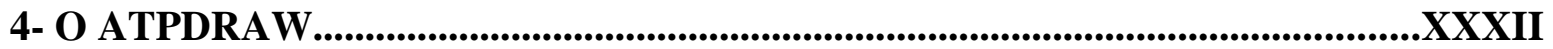

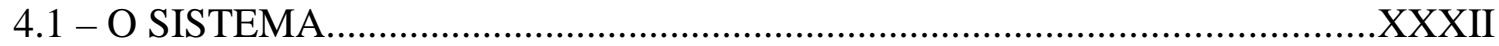

4.2 - IMPLEMENTAÇÃO DO SISTEMA NO ATPDRAW ……………………...XXXIV

4.2.1 - Dimensionamento dos parâmetros de linha....................................................xxxiv

4.2.2 - Dimensionamento dos parâmetros da carga...................................................xxxv

4.2.3 - Dimensionamento dos transformadores........................................................xxxvi 


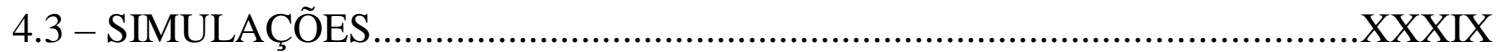

4.3.1 - Curtos monofásicos..............................................................................xxxix

4.3.2 - Variações nas Simulações das Condições de Faltas........................................tiii

4.4 - O ALGORITMO DO RELÉ DE DISTÂNCIA.....................................................

4.5 - LÓGICA COMPUTACIONAL IMPLEMENTADA PARA O RELÉ DE

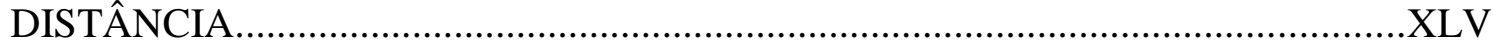

5 - TESTES E RESULTADOS OBTIDOS RELATIVO AOS ALGORITMOS ESTUDADOS........................................................................................................................XLVI

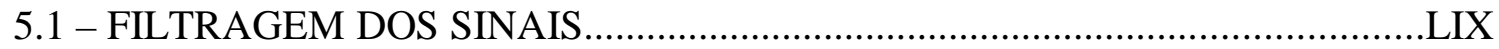

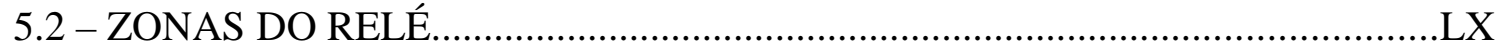

5.3 - RESULTADOS ALCANÇADOS...................................................................XI

6 - CONCLUSÃO ......................................................................................................

REFERÊNCIAS BIBLIOGRÁFICAS ...............................................................................LXIII

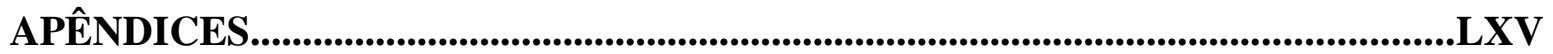

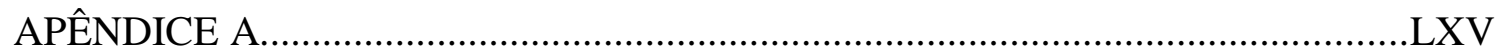

APÊNDICE B

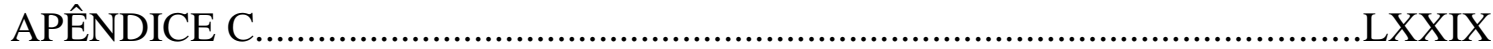




\section{INDICE DE FIGURAS}

\section{INDICE DE TABELAS}

Tabela 2.1.- Tensões e correntes compensadas em $\Delta$ (delta) para um curto-circuito entre

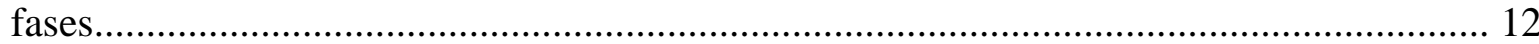
Tabela 2.2. - Tensão e corrente alimentando um relé de distância em um curto-circuito para

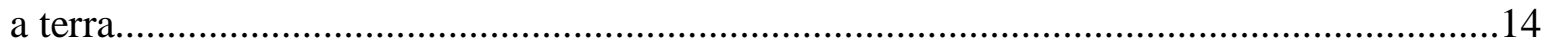

Tabela 4.1 - Parâmetros para as linhas de transmissão...............................................26

Tabela 4.2 - Parâmetros para as cargas......................................................................27

Tabela 4.3 - Parâmetros para os transformadores........................................................29

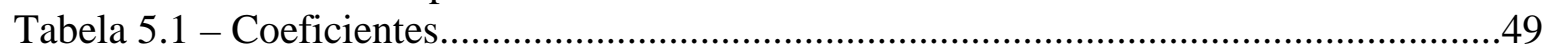

Tabela 5.2 - Distâncias Calculadas..............................................................................51 


\section{1- INTRODUÇÃO}

\section{1 - CONSIDERAÇÕES INICIAIS}

Os Sistemas Elétricos de Potência (SEP) são projetados para fornecer energia dentro de padrões de qualidade, confiabilidade e continuidade. No entanto, os SEPs serão exposto a condições adversas e imprevisíveis, podendo acorrer interrupções em pontos aleatórios do sistema. Nesse contexto, o sistema de proteção deve promover a rápida retirada de operação de um elemento defeituoso do SEP, que possa causar danos, ou interferência na correta operação do sistema [1].

O elemento mais susceptível a falhas, dentre os componentes de um SEP, é a linha de transmissão (LT), especialmente se considerarmos suas dimensões físicas, e mais ainda, por apresentarem maior dificuldade para manutenção, reparo e monitoramento devido à abrangência de locais de difícil acesso e a variabilidade de climas cujas linhas estão expostas. 
Para proteção de linhas de transmissão frente às possíveis situações de faltas, podemos delegar, em primeira instância, as funções de proteção aos relés, sejam eles convencionais ou digitais. Dentre os diversos tipos de relés convencionais, os mais empregados para a proteção das linhas de transmissão são os relés de distância eletromecânicos e de estado sólido. Como a impedância por quilômetro de uma linha de transmissão [2] é praticamente constante, eles respondem à distância da falta sobre a linha de transmissão. O relé de distância recebeu esta denominação, porque sua atuação baseia-se na observação da impedância entre a localização da falta e a localização do relé, obtida em função dos valores de tensão e corrente registrados. Assim, esse relé reconhece falta que ocorre dentro de uma seção ou zona protegida da linha. Contudo, essa seção ou zona de proteção do relé de distância não pode ser precisamente determinada, e uma certa incerteza sobre o seu exato alcance na proteção deve ser respeitada, para aumentar a confiabilidade do sistema, evitando-se o desligamento de zonas além da área de cobertura do relé. A incerteza sobre o alcance da zona de proteção é tipicamente da ordem de $5 \%$ da zona marcada.

\section{2- OBJETIVO DO PRESENTE TRABALHO}

O presente trabalho tem como objetivo o estudo da proteção de um SEP empregando-se ferramentas computacionais para proteção digital de distância. O desenvolvimento deste trabalho baseia-se no estudo de um algoritmo para proteção digital.

O algoritmo foi implementado com o uso do software Matlab® e posteriormente testado, usando-se dados de faltas obtidos através de simulações, dispondo-se do software ATPDraw.

Muitos algoritmos foram estudados visando identificar o comportamento de tensão e correntes frente à freqüência industrial, no entanto este projeto baseou-se no estudo dos algoritmos propostos por Mc-INNES \& MORRINSSON [3], [4], e RAMAMOORTY [5]. Os algoritmos propostos baseiam-se respectivamente no principio da integração da equação que modela uma linha curta, sendo um algoritmo filtrante e o outro em um ciclo completo da transformada de Fourier. 


\section{3 - ORGANIZAÇÃO DO TRABALHO}

No Capítulo 2 apresenta-se uma revisão do trabalho referente à metodologia aplicada à proteção digital para linhas de transmissão. A técnica baseada nos cálculos de parâmetros do modelo RL-série da linha de transmissão e a apresentação dos algoritmos de proteção digital de distância que são analisados através de simulações com o software Matlab®, são descritos os principais tipos de proteção e em especial da proteção de distância e também das compensações usadas para tensão.

No capítulo 3, são abordados estudos sobre a filtragem de sinais, a passagem do domínio contínuo s para o domínio discreto z. Apresenta-se técnicas de modelo de linha de transmissão baseado na resistência e na indutância da linha e os algoritmos usados.

A modelagem do SEP a ser analisado, bem como as variações nas simulações das faltas aplicadas sobre o sistema proposto são apresentadas no Capítulo 4.

Já no capítulo 5 é feita uma análise dos resultados obtidos.

Por fim, o Capítulo 6 destaca as conclusões sobre o trabalho, e ainda apresenta sugestões para continuidade do trabalho.

\section{2 - REVISÃO BIBLIOGRÁFICA}

\section{1- ESTUDO GERAL DA PROTEÇÃO}

Neste capítulo apresenta-se um panorama da proteção de linhas e seus requisitos principais. Enfatiza-se a proteção de distância, mostrando-se suas principais características de disparo que são implementadas no plano R-X [6]. Estas características são simuladas adequadamente quando se trabalha com relés digitais que são alimentados por sinais de tensão e/ou corrente digitalizados.

\section{2 - OBJETIVO DA PROTEÇÃO}

Em oposição à garantia de economia e qualidade do serviço, além de vida útil razoável das instalações, as concessionárias enfrentam perturbações e anomalias de funcionamento que afetam as redes elétricas e seus órgãos de controle, trazendo assim a necessidade contínua 
do aperfeiçoamento e manutenção dos sistemas elétricos de potência para que haja confiabilidade no sistema.

Estas perturbações e anomalias que abalam o sistema são de diversas naturezas, como por exemplo: isoladores curto-circuitados ou rachados, isolação de transformadores e geradores afetados por umidade, descargas atmosféricas, sobretensões de manobra, entrada de roedores ou aves dentro dos equipamentos, galhos de árvores, etc.

Quando ocorrem faltas de isolamento e, conseqüentemente, curto-circuito, o sistema pode ser submetido a uma forte solicitação que poderia causar severos danos aos equipamentos devido à grande quantidade de energia que circula por eles.

De acordo com o levantamento estatístico realizado [16], na Inglaterra, a maior ocorrência de faltas dá-se nas linhas de transmissão. Como estas faltas são inevitáveis, elementos protetores são desenvolvidos para evitar esses possíveis danos e ainda satisfazer requisitos de custo, sensibilidade, seletividade, velocidade e confiabilidade. Estes elementos são os relés de proteção.

Dentre as vantagens oferecidas pela utilização dos relés digitais em relação às tecnologias convencionais (eletromecânicos, estado sólido), [8] temos:

- custo: o custo do relé é a sua principal consideração na aceitação. O custo dos primeiros relés computadorizados era de 10 a 20 vezes maior que o custo dos relés convencionais. Com a evolução dos processadores, esse custo diminuiu e houve um aumento na capacidade de processamento. Estima-se hoje que o custo do relé computadorizado, incluindo custos de software, seja equivalente ao custo de um relé convencional;

- autochecagem e confiabilidade: um relé digital pode ser programado para monitorar seu hardware e software continuamente e detectar qualquer mau funcionamento que possa ocorrer. Além disso, o relé pode ser retirado de operação se a falha for detectada e diminuir a chance de falha de operação. Essa característica do relé digital é o argumento mais forte em favor da digitalização das subestações;

- sensibilidade: é a capacidade da proteção responder às anomalias nas condições de operação e aos curtos-circuitos para os quais foi projetada.

- integração digital: os computadores e a tecnologia digital têm se tornado a base da maioria dos sistemas empregados nas subestações. Medições, comunicação, 
telemetria e controle são funções executadas por computadores digitais. Nas subestações modernas, os relés digitais devem estar integrados naturalmente nesses sistemas;

- flexibilidade funcional: o relé digital pode ser programado para realizar diversas funções em uma subestação, tais como: medição, monitoramento e controle, entre outras. Esse relé pode ainda possuir característica adaptativa, modificando sua atuação em varias funções, para torná-las mais adequadas às condições do SEP;

- velocidade de operação: o tempo entre a incidência da falta e o comando de abertura do disjuntor dado pelo relé é determinado pela configuração do sistema e, no caso da proteção digital, são tipicamente alguns ciclos de freqüência do sistema. Assim, deseja-se que o relé tenha uma velocidade de atuação necessária para assegurar um rápido isolamento da menor porção possível do sistema que está sob falta do resto dele, dentro da sua zona de proteção.

- Seletividade: é a habilidade do relé de isolar a menor parte possível do sistema que está sob falta do resto deste, operando os disjuntores adequados a ele associados o mais rápido possível, dentro da sua zona de proteção, para assegurar a máxima continuidade dos serviços com a retirada de proteção do sistema apenas das linhas que estejam sob falta.

Os relés são projetados para atuarem continuamente, reconhecerem e localizarem as faltas nos momentos de regime transitório. Os relés medem as seguintes grandezas elétricas do sistema: corrente, tensão e ângulo de fase da componente fundamental [9].

\section{3 - TIPOS DE PROTEÇÃO}

Para a proteção de linhas de transmissão frente às possíveis situações de faltas, têm-se várias opções possíveis, porém as mais importantes são os relés diferenciais de corrente, os relés de sobrecorrente, os relés direcionais e os relés de distância.

\subsection{1 - Relé Diferencial de Corrente}


Seu princípio é baseado na comparação das fases e magnitudes das correntes passando através da parte protegida do sistema de alta tensão. É usado em algumas linhas e em proteção de barramento [10], [11], [12].

\subsection{2 - Relé de Sobrecorrente}

É mais usado em sistemas de distribuição. Ele usa a corrente local para verificar se há um defeito ou não. Este método é possível em sistemas de distribuição porque a corrente de curto-circuito é grande comparada àquela de carga e porque a seção em falta tem a maioria da corrente, uma vez que é alimentada por todos os circuitos vizinhos não faltosos. Estes relés são usados também como backup em linhas de transmissão.

\subsection{3 - Relé direcional}

Tem o seu princípio baseado na direção do fluxo de potência ou corrente nos terminais de uma linha de transmissão que é comparada com a ajuda de correntes de altas freqüências. A proteção é bloqueada quando curtos-circuitos externos ocorrem. Quando uma falta ocorre dentro da zona protegida não há nenhuma corrente circulando no canal piloto ou é de tal proporção que o equipamento de proteção já atuou, clareando a falta.

Pesquisas [13], [14], [15] descrevem o uso de microcomputadores neste tipo de proteção, onde os valores instantâneos de tensão e corrente em cada terminal são amostrados a uma mesma freqüência e transmitidos usando modulação por código de pulsos (PCM) [14] via canal de microondas.

\subsection{4 - Relé de Distância}

A avaliação da distância desde o seu ponto de localização até o ponto em defeito a partir de medidas locais de corrente e tensão é o princípio no qual se baseia. Os principais tipos são: impedância, mho e reatância.

\subsubsection{1 - Tipos}


a) Relé tipo impedância: é um relé de sobrecorrente com retenção por tensão cujo diagrama R-X é mostrado na Figura 2.1. A característica deste tipo de relé é uma impedância constante e haverá operação quando a relação tensão-corrente de entrada ao relé for menor que $|\mathrm{Z}|$. O relé é insensível ao ângulo $\theta$ entre $\mathbf{V}$ e $\mathbf{I}$.

Na realidade este tipo de relé tem como área de atuação as duas direções em relação à barra e não é, dessa forma, inerentemente direcional, necessitando, portanto de uma unidade direcional para que a região de disparo atue de forma a proteger a seção de linha vista à jusante do relé.
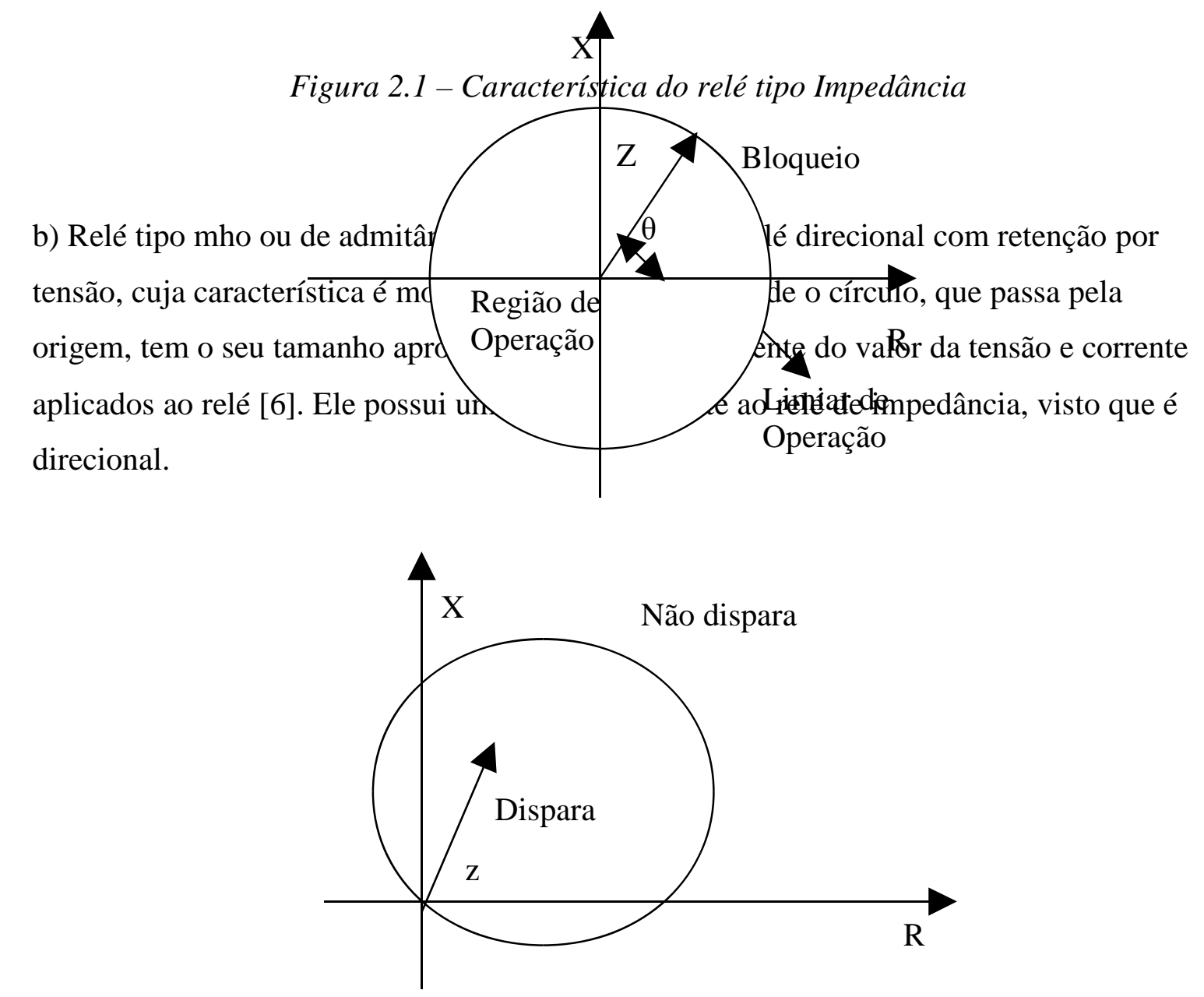

Figura 2.2 - Característica do relé tipo mho

Uma segunda vantagem é que há melhor acomodação de uma possível resistência de arco. Constata-se que para proteger um mesmo comprimento de linha e de uma dada resistência 
de arco, o relé abrange uma menor área no plano R-X, o que é vantajoso quanto à sensibilidade menor às possíveis oscilações do sistema.

c) Relé tipo reatância: é um relé de sobrecorrente com retenção direcional, cuja característica é mostrada na Figura 2.3. Este é um relé direcional seletivo que pode distinguir distância, baseando-se apenas na componente reativa da impedância [6].

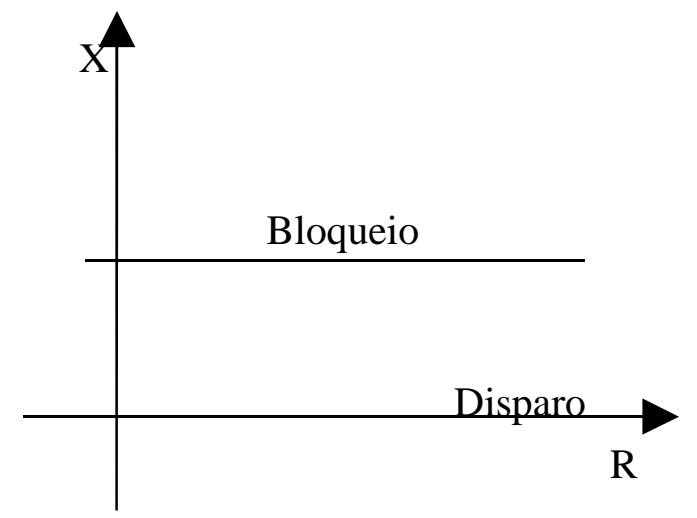

Figura 2.3 - Característica do relé tipo reatância

O relé de reatância operando isoladamente atuaria para defeitos à montante e correntes de carga com componente $\mathrm{X}$ abaixo do seu ajuste. Estas características o tornariam inútil à proteção de linhas, face à sensibilidade de oscilações de potência. Desta forma ele requer uma supervisão por parte de outro relé que seja direcional e insensível às correntes de carga. Para esta finalidade usa-se, em geral, o relé e uma unidade mho, como mostra a Figura 2.4. Neste caso, Z1, Z2 e Z3 são as três zonas de proteção à jusante do relé. Z1 atua instantaneamente e protege uma seção de linha adjacente, enquanto Z2 e Z3 são temporizados e atuam como retaguarda para as linhas adjacentes. 


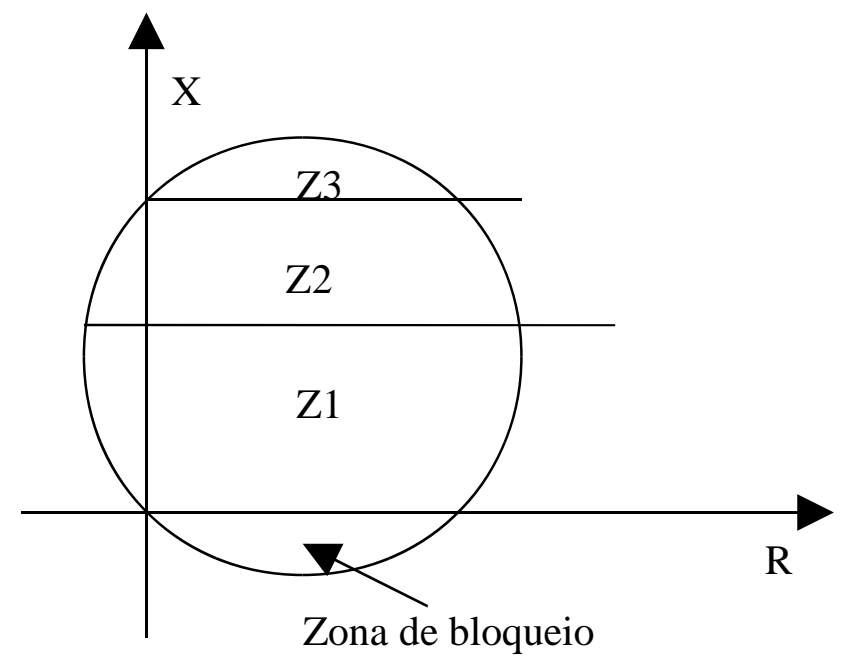

Figura 2.4 - Característica do relé mho com o relé tipo reatância

Nesta aplicação o relé mho é denominado unidade de partida.

\subsubsection{2. - Zonas de Atuação}

A proteção de distância comporta, em geral, três zonas de funcionamento, no caso de um defeito a jusante do relé. As três zonas a jusante são ajustadas em função do comprimento da linha entre duas subestações. Em alguns casos é delimitada uma quarta zona, denominada Zona de Bloqueio, que atua a montante do relé.

- Primeira Zona -até $80 \%$

- Segunda Zona - entre $80 \%$ e $120 \%$

- Terceira Zona - entre $120 \%$ e $160 \%$

- Zona de Bloqueio - protege um certo cumprimento visto a montante do relé.

A segunda, a terceira e a zona de bloqueio funcionam como retaguarda para as linhas adjacentes que têm proteção própria. O relé de retaguarda só virá a atuar se, por alguma eventualidade, um defeito não for eliminado rapidamente pela própria proteção principal. Estas zonas são mostradas também na Figura 2.4. 


\section{4 - PROTEÇÃO DE DISTÂNCIA}

Atualmente, devido a grande expansão e complexidade dos SEPs, torna-se cada vez mais importante o desenvolvimento de relés de proteção mais rápidos e eficientes.

Os relés de distância em operação cobrem uma larga gama tecnológica, variando desde o relé eletromecânico, passando pelos relés estáticos, e atingindo os mais modernos controlados por microcomputadores.

\subsubsection{Relés Eletromecânicos}

Os primeiros relés projetados eram dispositivos eletromecânicos, mais conhecidos como relés convencionais. Eles foram os primeiros a serem projetados e estão presentes ainda na maioria das usinas e subestações. Esses relés atuam através de forças que são produzidas pela interação eletromagnética entre corrente e fluxos. De forma geral, os relés eletromecânicos respondem a uma ou mais entradas: tensão, corrente, produto entre tensão, corrente e o ângulo entre esses fasores ou então pela força física produzida por molas. A baixa confiabilidade desses relés representa seu grande problema. Sendo assim, estes tipos de relés dependem da interação de forças que podem se alterar com o tempo. As molas, eixos, discos e outros componentes mecânicos de relé sofrem um processo natural de desgaste que muitas vezes reduz a confiabilidade do relé, pois podem provocar a falha de operação.

\subsection{2. - Relés Estáticos, ou de Estado Sólido.}

Os relés de estado sólido foram desenvolvidos posteriormente e possuem desempenho e características mais sofisticadas em relação aos eletromecânicos. O desenvolvimento de dispositivos semicondutores e de outros componentes eletrônicos possibilitou a criação dos mesmos. Todas as funções e características disponíveis nos relés eletromecânicos podem ser implementadas nos equipamentos de estado sólido constituído de componentes discretos ou integrados. Os relés de estado sólido utilizam componentes de baixa potência com pouca tolerância a altas temperaturas, umidade, sobrecorrente e sobretensões. Estas características 
os tornam mais suscetíveis às falhas frente ao ambiente hostil de subestações e usinas. Entretanto, esses relés possuem menor tamanho físico e maior desempenho e flexibilidade em relação aos eletromecânicos, além de não serem prejudicados por vibrações e poeira e não possuírem partes móveis.

\subsection{3. - Relés Digitais}

Com o avanço da tecnologia digital, deu-se início ao desenvolvimento dos relés computadorizados ou digitais. Esses relés são gerenciados por um microprocessador específico, controlado por um software. Os sinais de entrada para esses relés são os sinais de tensão e corrente obtidos através de transdutores. Portanto, é necessário obter uma representação digital para esses sinais e, usando-se um algoritmo apropriado, a abertura dos disjuntores é realizada.

Esses relés são extremamente rápidos em comparação com os relés eletromecânicos e eletrônicos, porém são muito suscetíveis a interferências eletromagnéticas, necessitando de filtros do tipo passa-baixa analógicos e digitais. Estes filtros são empregados para atenuação ou eliminação das componentes de alta freqüência presentes no sinal. Finalmente, os relés são normalmente modulares e necessitam de fonte de alimentação.

\section{5 - Condicionamento de sinais}

Os relés de distância são projetados de modo que haja distinção entre os tipos de falta, falta entre fases e falta para a terra, para haver proteção. O princípio usado para compensar a tensão ou a corrente em todos os tipos de relés de distância é dito compensação. Os dois tipos de compensação utilizados aqui são: compensação de tensão de linha na presença de curtos-circuitos entre fases e compensação de tensão de fase na presença de faltas para a terra.[10]

Nesses casos, os curtos-circuitos são assumidos metálicos, ou seja, não apresentam resistência de falta. 


\subsection{1 - Compensação de Tensões de Linha na Presença de curtos-circuitos entre Fases $[10],[14]$}

Seja $Z_{1}$ a impedância de sequiência positiva da seção de linha de transmissão do ponto onde está instalado o relé até o ponto de curto-circuito.

A tensão entre as fases faltosas, por exemplo, B e C, vista pelo relé, seja para um curto trifásico, bifásico ou bifásico para a terra é

$$
V_{b c}=Z_{1}\left(I_{B}-I_{C}\right)
$$

conseqüentemente, para reconhecer a impedância vista pela unidade do relé que protege a linha contra defeitos polifásicos, neste caso é necessário usar a diferença de correntes das fases faltosas. Desta forma, a impedância vista pelo relé desde o ponto onde está localizado o relé até o ponto de falta é:

$$
Z_{R}=\frac{V_{B C}}{I_{B}-I_{C}}=Z_{1}
$$

A Figura 2.5 mostra o trecho de uma linha de transmissão protegida, sendo $Z_{\mathrm{KL}}$ a impedância do trecho da linha de transmissão protegida entre as subestações K e L.

$$
Z_{K L}=Z_{1}+Z^{\prime}
$$

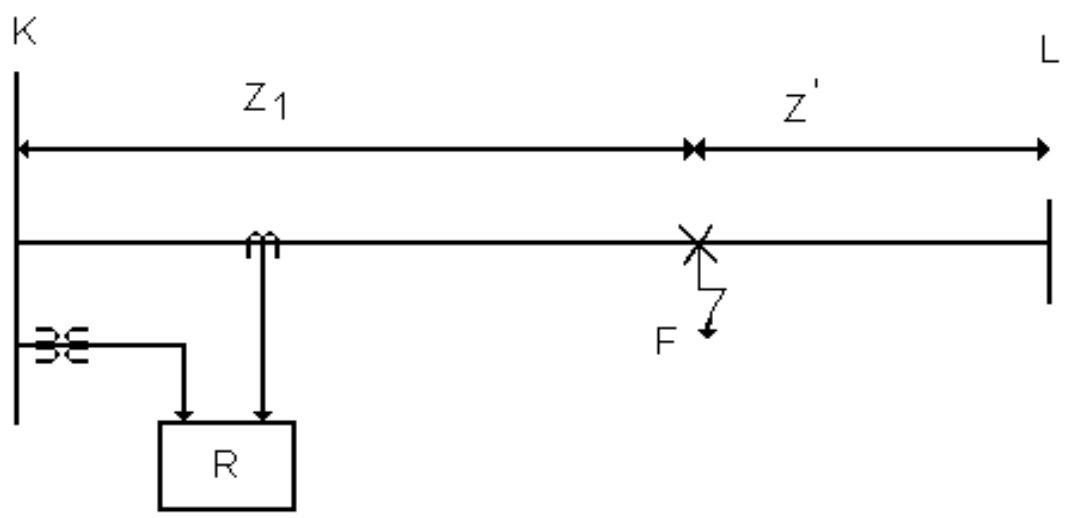

Figura 2.5 - Linha de Transmissão submetida a um curto-circuito

Denota-se esta combinação de tensão e corrente nos terminais do relé por $\mathrm{V}_{\Delta} / \mathrm{I}_{\Delta}$ e é conhecida como conexão delta, onde

$$
V_{\Delta}=V_{B}-V_{C}=V_{B C}
$$




$$
I_{\Delta}=I_{B}-I_{C}
$$

As tensões e correntes compensadas nos terminais dos relés de distância para proteção contra curtos-circuitos entre fases são mostrados na Tabela 2.1

Tabela 2.1.- Tensões e correntes compensadas em $\Delta$ (delta) para um curto-circuito entre fases

\begin{tabular}{|c|c|}
\hline $\mathbf{V}_{\Delta}$ (Tensão) & $\mathbf{I}_{\Delta}$ (corrente) \\
\hline $\mathbf{V}_{\mathbf{A}}-\mathbf{V}_{\mathbf{B}}$ & $\mathbf{I}_{\mathbf{A}}-\mathbf{I}_{\mathbf{B}}$ \\
\hline $\mathbf{V}_{\mathbf{B}}-\mathbf{V}_{\mathbf{C}}$ & $\mathbf{I}_{\mathbf{B}}-\mathbf{I}_{\mathbf{C}}$ \\
\hline $\mathbf{V}_{\mathbf{C}}-\mathbf{V}_{\mathbf{A}}$ & $\mathbf{I}_{\mathbf{C}}-\mathbf{I}_{\mathbf{A}}$ \\
\hline
\end{tabular}

Os relés convencionais são alimentados com sinais conforme a Tabela 2.1 no caso de faltas entre fases, mostrada na Figura 2.6. No caso de relés digitais a diferença independe do tipo de ligação dos TC's, pois ela é calculada computacionalmente, tomando-se a diferença entre as amostras dos sinais.

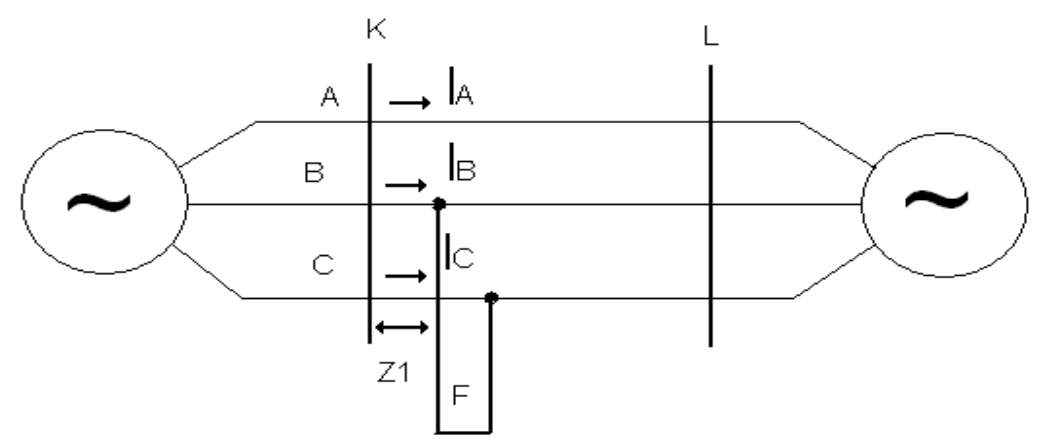

Figura 2.6 - Falta bifásica entre as fases B e C 
Seja $Z_{0}$ a impedância de seqüência zero da seção de linha de transmissão do ponto onde está o relé até o ponto de curto. Considere-se o caso de uma falta monofásica para a terra mostrada na Figura 2.7.

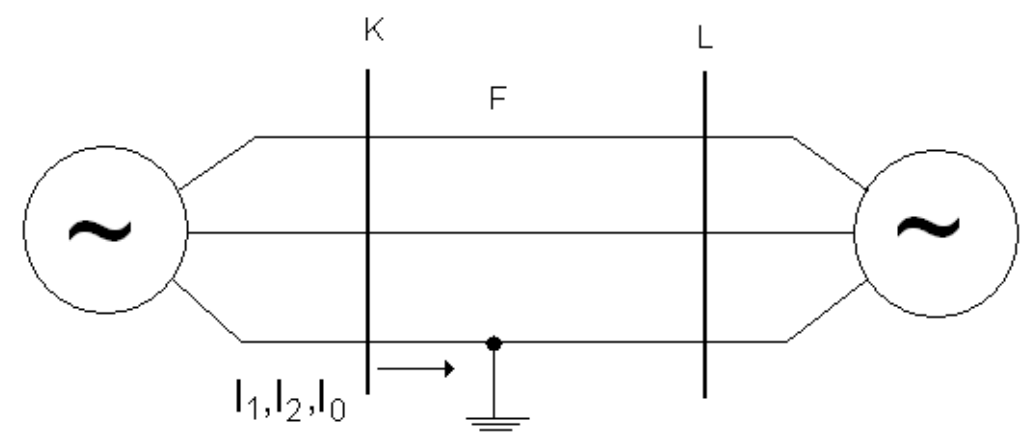

Figura 2.7 - Falta monofásica para terra

A tensão de fase $\mathrm{V}$ no ponto onde está instalado o relé é

$$
\mathrm{V}=\mathrm{Z}_{1}\left(\mathrm{I}_{1}+\mathrm{I}_{2}\right)+\mathrm{Z}_{0} \mathrm{I}_{0}=\mathrm{Z}_{1}\left(\mathrm{I}_{1}+\mathrm{I}_{2}+\frac{\mathrm{Z}_{0}}{Z_{1}} \mathrm{I}_{0}\right)
$$

onde $\mathrm{I}_{1}, \mathrm{I}_{2}$ e $\mathrm{I}_{0}$ são as componentes simétricas de corrente da fase faltosa no ponto onde está instalado o relé. Adicionando e subtraindo $\mathrm{I}_{0}$ dentro dos parênteses, obtêm-se [9].

$$
V=Z_{1}\left(I+\frac{Z_{0}-Z_{1}}{Z_{1}} I_{O}\right)
$$

ou alternativamente

$$
V=Z_{1}\left(I+K I_{N}\right)
$$

onde

$$
K=\frac{Z_{0}-Z_{1}}{3 Z_{1}} \text { e } I_{N}=3 I_{0}
$$

onde I é a corrente $\mathrm{KI}_{\mathrm{N}}$ à componente de fase é chamada compensação de corrente.

$$
I_{P}=I+K I_{N}
$$


Quando tal combinação de corrente e tensão é aplicada ao relé, a impedância até o ponto de defeito é a mesma, tanto para um defeito bifásico para a terra, como trifásico também para a terra.

$$
Z_{1}=\frac{V}{I+K I_{N}}
$$

A Tabela 2.2 mostra as tensões e correntes compensadas a serem introduzidas num relé de distância para o caso de um defeito para a terra.

Tabela 2.2. - Tensão e corrente alimentando um relé de distância em um curto-circuito para a terra.

\begin{tabular}{|c|c|}
\hline $\mathbf{V}_{\mathbf{Y}}$ (tensão de linha) & $\mathbf{I}_{\mathbf{Y}}$ (corrente de linha) \\
\hline $\mathbf{V}_{\mathbf{A}}$ & $\mathbf{I}_{\mathbf{A}}+\mathbf{K} . \mathbf{I}_{\mathbf{N}}$ \\
\hline $\mathbf{V}_{\mathbf{B}}$ & $\mathbf{I}_{\mathbf{B}}+\mathbf{K} . \mathbf{I}_{\mathbf{N}}$ \\
\hline $\mathbf{V}_{\mathbf{C}}$ & $\mathbf{I}_{\mathbf{C}}+\mathbf{K} . \mathbf{I}_{\mathbf{N}}$ \\
\hline
\end{tabular}

\section{3 - ESTUDO DA PROTEÇÃO DIGITAL DE DISTÂNCIA}


No presente capítulo, estuda-se os fundamentos teóricos da proteção digital de distância e dois algoritmos de proteção digital, como também um filtro digital.

\section{1 - FILTRAGEM DIGITAL}

Um filtro digital é um processo computacional, ou algoritmo, pelo qual um sinal digital ou uma seqüência de números é transformada em uma outra seqüência denominada saída do sinal digital.

O processo geral de projeto de um filtro digital envolve os seguintes passos básicos [14].

- Resolver o problema da aproximação para determinar coeficientes do filtro que satisfaçam as especificações;

- Escolher uma estrutura específica no qual o filtro será realizado e quantizar os coeficientes do filtro a um tamanho de palavra fixa;

- Quantizar as variáveis do filtro digital;

- Verificar, através de simulações, que os resultados atendem as especificações desejadas.

Os filtros digitais podem apresentar resposta impulsional de duração finita (FIR) ou resposta impulsional de duração infinita (IIR). Consideraremos aqui, os filtros FIR.

Os filtros FIR são sempre estáveis e podem ser projetados de forma a apresentar uma fase sempre linear. Eles se caracterizam por uma função de transferência no domínio z dada por

$$
H(z)=\sum_{n=0}^{N-1} h_{n} z^{-n}
$$

Para escolha da estrutura do filtro FIR a ser utilizado é necessário conhecer as suas vantagens e desvantagens:

- Vantagens: estabilidade assegurada, realização evidente, facilmente realizável;

- Desvantagens: grande número de coeficientes e grande número de operações aritméticas.

A transformação do plano s para o plano z é feita usando a transformação bilinear. 


\subsection{1 - Transformação Bilinear}

A transformação conforme que mapeia o plano $\mathrm{s}$ no plano $\mathrm{z}$ é conhecida como transformação bilinear que é dada por:

$$
s=\frac{2}{T} \frac{1-z^{-1}}{1+z^{-1}}
$$

onde T é o período de amostragem do sinal discreto.

A natureza deste mapeamento é bem entendida, observando-se a Figura 3.1 que mostra como o plano s é mapeado no plano z. Como é visto, o eixo jw em s é mapeado sobre o circulo unitário em z.

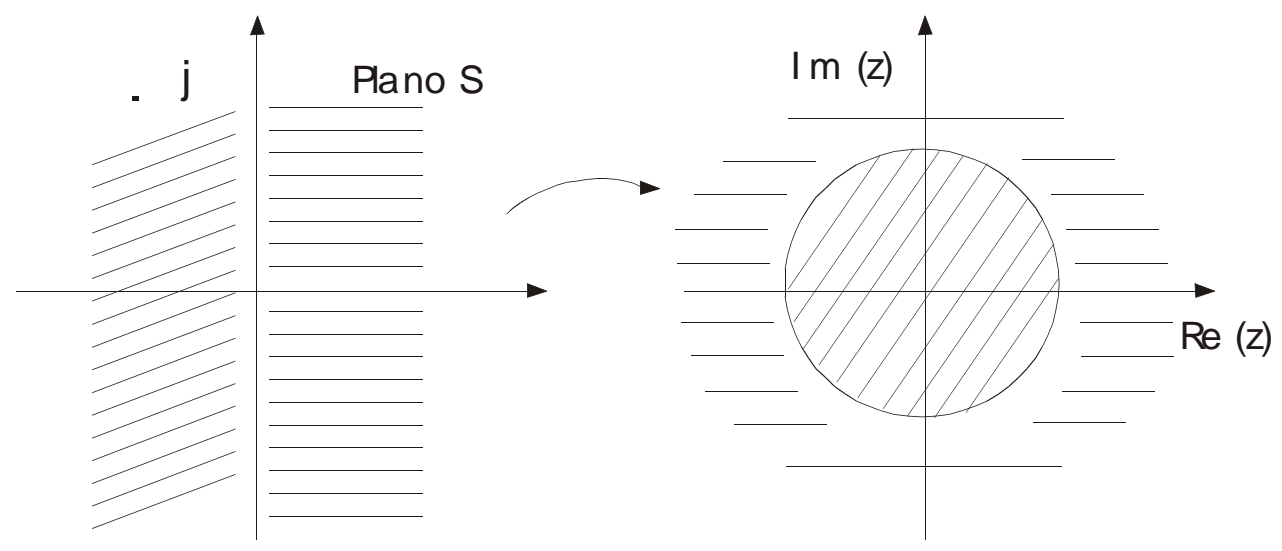

Figura 3.1 - Mapeamento do plano s no plano z.

A equação (3.2) correspondente a um mapeamento de s não normalizado. Deve-se então dividir s pelo valor da frequiência de corte do filtro analógico, obtida a partir dos dados do filtro digital.

Sendo

$$
\Omega_{c}=\frac{2}{T} \operatorname{tg}\left(\frac{\omega_{c} T}{2}\right)
$$

a frequiência de corte do filtro analógico e $\mathrm{w}_{\mathrm{c}}$ a freqüência de corte do filtro digital, ambos em radianos por segundos, então 


$$
s=\frac{1-z^{-1}}{\operatorname{tg} \pi F_{c}\left(1+z^{-1}\right)}
$$

onde $\mathrm{F}_{\mathrm{C}}$ é a freqüência de corte do filtro digital passa-baixa normalizado em relação à freqüência de amostragem.

O período de amostragem é de $0,5 \mathrm{~ms}$, portanto a frequiência de corte Fc é $2000 \mathrm{~Hz}$.

Desta forma usando-se o mapeamento conforme em uma função $H$ (s), na qual s representa a freqüência complexa normalizada, obtêm-se a função $\mathrm{H}(\mathrm{z})$ do filtro digital correspondente.

\section{2 -TÉCNICAS BASEADAS NOS CÁLCULOS DE PARÂMETROS DO MODELO RL-SÉRIE DA LINHA DE TRANSMISSÃO}

Essas técnicas assumem a representação de um modelo de linha de transmissão baseado na resistência e na indutância da linha. Os algoritmos que usam essa teoria, apoiados no modelo resistivo-indutivo da linha, usualmente desprezam a capacitância shunt. A tensão e a corrente que são fornecidas para diferentes tipos de faltas são expressas pela equação geral:

$$
V=R i+L \frac{d i}{d t}
$$

em que:

v e i representam os valores no tempo dos sinais de tensão e corrente provenientes dos terminais do relé, R e L são os valores de resistência e indutância da linha por quilômetro, respectivamente.

As grandezas v e i são amostradas transformando-se em informações discretas. Obtendo amostras digitalizadas dos sinais de tensão e corrente resolve-se a equação diferencial da linha com respeito à resistência e a indutância de sequiência positiva. Essa representação admite a correspondente contínua como parte válida da solução. Assim, a equação diferencial será usada para determinar os parâmetros do sistema sob condições de falta.

Observa-se de início que o modelo (3.5), é fundamentado em baixas frequiências e para linhas relativamente curtas. É importante, portanto que os princípios de cálculo usados eliminem a altas freqüências. 
Na literatura, são propostos vários métodos para a solução das equações diferenciais da linha, e dois deste são apresentados a seguir.

\section{3 - ALGORTIMOS DE PROTEÇÃO DIGITAL DE DISTÂNCIA}

Os algoritmos estudados aqui são baseados no sistema linear

$$
\begin{aligned}
& {[\mathrm{A}][\mathrm{Z}]=[\mathrm{B}]} \\
& {[Z]=\left[\begin{array}{l}
\mathbf{R} \\
\mathbf{X}
\end{array}\right]}
\end{aligned}
$$

As expressões matemáticas das matrizes $[\mathrm{A}]$ e [B] dependem da técnica de resolução do problema e das hipóteses de cálculo formuladas.

Para simplificar a representação das correntes e tensões usadas nos algoritmos, não nos preocupamos com o tipo de compensação, seja ela para defeitos entre fases ou defeitos com corrente para terra.

\subsection{1 - Algoritmos Filtrantes Passa-Baixa}

McInnes e Morrinson [3] sugeriram a integração da equação (3.5) sob dois intervalos de tempo, para que um número de equações seja solucionado. As integrais foram resolvidas numericamente utilizando-se a regra trapezoidal, em que foram obtidos os valores da resistência e da indutância da linha [3], [4], [5].

$$
\begin{aligned}
& \int_{t_{0}}^{t_{1}} v d t=R \int_{t_{0}}^{t_{1}} i d t+\frac{x}{\omega}\left(i\left(t_{1}\right)-i\left(t_{0}\right)\right) \\
& \int_{t 1}^{t 2} v d t=R \int_{t_{1}}^{t 2} i d t+\frac{x}{\omega}\left(i\left(t_{2}\right)-i\left(t_{1}\right)\right)
\end{aligned}
$$

No qual: 


$$
\int_{k-1}^{k} x d t=\frac{T}{2}\left(x_{k}+x_{k-1}\right)
$$

O desempenho deste algoritmo é deteriorado pelas componentes não causais dos sinais de i e v. Uma leve filtragem analógica passa-baixa se faz necessária para evitar a contaminação da parte superior do espectro de freqüência pelos ruídos de altas freqüências. Utilizou-se o filtro de Butterworth com dois pólos, com essa finalidade.

Alguns autores aconselham uma freqüência de amostragem de 8 amostras por ciclo. No presente trabalho foi utilizado uma freqüência de amostragem de 12 amostras por ciclo.

Convém observar que a janela de dados é relativamente curta (três amostras) e na precisão do algoritmo passa por um tratamento lógico complementar, permitindo-se apreciar a estacionaridade de R e X durante um tempo suficientemente longo.

\subsection{2 - Algoritmo Seletivo}

RAMAMOORTHY et all [5] propuseram a utilização do princípio de detecção síncrona, o qual proporciona a seguinte expressão para identificação de $\mathrm{R}$ e $\mathrm{X}$

$$
\int_{0}^{N T} v e^{-j \omega t} d t=(R+j X) \int_{0}^{N T} i e^{-j \omega t} d t
$$

onde NT corresponde ao período de onda fundamental.

A separação das partes real e imaginaria fornece duas equações lineares do tipo (3.6) que permite o cálculo de $\mathrm{R}$ e $\mathrm{X}$.

Em [5] esta procura de R e X é feita sob a designação de análise de Fourier com janela de um ciclo. $\mathrm{O}$ algoritmo proposto correlaciona as amostras de entrada para um ciclo de sinal fundamental com coeficientes previamente armazenados em memória que são referências das formas de onda senoidal e cossenoidal, na freqüência fundamental, a fim de se extrair o valor complexo da componente fundamental do sinal na forma retangular.

As expressões gerais para as componentes senoidal (Vs) e cossenoidal (Vc) de tensão em um conjunto de $n$ amostras são [5]: 


$$
\begin{gathered}
V_{s}=\frac{1}{N}\left[2 \sum_{l=1}^{N-1} V_{k-N+l} \operatorname{sen}\left(\frac{2 \pi l}{N}\right)\right] \\
V_{c}=\frac{1}{N}\left[V_{k-N}+V_{k+} 2 \sum_{l=1}^{N-1} V_{k-N+l} \operatorname{sen}\left(\frac{2 \pi l}{N}\right)\right]
\end{gathered}
$$

onde $\mathrm{V}$ é a amostra de tensão e $\mathrm{N}$ é o número de amostras por ciclo da componente fundamental. Expressões similares são avaliadas para as componentes Is e Ic de corrente. Os quatro resultados podem ser usados para gerar a magnitude e a fase do fasor impedância na forma polar ou retangular.

$\mathrm{Na}$ forma polar calculam-se o módulo $|\mathrm{z}|$ e a fase $\theta_{\mathrm{z}}$ :

$$
\begin{gathered}
|Z|^{2}=\frac{V_{s}^{2}+V_{c}^{2}}{I_{s}^{2}+I_{c}^{2}} \\
\theta_{z}=\operatorname{arctg}\left(\frac{I_{s}}{I_{c}}\right)-\operatorname{arctg}\left(\frac{V_{s}}{V_{c}}\right)
\end{gathered}
$$

Na forma retangular:

$$
\begin{aligned}
& V=V_{c}-j V_{s} \\
& I=I_{c}-j I_{s}
\end{aligned}
$$

Portanto a impedância complexa obtida da relação fasorial V/I:

$$
Z=\frac{V_{c} I_{c}+V_{s} I_{s}}{I_{s}{ }^{2}+I_{c}{ }^{2}}+j \frac{V_{c} I_{s}-V_{s} I_{c}}{I_{s}{ }^{2}+I_{c}{ }^{2}}
$$

Lembrando que $\mathrm{R}$ é parte real de $\mathrm{Z}$, e $\mathrm{X}$ a parte imaginária de $\mathrm{Z}$.

As qualidades filtrantes deste algoritmo são evidentemente excelentes, explorando o seu princípio básico (filtragem seletiva à freqüência $\omega$ ). Nele está implícito uma drástica filtragem dos dados. A saída responde lenta, suave para uma forma de onda distorcida arbitrária. A desvantagem deste algoritmo é o grande volume de cálculo requerido e a 
janela de dados que deve comportar amostras em um período da forma de onda fundamental.

\section{4 - Ajuste da unidade de disparo do relé}

O ajuste da característica de disparo do relé digital de distância é implementado como mostrado na Figura 3.2. A característica é modelada em três zonas à jusante e uma a montante. As zonas são limitadas por segmentos de retas como pode ser observado na Figura 3.2.

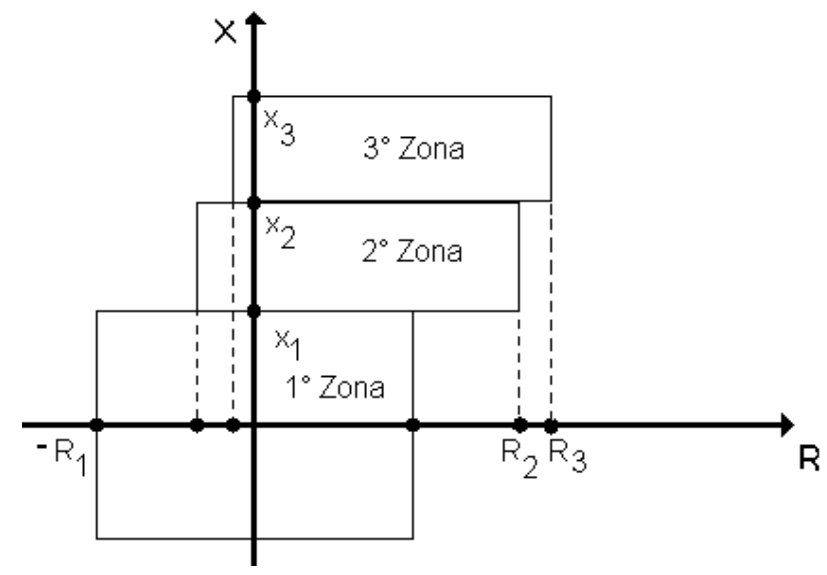

Figura 3.2 - Unidade de disparo de uma proteção de distância

\section{5 - CÁlCULO DA DISTÂNCIA ATÉ A FALTA}

A impedância de uma linha é diretamente proporcional ao seu comprimento. E em um curto-circuito, a medida da reatância através do relé dá uma noção aproximada da distância até o ponto de falta. Na ausência de um curto-circuito, a impedância medida é a de serviço a qual fica fora da característica de disparo mostrada na Figura 3.2.

Um método para se obter uma boa precisão no cálculo deste parâmetro seria tomar uma serie de valores de $\mathrm{X}$ e obter a sua média.

O valor médio de X é computado como: 


$$
X_{N}=\frac{1}{N} \sum_{k=1}^{N} X_{k}
$$

onde $\mathrm{N}$ é o número de amostras computadas a partir da confirmação do defeito e $\mathrm{X}_{\mathrm{k}}$ é o valor da reatância calculado no passo k.

A distância vista pelo relé até o ponto de defeito é

$$
l=\frac{X_{N}}{X_{1}}
$$

onde $\mathrm{x}_{1}$ é a reatância de seqüência positiva da linha por quilômetro. 


\section{4- O ATPDraw}

Neste projeto o ATP foi utilizado para simulação de transitórios como ferramenta computacional. O ATP é um poderoso software de simulação de transitórios eletromagnéticos em sistemas de energia elétrica (ou redes polifásicas), que aplica o método baseado na utilização da matriz de admitância de barras. O conceito matemático que constitui o programa tem como pilar, parâmetros distribuídos, o método das características e parâmetros concentrados, a regra da integração trapezoidal. Durante a solução são utilizadas técnicas de esparsidade e de fatorização triangular otimizada de matrizes.

O ATPDraw é uma interface gráfica para o ATP. É um software similar a qualquer outro de simulação de circuitos elétricos, é importante ressaltar a existência de algumas peculiaridades pertinentes à sua utilização. Portanto, apesar do ATPDraw ser uma

ferramenta de fácil utilização, é recomendável que os principiantes sejam orientados por um usuário mais experiente, ou então adquiram o conhecimento gradativo do programa a partir de simulação de circuito simples, cuja resposta ele já conheça.

O programa ATPDraw usualmente é utilizado como passo inicial para uma simulação com o ATP. Com o programa ATPDraw o usuário pode construir um circuito elétrico convencional, bastando para isso selecionar modelos pré-definidos dos principais elementos componentes de uma rede elétrica.

Tanto circuitos monofásicos quanto trifásicos, podem ser construídos pelo ATPDraw, com a facilidade de se usar um diagrama unifilar para circuitos trifásicos complexos, não havendo a necessidade de se montar o circuito fase a fase. Isso oferece um leque muito maior de aplicações possíveis não encontradas em outros softwares de simulação de circuitos elétricos.

\section{1 - O SISTEMA}

O circuito escolhido apresenta um diagrama unifilar, com nove barras, contendo um diagrama de impedância e um diagrama de fluxo, que estão presentes na figura 4.1 e na figura 4.2 a seguir. Esse sistema não tinha dados físicos disponíveis, os mesmos foram estimados a partir de dados típicos e dos valores em pu do sistema original. 


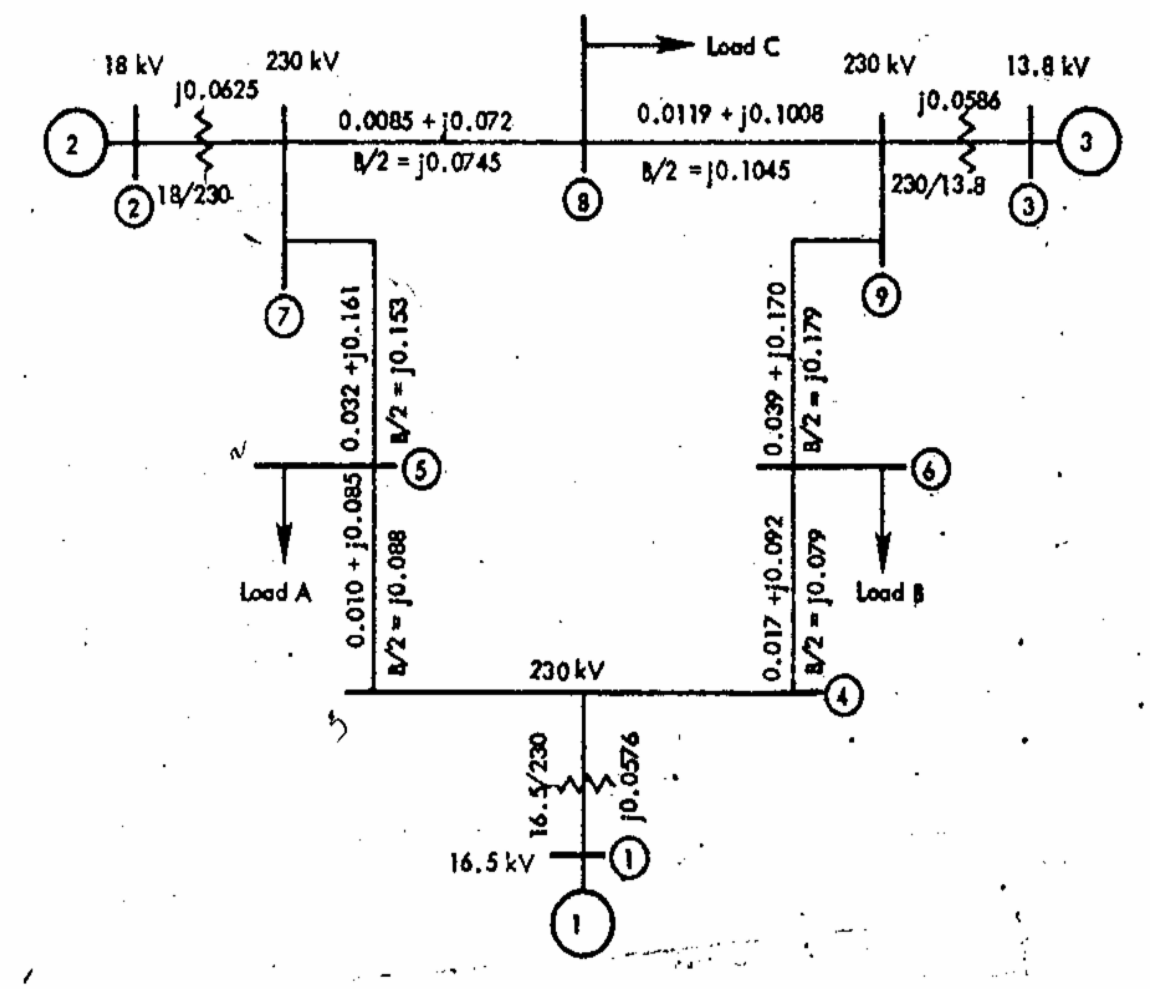

Figura 4.1 - Diagrama de impedância da rede, em pu, com 100 MVA de base.

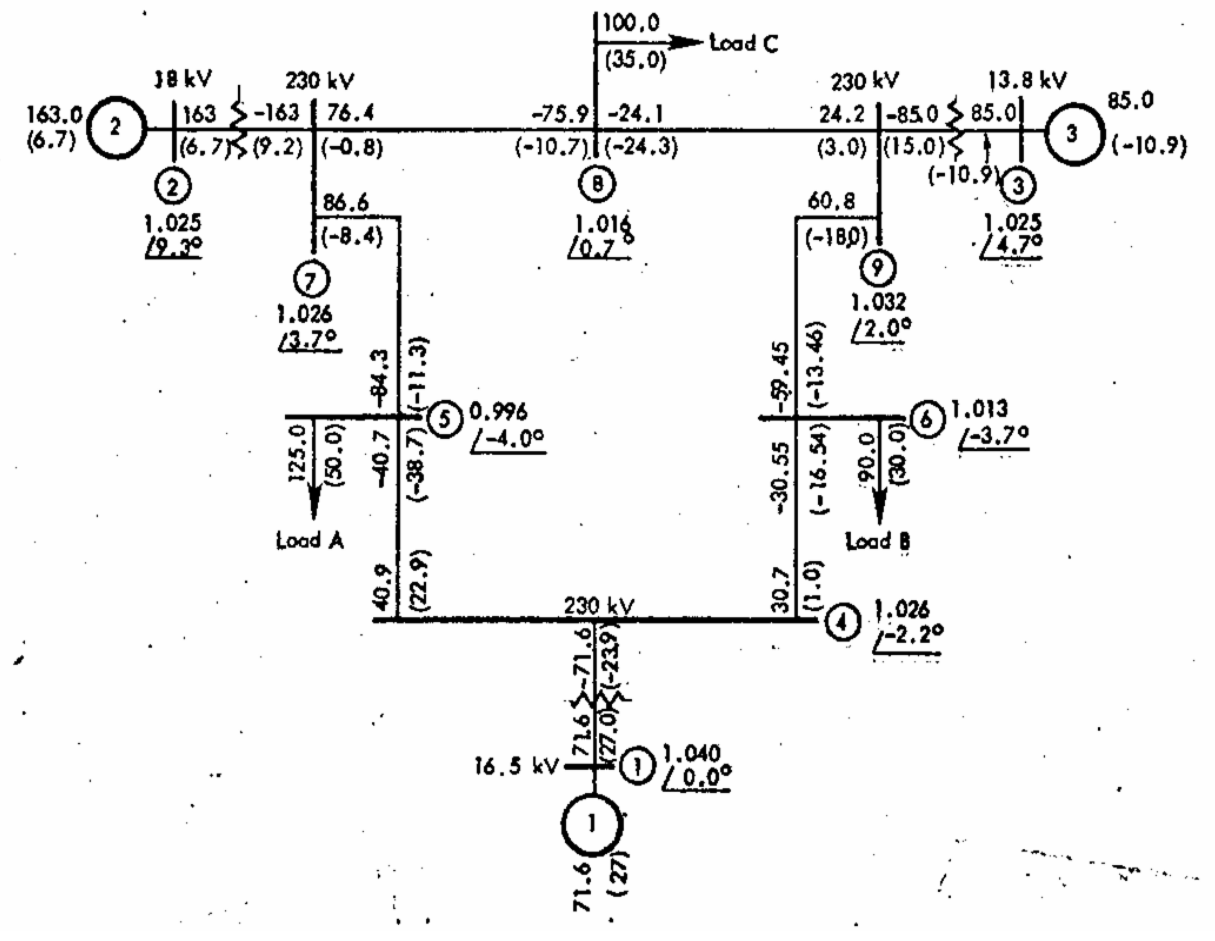

Figura 4.2 - Diagrama de fluxo do circuito, todos os fluxos estão em MW e MVAr. 


\section{2 - IMPLEMENTAÇÃO DO SISTEMA NO ATPDraw}

\subsection{1 - Dimensionamento dos parâmetros de linha}

Para a obtenção dos parâmetros da linha de transmissão, foram consideradas as características dos condutores e suas respectivas disposições geométricas das torres de transmissão. Dentre as considerações, optou-se por linhas de transmissão transpostas.

Sabendo que, para o diagrama de impedância da figura 4.1, a potência de base $\left(\mathrm{S}_{\mathrm{b}}\right)$ é de 100 MVA e que como as linhas de transmissão se encontram, todas, no lado de alta dos transformadores, cuja tensão de linha é de $230 \mathrm{kV}$, e adotando-se como a tensão de base $\left(\mathrm{V}_{\mathrm{b}}\right)$ no lado da linha, calcula-se a impedância de base $\left(\mathrm{Z}_{\mathrm{b}}\right)$ :

$$
Z_{b}=\frac{V_{b}^{2}}{S_{b}}=\frac{230^{2}}{100}=529 \Omega
$$

De posse do valor de $Z_{b}$, efetua-se, o cálculo dos parâmetros das linhas de transmissão. Estes serão obtidos, como abaixo [15]:

$$
Z_{\text {barra }}=Z_{L} \cdot Z_{b}=R_{\text {barra }}+j X_{\text {barra }}
$$

Uma vez obtido $Z_{\text {barra }}$ é necessário, pelo tipo de linha escolhida, dividi-la pelo comprimento da linha, obtendo assim um $Z_{\text {barra }}$ em $[\Omega / \mathrm{km}]$. A parte real de $Z_{\text {barra }}$ é a própria resistência de sequiência positiva, e a parte imaginária é a reatância de seqüência positiva, em ohms:

$$
L^{+}=X_{\text {barra }}
$$

Para a obtenção da capacitância outro parâmetro, a impedância shunt (B/2), fornecida no diagrama é utilizada, a relação com a capacitância se dá através de:

$$
C^{+}=\frac{B}{\omega}=\frac{B}{2 \pi f} \cong \frac{B}{377}
$$


Os parâmetros de sequiência zero são estimados através da multiplicação dos valores de seqüência positiva por três.

Para calcular as impedâncias, em ohms, para todas as linhas multiplica-se $\mathrm{Z}_{\mathrm{b}}(\cdot)$ por $\mathrm{Z}_{\mathrm{l}}$.(pu).

Para a capacitância, de posse do valor da impedância shunt em pu, o cálculo direto fica.

$$
B^{+}=\frac{B}{Z_{b}}
$$

Tabela 4.1 - Parâmetros para as linhas de transmissão.

\begin{tabular}{|c|c|c|c|c|c|c|c|c|c|}
\hline Barras & Impedância-Z $\mathrm{Z}_{\mathrm{L}}(\mathrm{pu})$ & $B / 2(p u)$ & $\mathbf{R}_{\mathbf{0}}$ (ohm) & $\mathbf{R}+(\mathrm{ohm})$ & Xo (ohm) & $\mathrm{X}+(\mathrm{ohm})$ & $\mathrm{C}_{0}$ (Mho) & C+ (Mho) & I (km) \\
\hline $4->5$ & $0.01+j 0.085$ & j 0.088 & 0,1587 & 0,0529 & 1,34895 & 0,44965 & 0,026475 & 0,008825 & 100 \\
\hline $4 \rightarrow 6$ & $0.017+\mathrm{j} 0.092$ & j 0.079 & 0,26979 & 0,08993 & 1,46004 & 0,48668 & 0,023766 & 0,007922 & 100 \\
\hline $5->7$ & $0.032+j 0.161$ & j 0.153 & 0,51 & 0,17 & 2,55507 & 0,85169 & 0,04602 & 0,01534 & 100 \\
\hline $6->9$ & $0.039+\mathrm{j} 0.170$ & $\mathrm{j} 0.179$ & 0,61893 & 0,20631 & 2,6979 & 0,8993 & 0,05385 & 0,01795 & 100 \\
\hline $7 \rightarrow>8$ & $0.0085+10.072$ & 0.0745 & 0,1686 & 0,0562 & 1,4283 & 0,4761 & 0,028014 & 0,009338 & 80 \\
\hline $8 \rightarrow>9$ & $0.0119+j 0.1008$ & 0.1045 & 0,18885 & 0,06295 & 1,5996 & 0,5332 & 0,03144 & 0,01048 & 100 \\
\hline
\end{tabular}

\subsection{2 - Dimensionamento dos parâmetros da carga}

Como o valor das cargas foi fornecido em pu, e as mesmas se encontram no lado de alta, uma vez obtido o valor da impedância de base para o lado em questão, o que foi feito anteriormente, para extrair o valor em ohms basta multiplicá-los, como mostra a fórmula abaixo.

$$
Z_{C}(\Omega)=Z_{C}(p u) \cdot Z_{b}=R_{C} \pm j X_{C}
$$

$\mathrm{O}$ valor da resistência de cada carga é a parte real da impedância $\left(\mathrm{R}_{\mathrm{C}}\right)$, dada em ohms. Já no caso da reatância $\left(\mathrm{X}_{\mathrm{C}}\right)$, o que determina o tipo de reativo é o sinal. Se positivo trata-se de uma carga indutiva, caso contrário é capacitiva.

Para o caso indutivo a relação usada é: 


$$
L_{c}=\frac{X_{c}}{\omega} \cong \frac{X_{c}}{377}
$$

Já no caso capacitivo tem-se:

$$
C_{c}=\frac{1}{\omega X_{c}} \cong \frac{1}{377 X_{c}}
$$

Como para o circuito implementado as cargas consideradas são indutivas, não se fará necessária à utilização da equação (4.7).

\begin{tabular}{|c|c|c|c|c|}
\hline Cargas & Impedância $Z_{c}(p u)$ & Impedância $Z_{c}(o h m)$ & $R_{c}(\mathrm{ohm})$ & -c (ohm \\
\hline A & $0.68+j 0.27$ & $361.91+j 144.76$ & 361,91 & 144.76 \\
\hline $\bar{B}$ & $1.03+\mathrm{j} 0.34$ & $542.84+j 180.95$ & 542,84 & 180.95 \\
\hline $\bar{C}$ & $0.92+\mathrm{j} 0.32$ & $486.47+j 170.2$ & 486,47 & 170.2 \\
\hline
\end{tabular}

Tabela 4.2 - Parâmetros para as cargas.

\subsection{3 - Dimensionamento dos transformadores}

O transformador utilizado é o trifásico saturado, com seu lado de baixa conectado em delta e o lado de alta conectado em estrela, com um defasamento de $30^{\circ}$. Observa-se que o dispositivo usado apresenta uma configuração de um transformador utilizado em sistemas reais.

Os parâmetros que necessitam de um cálculo aprimorado são as reatâncias de cada lado do transformador, e para que esse tipo de modelamento seja feito, deve se obter a impedância de base de ambos os lados do dispositivo. Isto só é possível, porque a reatância equivalente de cada transformador presente no circuito, foi fornecida no sistema [15]. 
Divide-se a reatância de cada transformador por dois. Metade para o lado de alta e a outra metade para o lado de baixa. Com as impedâncias de base de cada lado calculada, tem-se:

$$
Z_{\text {baixa }}(\Omega)=\frac{Z_{\text {equivalente }}(p u)}{2} \cdot Z_{\text {b(baixa })}
$$

Como a impedância é puramente reativa, a indutância do lado primário é obtida conforme a equação abaixo:

$$
L_{\text {baixa }}=3 \frac{Z_{\text {baixa }}}{\omega}=3 \frac{Z_{\text {baixa }}}{377}
$$

O fator multiplicativo é justificado, porque essa forma de cálculo fornece o resultado para uma conexão em estrela, e o lado de baixa está conectado em delta, lembrando ainda que se trata de um sistema equilibrado.

A forma de dimensionamento do lado de alta é muito semelhante ao de baixa, assim a equação para a obtenção da impedância de alta é:

$$
Z_{\text {alta }}(\Omega)=\frac{Z_{\text {equivalente }}(p u)}{2} \cdot Z_{b(\text { alta })}
$$

Como essa ligação é feita em estrela, não é necessário multiplicar por três o valor de impedância encontrada. Vale lembrar, assim como aconteceu anteriormente, que a impedância é puramente reativa, com isso:

$$
L_{\text {baixa }}=\frac{Z_{\text {alta }}}{\omega}=\frac{Z_{\text {alta }}}{377}
$$

Para o cálculo dos parâmetros dos transformadores faz-se necessário o cálculo da impedância de base do lado de baixa dos mesmos. Deve-se lembrar que foi fornecido o valor da reatância equivalente de cada transformador. 
Cálculo da impedância de base do lado de baixa:

$$
\begin{gathered}
X_{b G 1}=\frac{V_{b G 1}^{2}}{S_{b}}=\frac{16,5^{2}\left(10^{3}\right)^{2}}{100.10^{6}}=2,72 \Omega \\
X_{b G 2}=\frac{V_{b G 2}^{2}}{S_{b}}=\frac{18^{2}\left(10^{3}\right)^{2}}{100.10^{6}}=3,24 \Omega \\
X_{b G 3}=\frac{V_{b G 3}^{2}}{S_{b}}=\frac{13,8^{2}\left(10^{3}\right)^{2}}{100.10^{6}}=1,904 \Omega
\end{gathered}
$$

Com isso o valor da reatância equivalente de cada transformador, para cada lado, em ohms, é dado por:

$$
\begin{aligned}
& Z_{G 1 A L T A}=\frac{Z_{G 1}(p u) Z_{b G 1}}{2}=15,23 \Omega \\
& Z_{G 2 A L T A}=\frac{Z_{G 2}(p u) Z_{b G 2}}{2}=16,53 \Omega \\
& Z_{G 3 A L T A}=\frac{Z_{G 3}(p u) Z_{b G 3}}{2}=15,5 \Omega \\
& Z_{G 1 B A I X A}=\frac{Z_{G 1}(p u) Z_{b G 1}}{2}=0,0783 \Omega \\
& Z_{G 2 B A I X A}=\frac{Z_{G 2}(p u) Z_{b G 2}}{2}=0,101 \Omega \\
& Z_{G 3 B A I X A}=\frac{Z_{G 3}(p u) Z_{b G 3}}{2}=0,0558 \Omega
\end{aligned}
$$

Com isso tem-se o valor da indutância referente a cada lado do transformador, lembrando que se o lado do transformador for ligado em delta, deve-se multiplicar por 3.

Tabela 4.3 - Parâmetros para os transformadores.

\begin{tabular}{|c|c|c|c|c|c|}
\hline Barra & $Z_{\text {equivalente }}(\mathrm{pu})$ & $\mathrm{V}_{\mathbf{1}}(\mathrm{kV})$ & $\mathrm{L}_{\mathbf{1}}(\mathrm{ohm})$ & $\mathbf{V}_{\mathbf{2}}(\mathrm{kV})$ & $\mathrm{L}_{\mathbf{2}}(\mathrm{ohm})$ \\
\hline $\mathbf{1} \rightarrow \mathbf{4}$ & $\mathrm{j} 0.0576$ & 16,5 & 0,2349 & 132,8 & 13,23 \\
\hline $\mathbf{2} \rightarrow \mathbf{7}$ & j 0.0625 & 18 & 0,3036 & 132,8 & 16,53 \\
\hline $\mathbf{3} \rightarrow \mathbf{9}$ & j 0.0586 & 132,8 & 15,5 & 13,8 & 0,1674 \\
\hline
\end{tabular}




\section{3 - SIMULAÇÕES}

Após a montagem e a especificação dos parâmetros do circuito escolhido, são estabelecidas as configurações para simulação. Esta é uma parte importante do processo, já que é nessa hora que se determina o tempo de simulação, o domínio em que se deseja trabalhar (tempo ou freqüência), existência ou não de harmônicos e o intervalo de análise. Isto é feito a partir da seleção do ícone “ATP” na barra de tarefas. Escolheu-se "Delta $T$ ” igual a $2 \mu \mathrm{s}$. Isto significa que este será o intervalo de cálculo, ou seja, a cada período o programa fará uma leitura do circuito, uma vez que um programa digital não permite obter uma solução contínua no tempo. "Tmax", corresponde ao tempo máximo de simulação do circuito. O valor desse parâmetro foi fixado em 0,2s. Isto representa a janela de amostras de resultados. O valor de "Xopt" determina qual a unidade será adotada pelo programa, se for igual a zero, tem-se que o valor da indutância será dado em $\mathrm{mH}$, caso contrário o sistema admitirá este valor em ohms. Sendo a freqüência $60 \mathrm{~Hz}$, adotou-se o valor de "Xopt" =60. Obtendo todas as unidades em ohms.

As configurações foram utilizadas em todas as simulações.

\subsection{1 - Curtos monofásicos}

Executando o arquivo da Figura 4.3, o qual se refere a uma falta fase-terra com resistência de falta de $0.001 \Omega$, aplicada a $60 \mathrm{~km}$ do relé, obtemos o registro das seguintes formas de onda de tensão e corrente apresentadas nas figuras (4.4) e (4.5) respectivamente.

A parte usada do arquivo gerado pelo programa ATPDraw executado pelo comando LISfile está mostrado no apêndice C. E ressalta-se que este é o arquivo utilizado pelo algoritmo implementado em Matlab® para as amostras. 


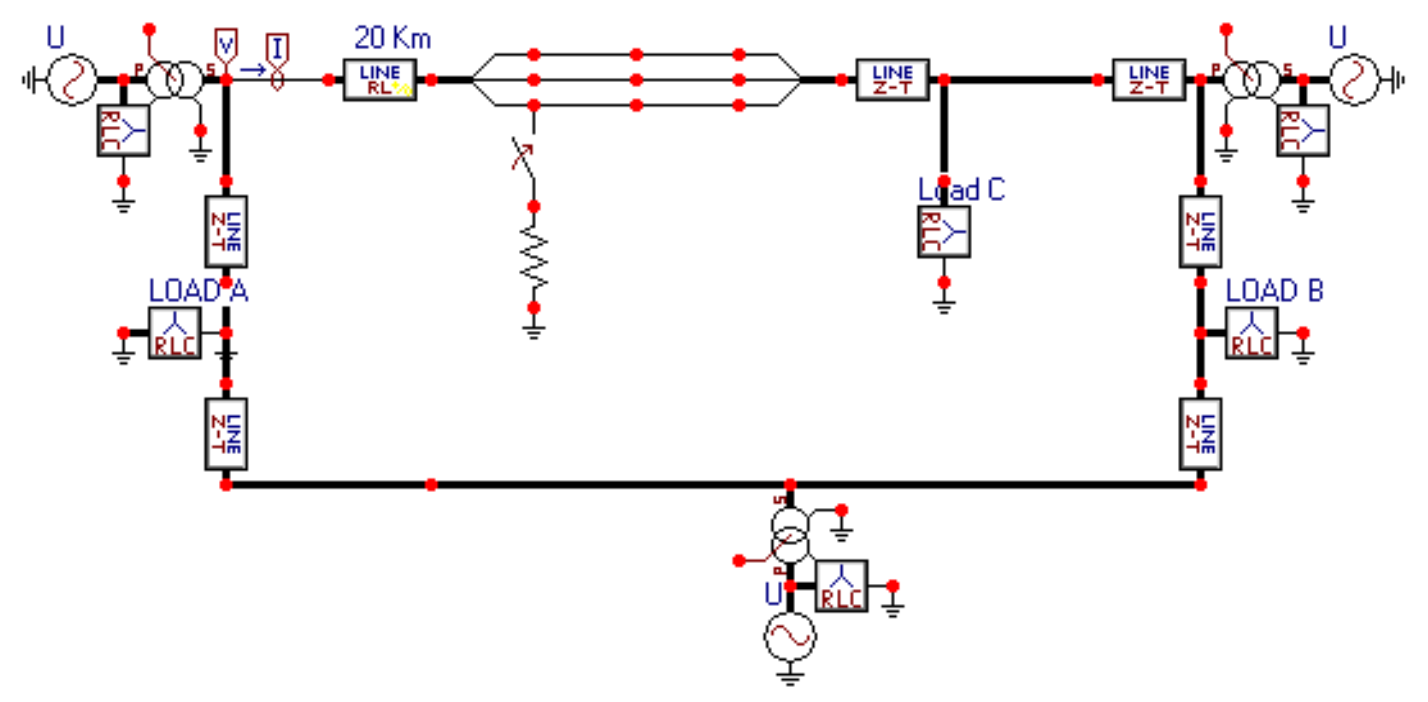

Figura 4.3 - Diagrama esquemático implementado no ATPDraw para simular uma para falta monofásica a $60 \mathrm{~km}$

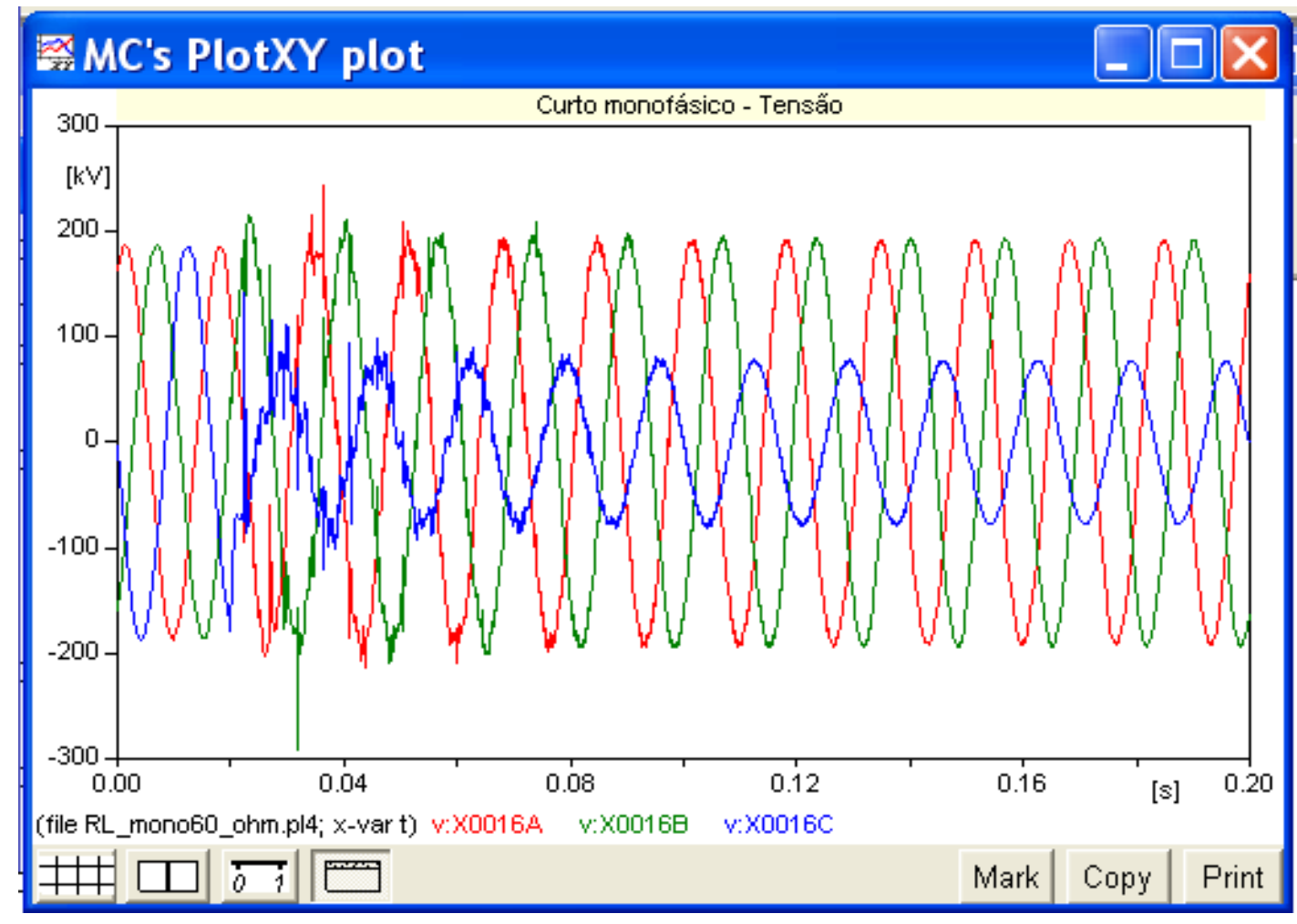

Figura 4.4 - Formas de onda de tensão para uma falta monofásica a $60 \mathrm{~km}$ do lado do terminal da esquerda da linha de transmissão 


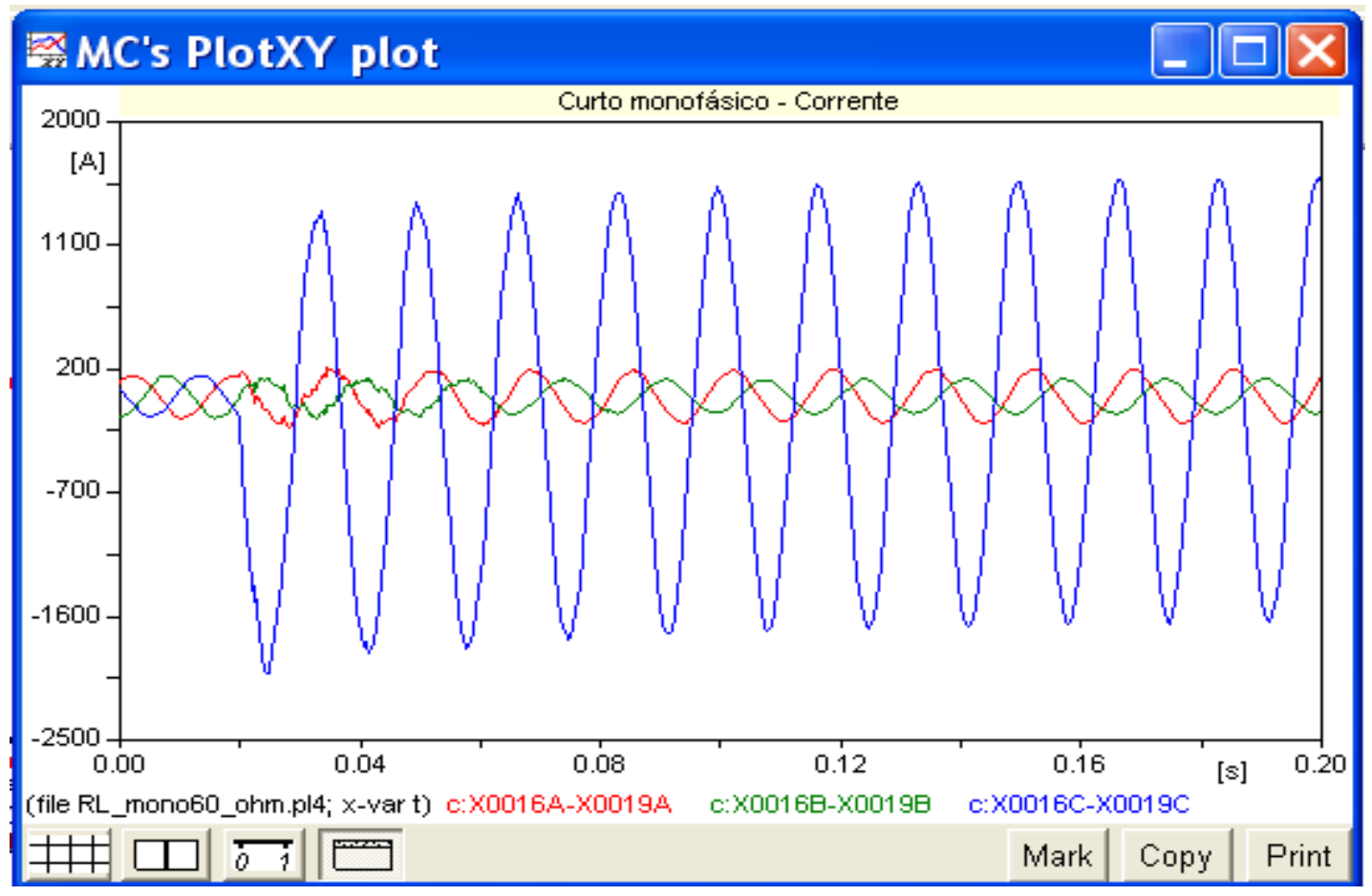

Figura 4.5 - Formas de onda de corrente para uma falta monofásica a $60 \mathrm{~km}$ do lado do terminal da esquerda da linha de transmissão

$\mathrm{O}$ arquivo da Figura 4.6, o qual se refere a uma falta fase-terra com resistência de falta de $0.001 \Omega$, aplicada a $130 \mathrm{~km}$ do relé. Este segundo circuito difere do primeiro pela distância do curto até o relé. As formas de onda de tensão e corrente estão apresentadas nas Figuras 4.7 e 4.8 respectivamente.

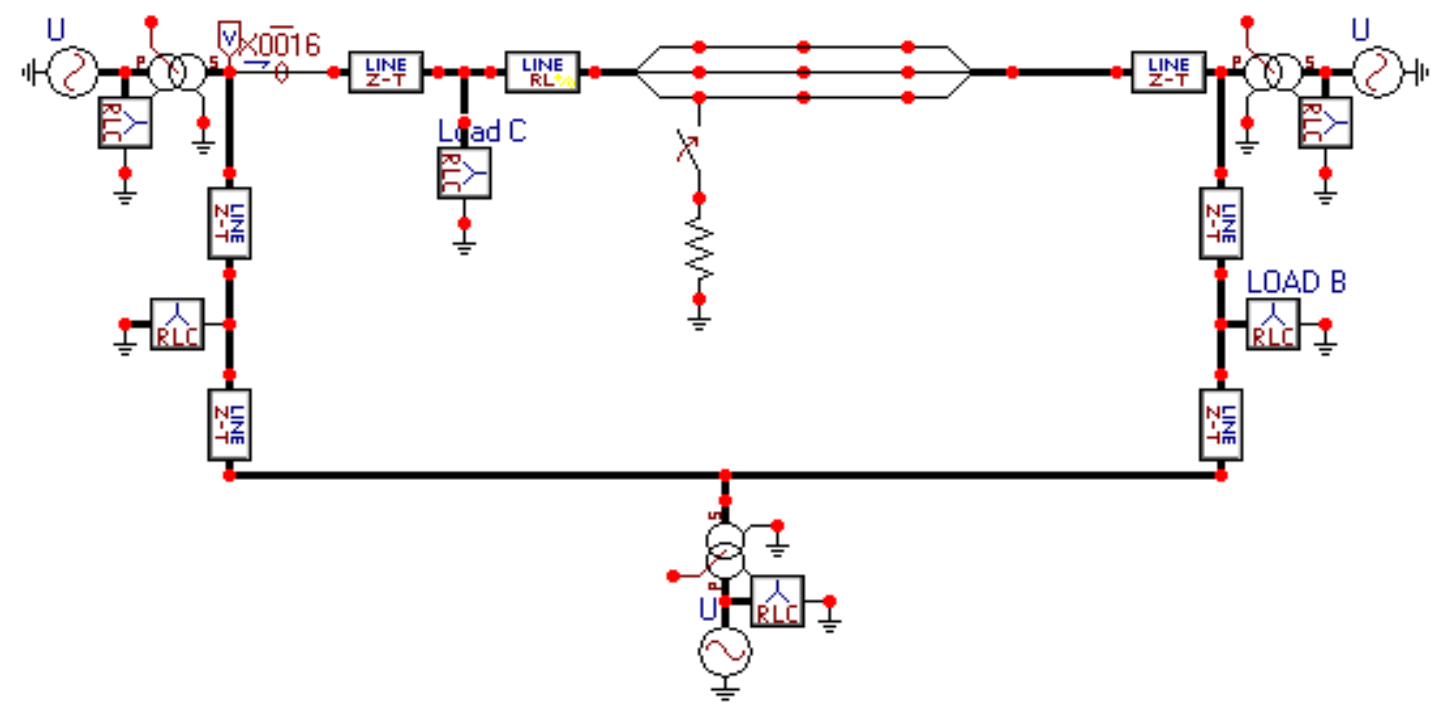

Figura 4.6 - Diagrama esquemático implementado no ATPDraw para simular uma para falta monofásica a $130 \mathrm{~km}$ 


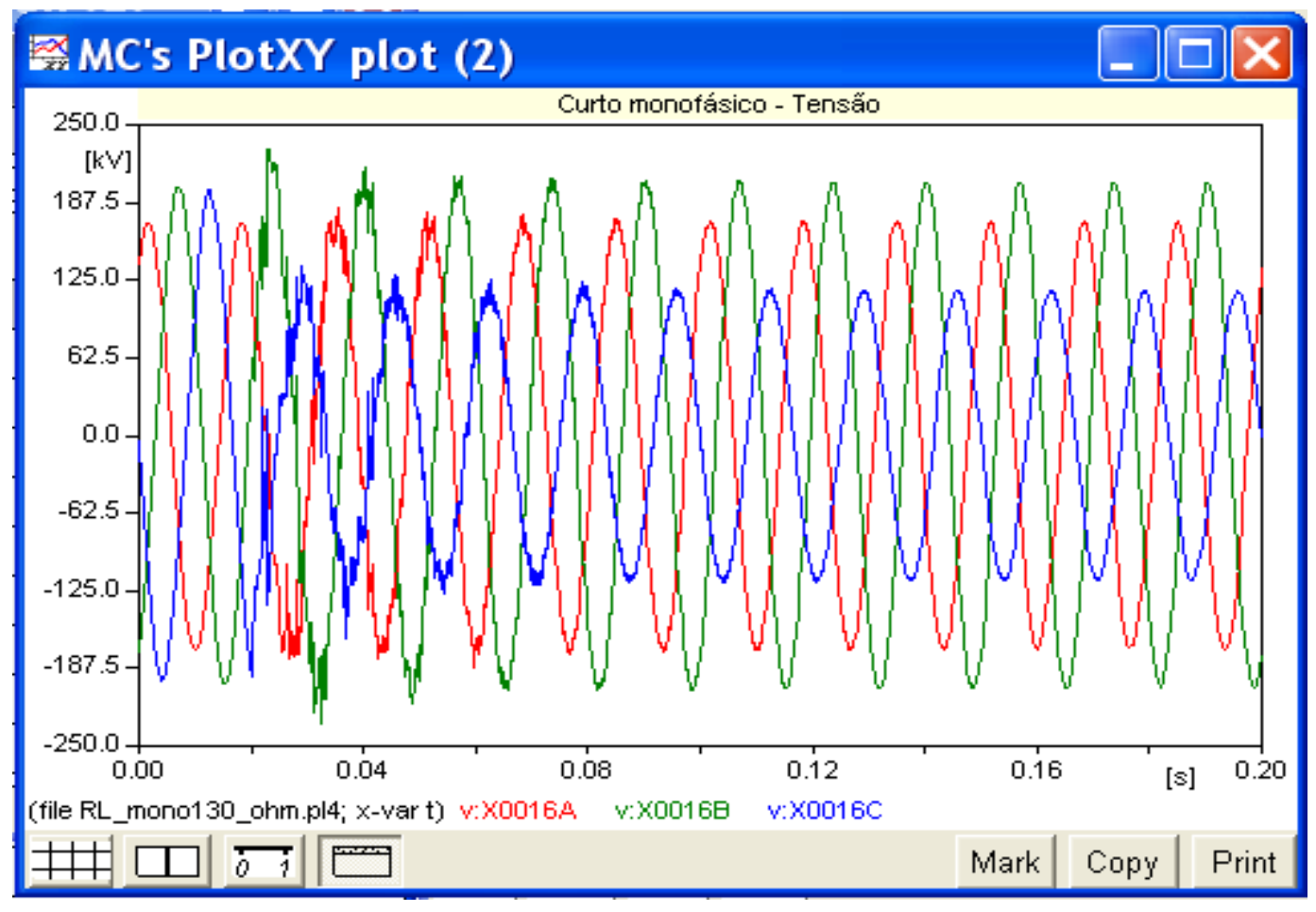

Figura 4.7 - Formas de onda de tensão para uma falta monofásica a $130 \mathrm{~km}$ do lado do terminal da esquerda da linha de transmissão

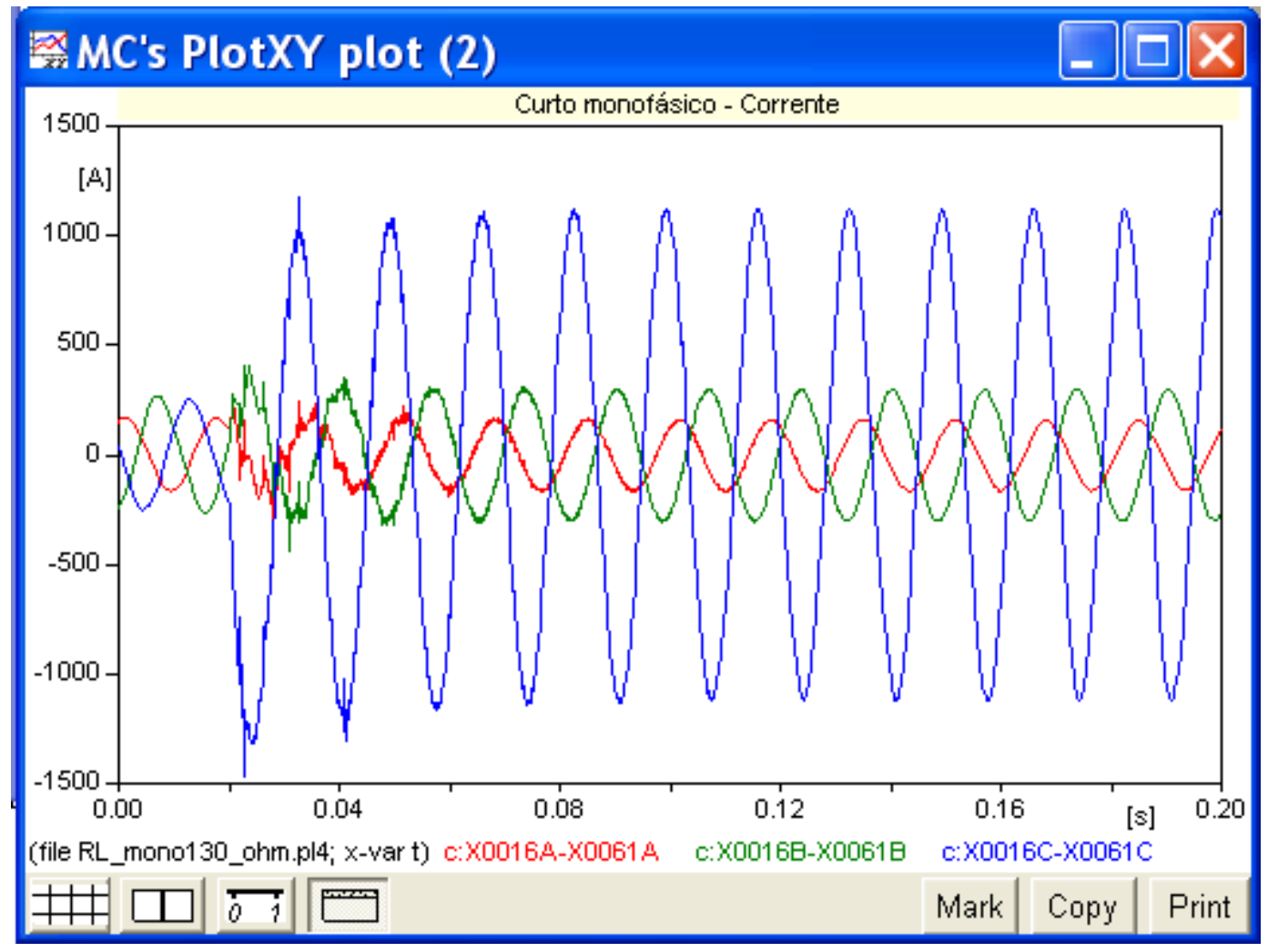

Figura 4.8 - Formas de onda de corrente para uma falta monofásica a $130 \mathrm{~km}$ do lado do terminal da esquerda da linha de transmissão 


\subsection{2 - Variações nas Simulações das Condições de Faltas}

Como já mencionado, os dados dos sinais faltosos foram obtidos dispondo-se do software ATPDraw, levando-se em consideração vários tipos de faltas em diferentes localizações ao longo das linhas entre os barramentos 7 e 9 . As variações consideradas são descritas a seguir:

a)Tipos de falta aplicadas:

Fase-terra

Fase-fase

Trifásica

b) Distâncias em que as faltas foram aplicadas

$20 \mathrm{~km}$ a partir do terminal 7

$60 \mathrm{~km}$ a partir do terminal 7

$90 \mathrm{~km}$ a partir do terminal 7 (sendo $10 \mathrm{~km}$ a partir do terminal 8)

$130 \mathrm{~km}$ a partir do terminal 7 (sendo $50 \mathrm{~km}$ a partir do terminal 8)

c) Resistência de falta

$0.001 \Omega$

d) Resistência de falta entre fases

$1 \Omega$

As situações de faltas foram implementadas conforme as combinações apresentadas na Figura 4.9.

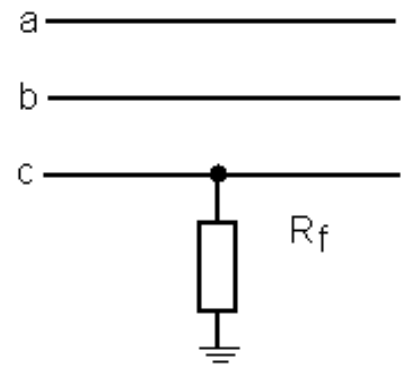

a) Falta Monofásica

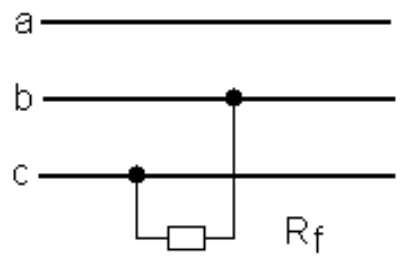

b) Falta Bifásica

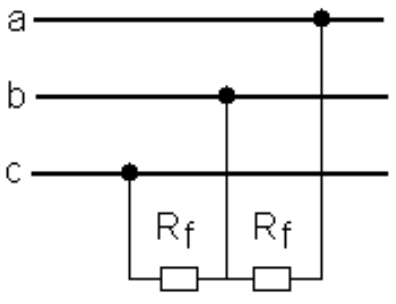

c) Falta Trifásica 


\section{4 - O ALGORITMO DO RELÉ DE DISTÂNCIA}

No capítulo 2, analisou-se o relé de distância que recebeu essa denominação, porque sua atuação baseia-se na observação da impedância entre a localização da falta e a localização do relé. Ou seja, esse relé reconhece faltas ocorrendo dentro de uma seção ou zona protegida.

Neste trabalho, tomando-se como referência o sistema elétrico representado nas Figuras 4.1 e 4.2, as zonas de proteção foram consideradas com as seguintes proporções:

- Primeira Zona - até $64 \mathrm{~km}$, a partir do barramento 7, o que corresponde a $80 \%$ da linha de transmissão entre os barramentos 7 e 8 .

- Segunda Zona - de 64 até $96 \mathrm{~km}$, a partir do barramento 7, o que corresponde a 100\% da primeira linha entre os barramentos 7 e 8 , e a $16 \%$ da segunda linha de transmissão entre os barramentos 8 e 9 .

- Terceira Zona - de 96 até $128 \mathrm{~km}$, a partir do barramento 7, o que corresponde a 100\% da primeira linha entre os barramentos 7 e 8 , e a $28 \%$ da segunda linha de transmissão entre os barramentos 8 e 9 . Representando um percentual de $120 \%$ e $160 \%$ desde o relé. 


\section{5 - LÓGICA COMPUTACIONAL IMPLEMENTADA PARA O RELÉ DE DISTÂNCIA}

A implementação do algoritmo computacional seguindo a abordagem proposta foi realizada da maneira como mostra a Figura 4.10.

Visando analisar o desempenho da proteção digital de distância, foi desenvolvido um programa em Matlab®, que é apresentado no Apêndice B.

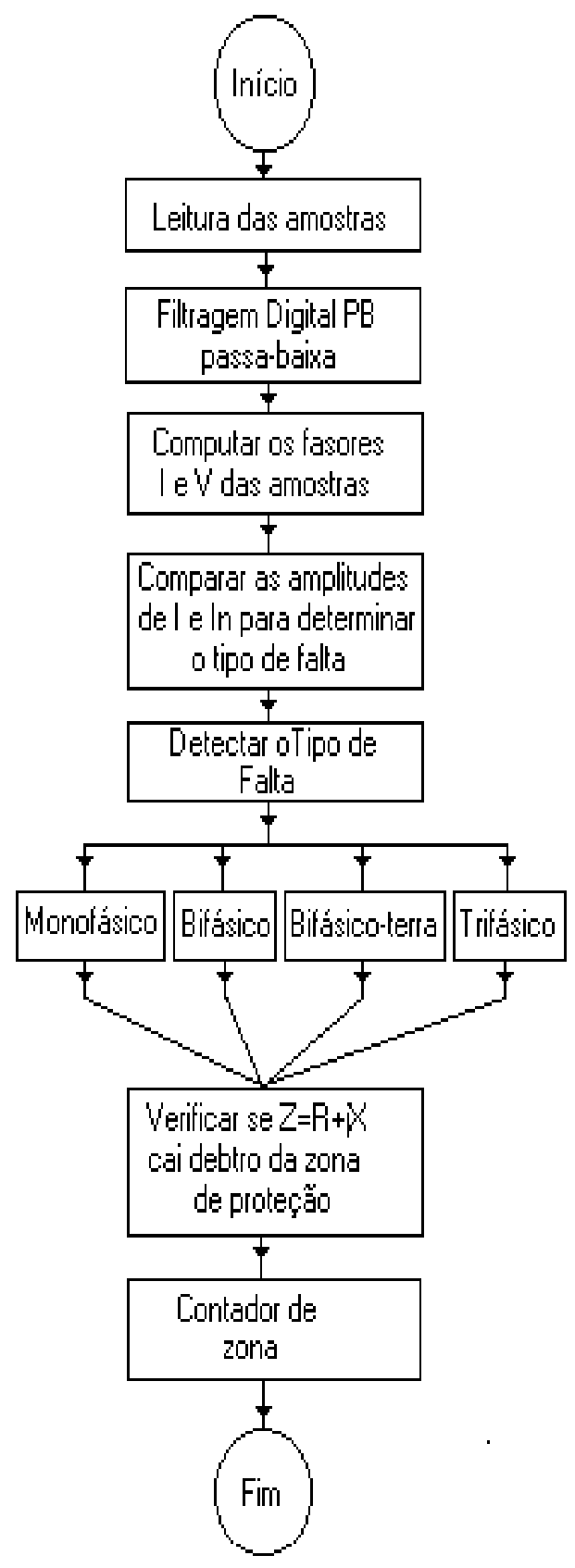

Figura 4.10 - Fluxograma do algoritmo do relé de distância 


\section{5 - TESTES E RESULTADOS OBTIDOS RELATIVO AOS ALGORITMOS ESTUDADOS}

O algoritmo para a detecção e localização das situações de falta que venham a ocorrer sobre determinado sistema de transmissão, com a conseqüente determinação das zonas de proteção, foi implementado através do software Matlab® e testado utilizando-se de dados obtidos através de simulações do software ATPDraw.

Os programas desenvolvidos relativos aos algoritmos de Ramamoorthy e Mc-Innes \& Morrinson são apresentados nos Apêndices A e B respectivamente.

Seguem agora os gráficos gerados com a implementação de tais algoritmos.

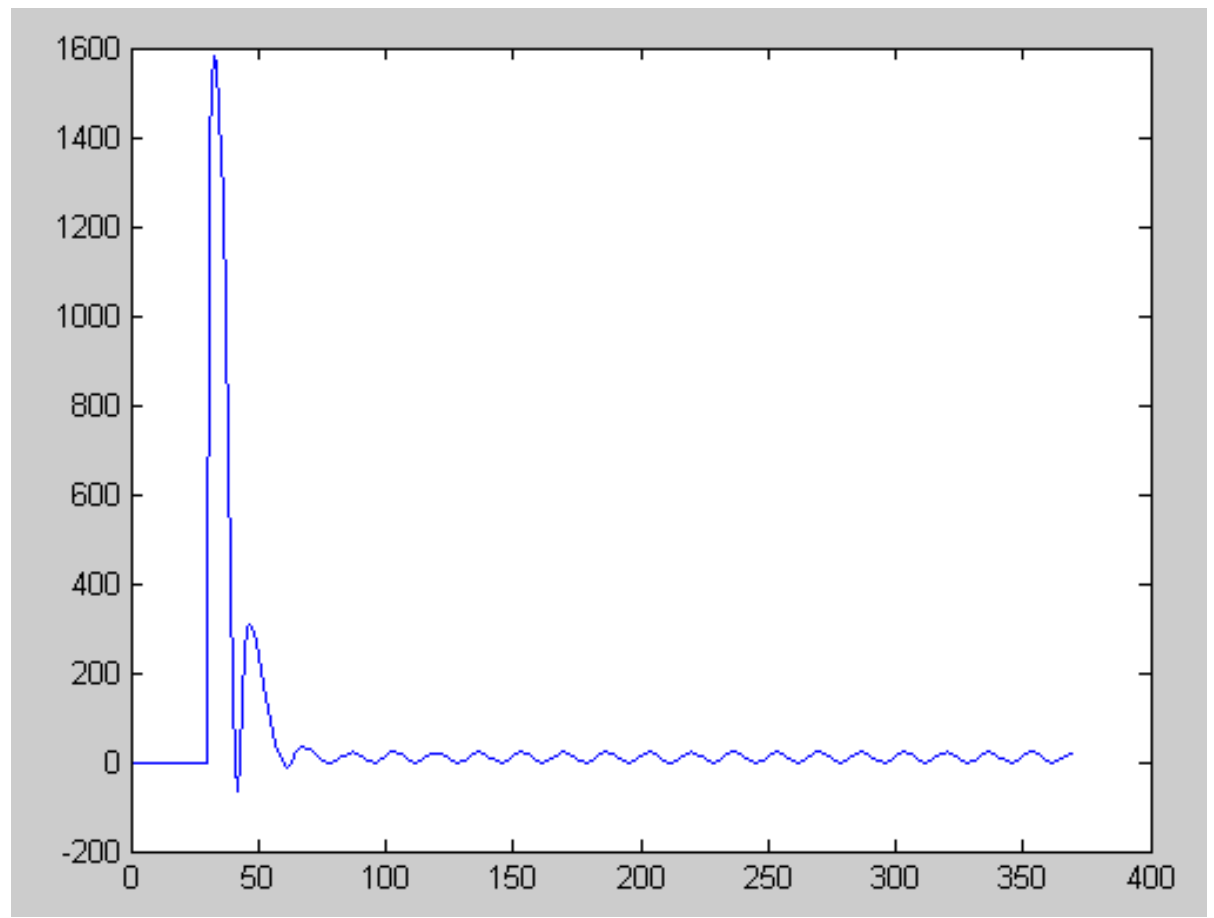

Figura 5.1 - Reatância relativa a um curto-circuito monofásico a $20 \mathrm{~km}$. Baseado no algoritmo de RAMAMOORTHY et all. 


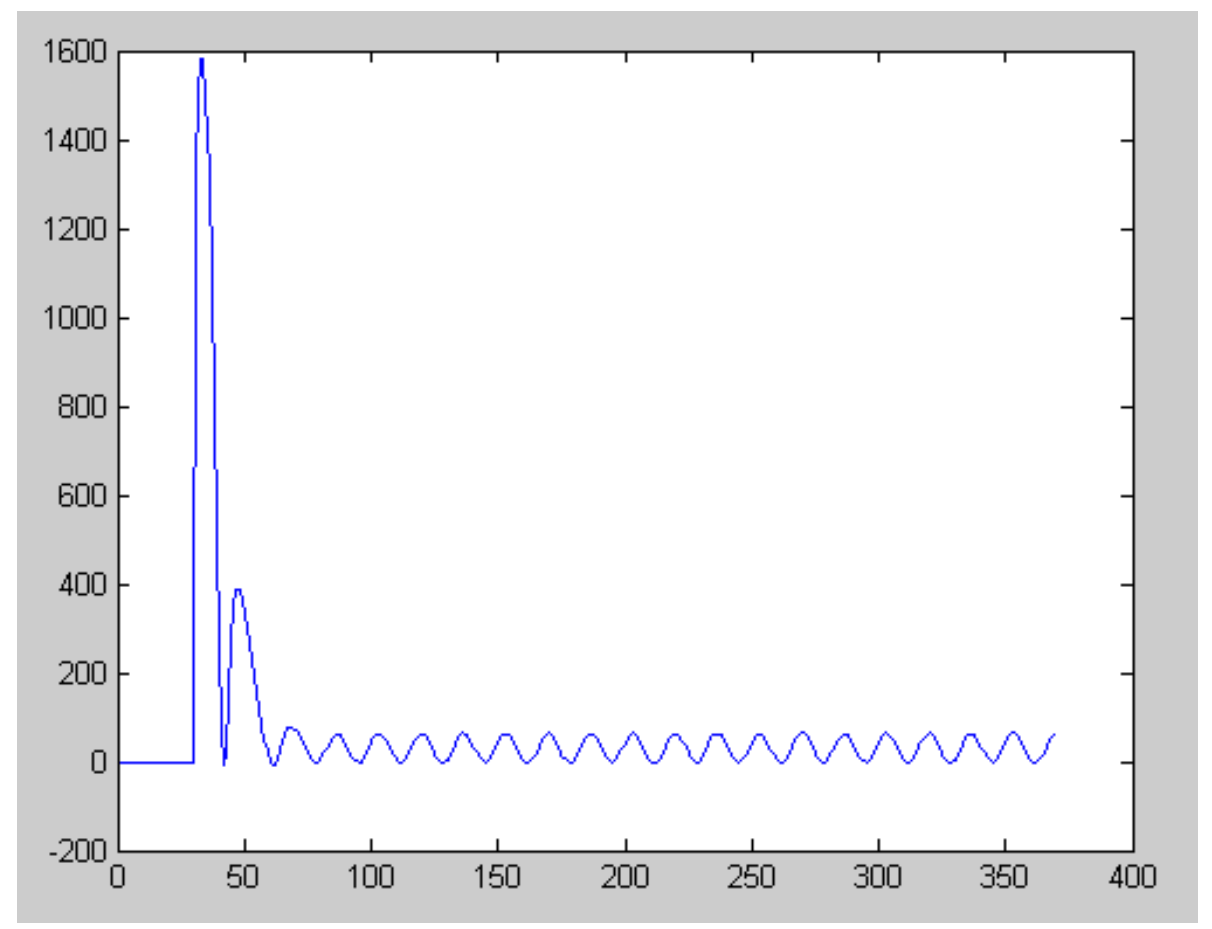

Figura 5.2 - Reatância relativa a um curto-circuito monofásico a $60 \mathrm{~km}$. Baseado no algoritmo de RAMAMOORTHY et all.

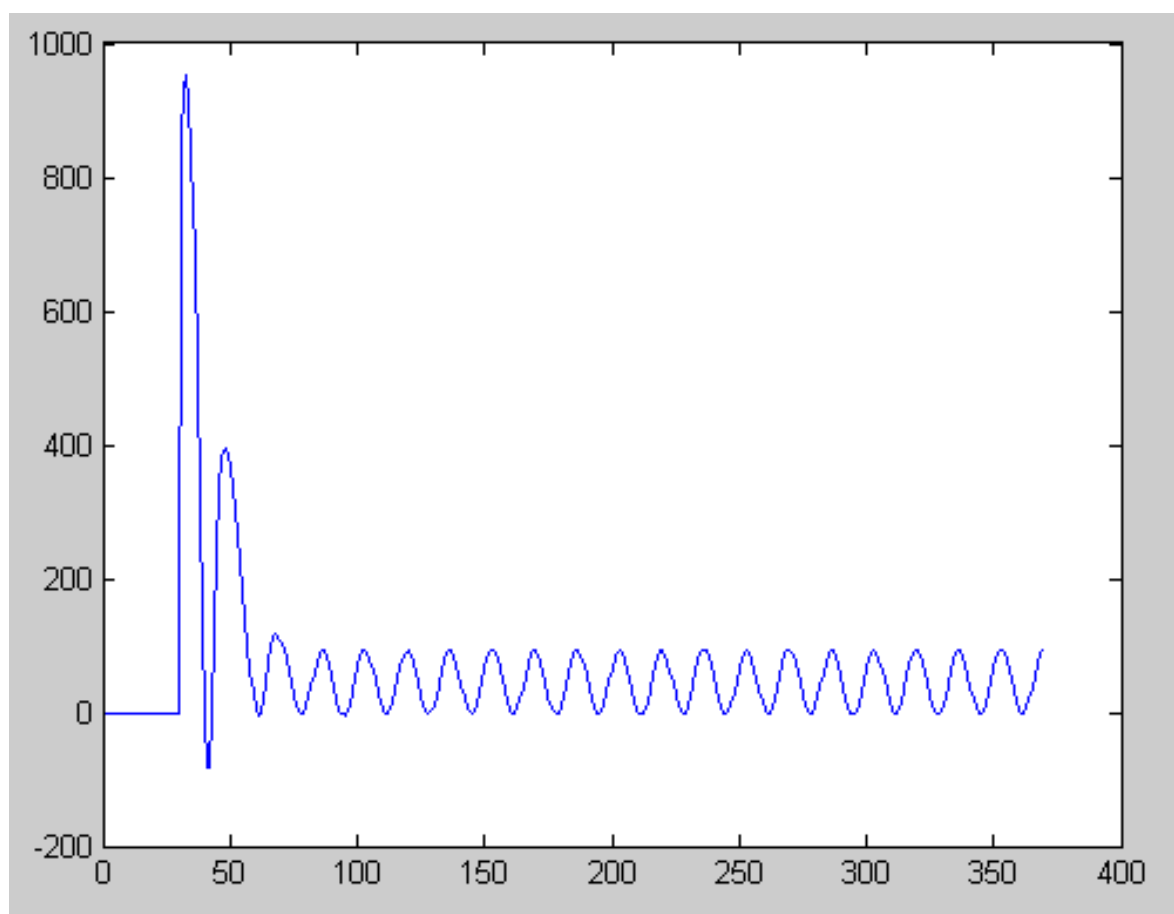

Figura 5.3 - Reatância relativa a um curto-circuito monofásico a $90 \mathrm{~km}$. Baseado no algoritmo de RAMAMOORTHY et all. 


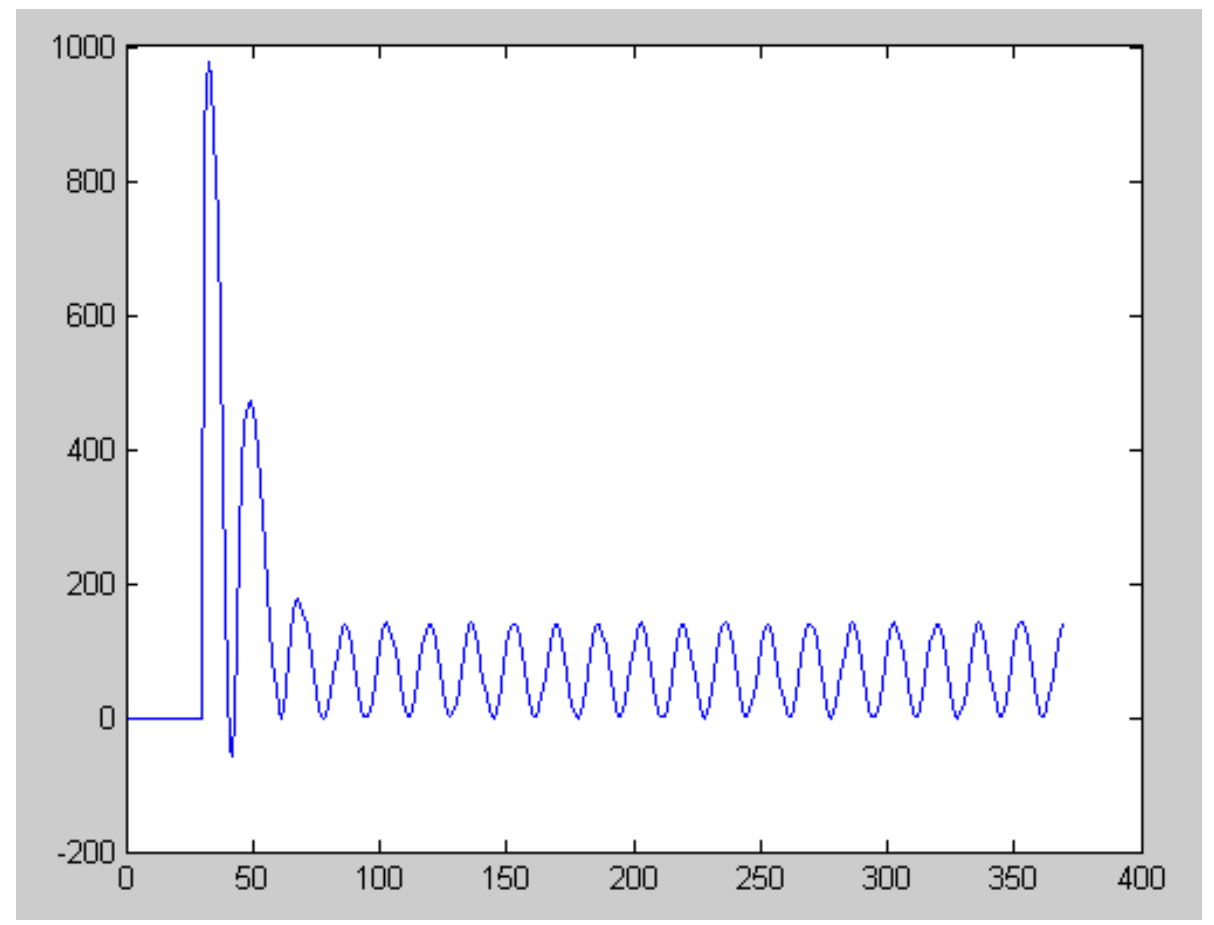

Figura 5.4 - Reatância relativa a um curto-circuito monofásico a $130 \mathrm{~km}$. Baseado no algoritmo de RAMAMOORTHY et all

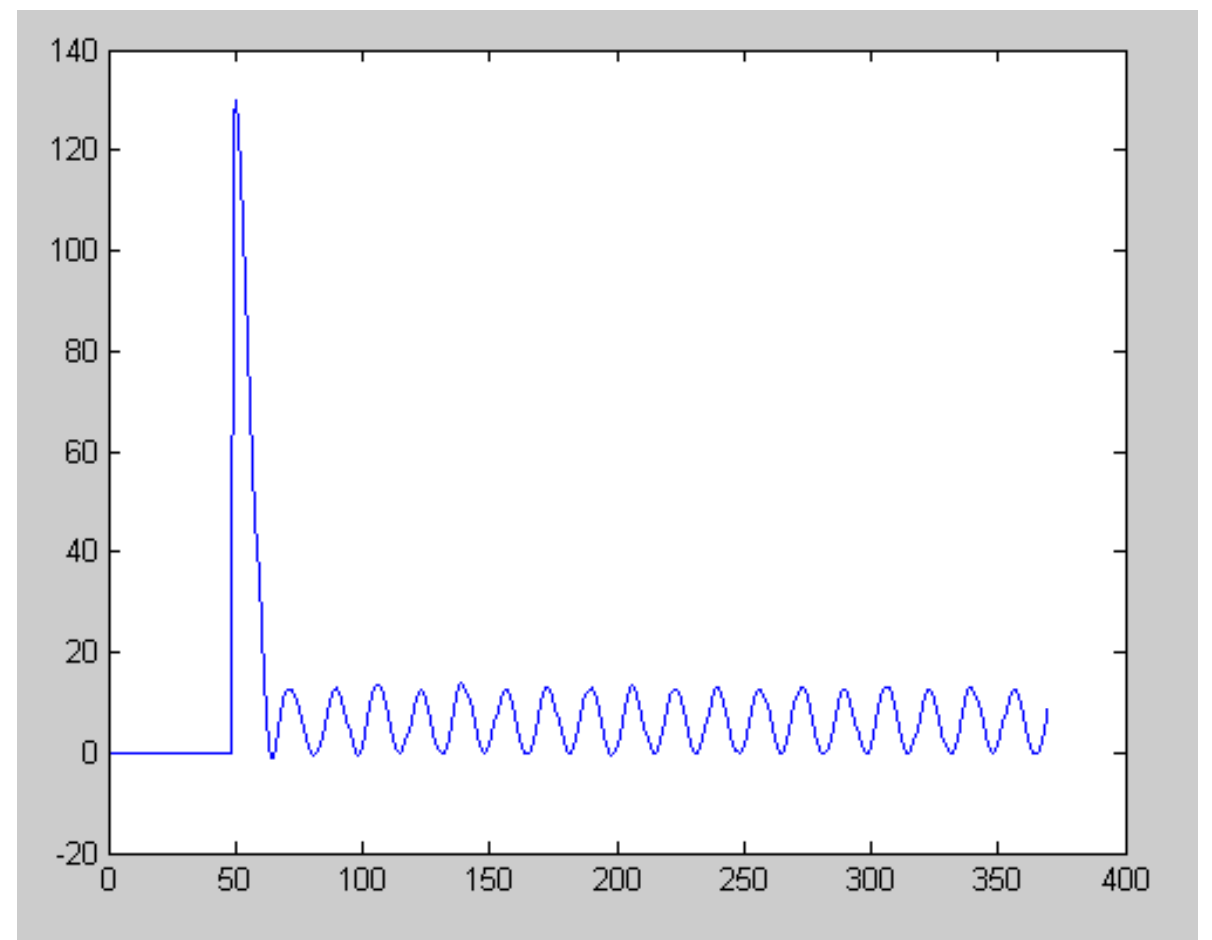

Figura 5.5 - Reatância relativa a um curto-circuito bifásico a $20 \mathrm{~km}$. Baseado no algoritmo de RAMAMOORTHY et all. 


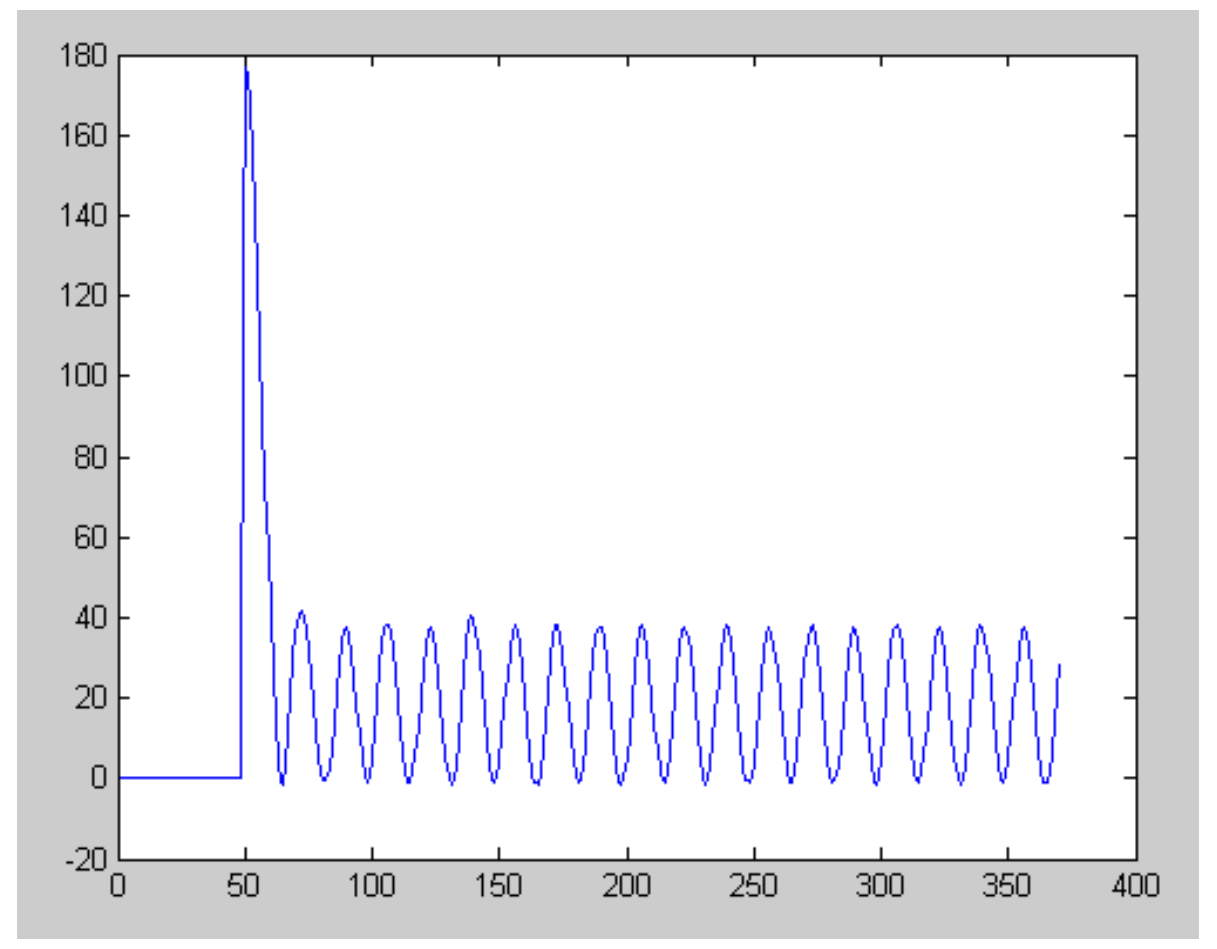

Figura 5.6 - Reatância relativa a um curto-circuito bifásico a $60 \mathrm{~km}$. Baseado no algoritmo de RAMAMOORTHY et all.

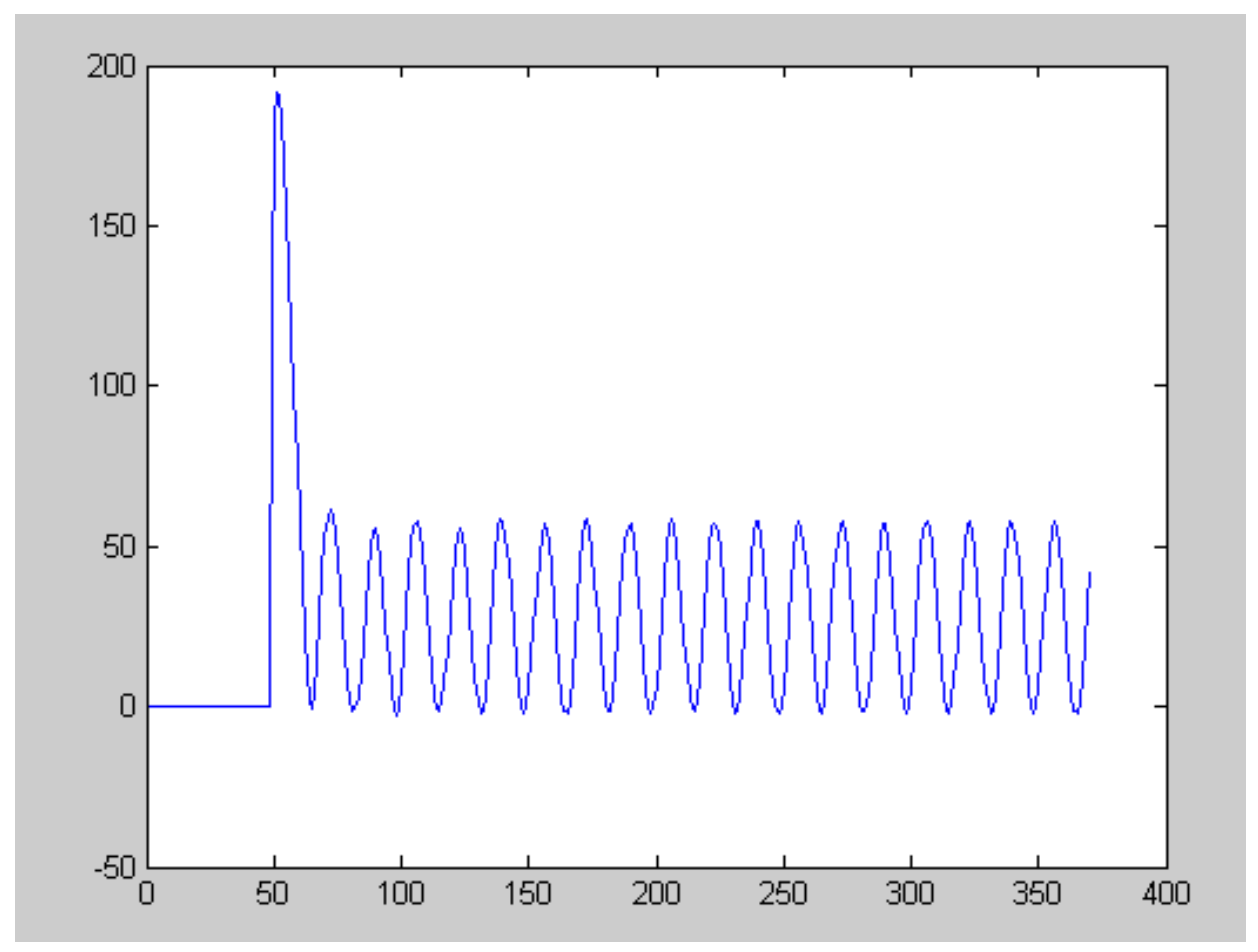

Figura 5.7 - Reatância relativa a um curto-circuito bifásico a $90 \mathrm{~km}$. Baseado no algoritmo de RAMAMOORTHY et all. 


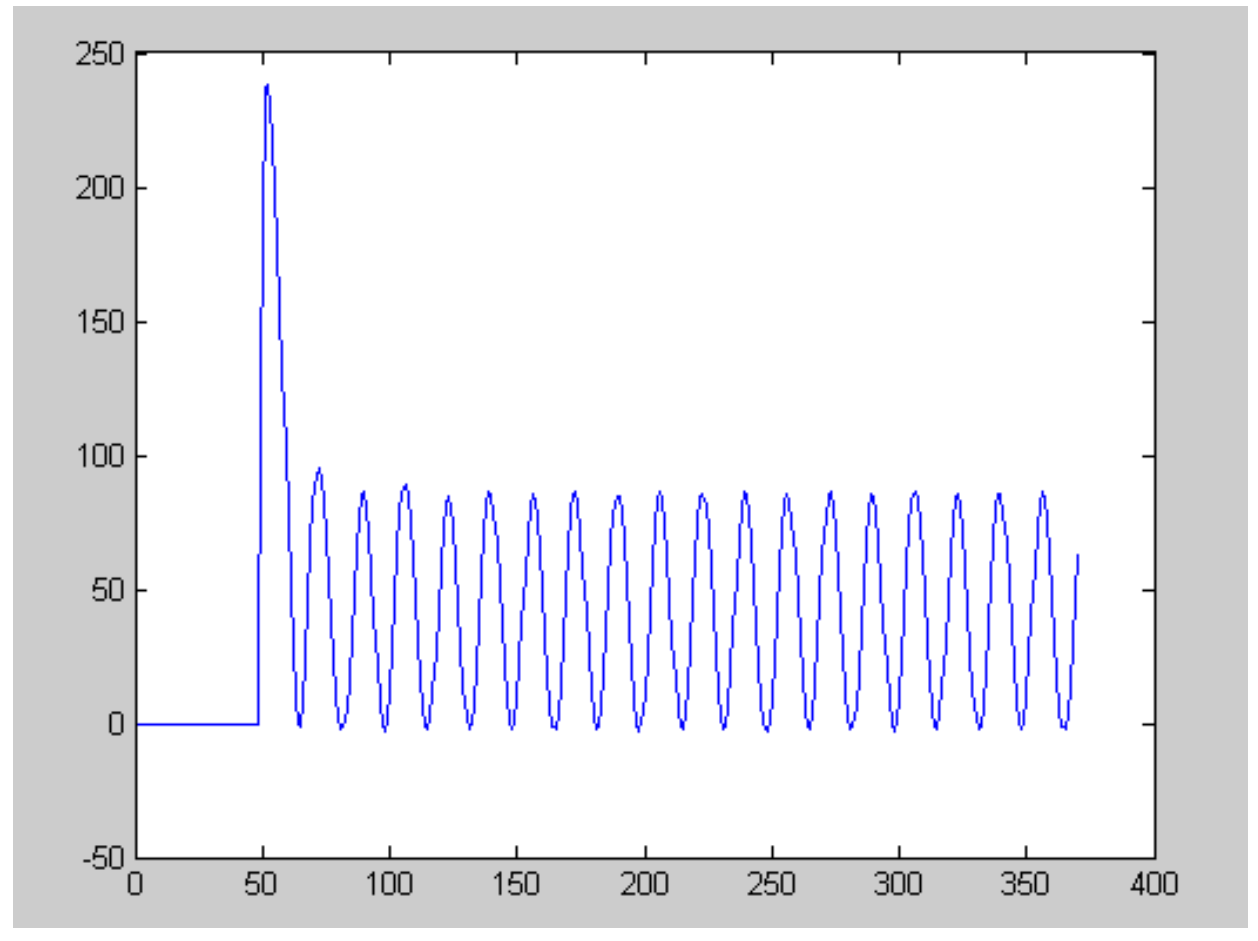

Figura 5.8 - Reatância relativa a um curto-circuito bifásico a $130 \mathrm{~km}$. Baseado no algoritmo de RAMAMOORTHY et all.

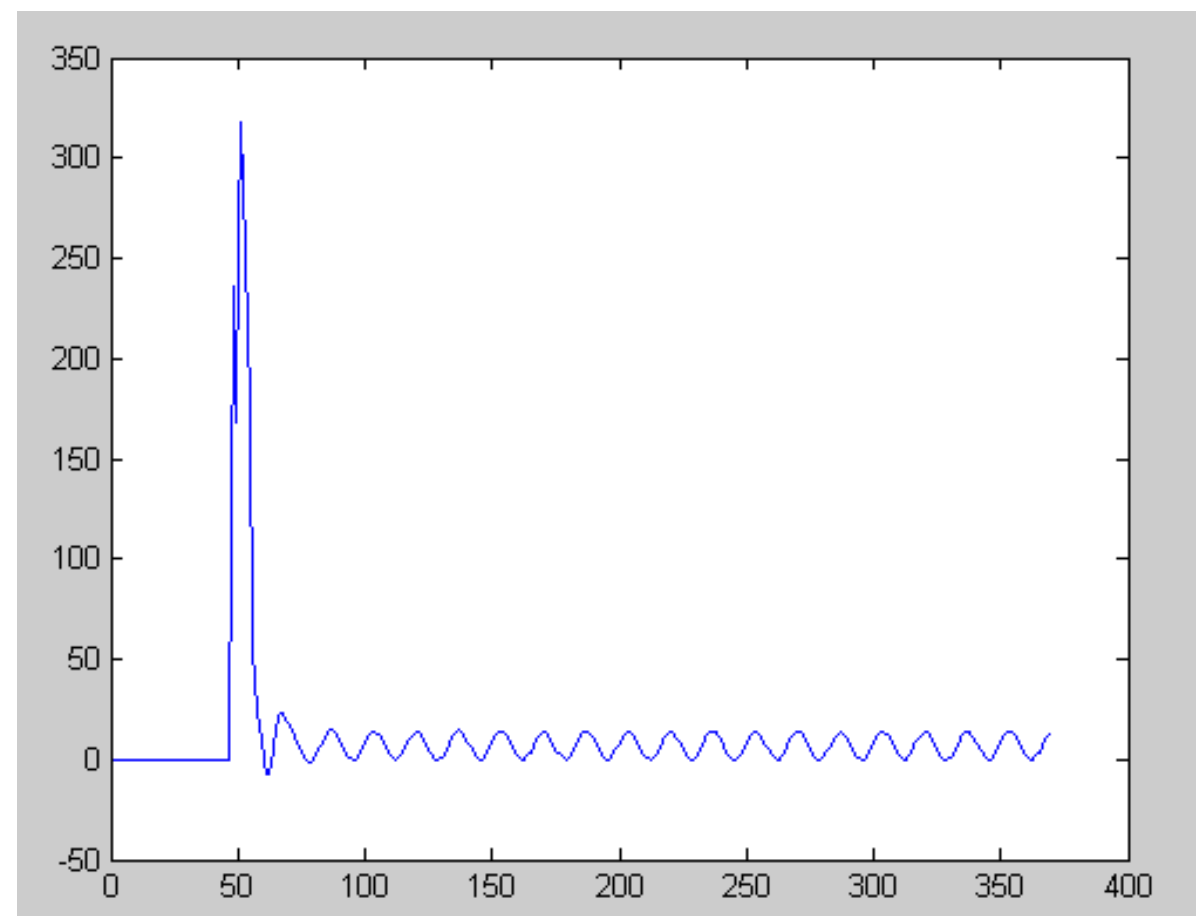

Figura 5.9 - Reatância relativa a um curto-circuito trifásico a $20 \mathrm{~km}$. Baseado no algoritmo de RAMAMOORTHY et all. 


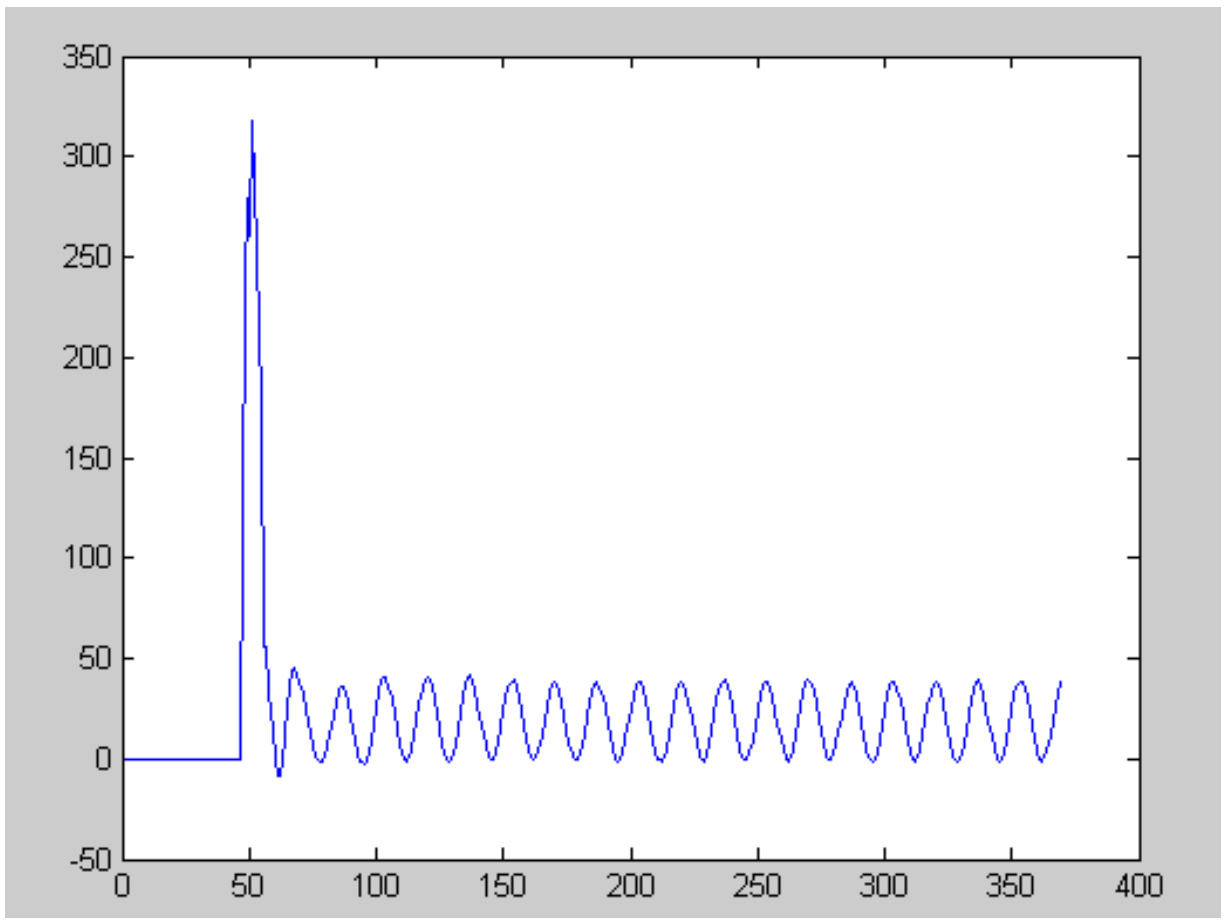

Figura 5.10 - Reatância relativa a um curto-circuito trifásico a $60 \mathrm{~km}$. Baseado no algoritmo de RAMAMOORTHY et all.

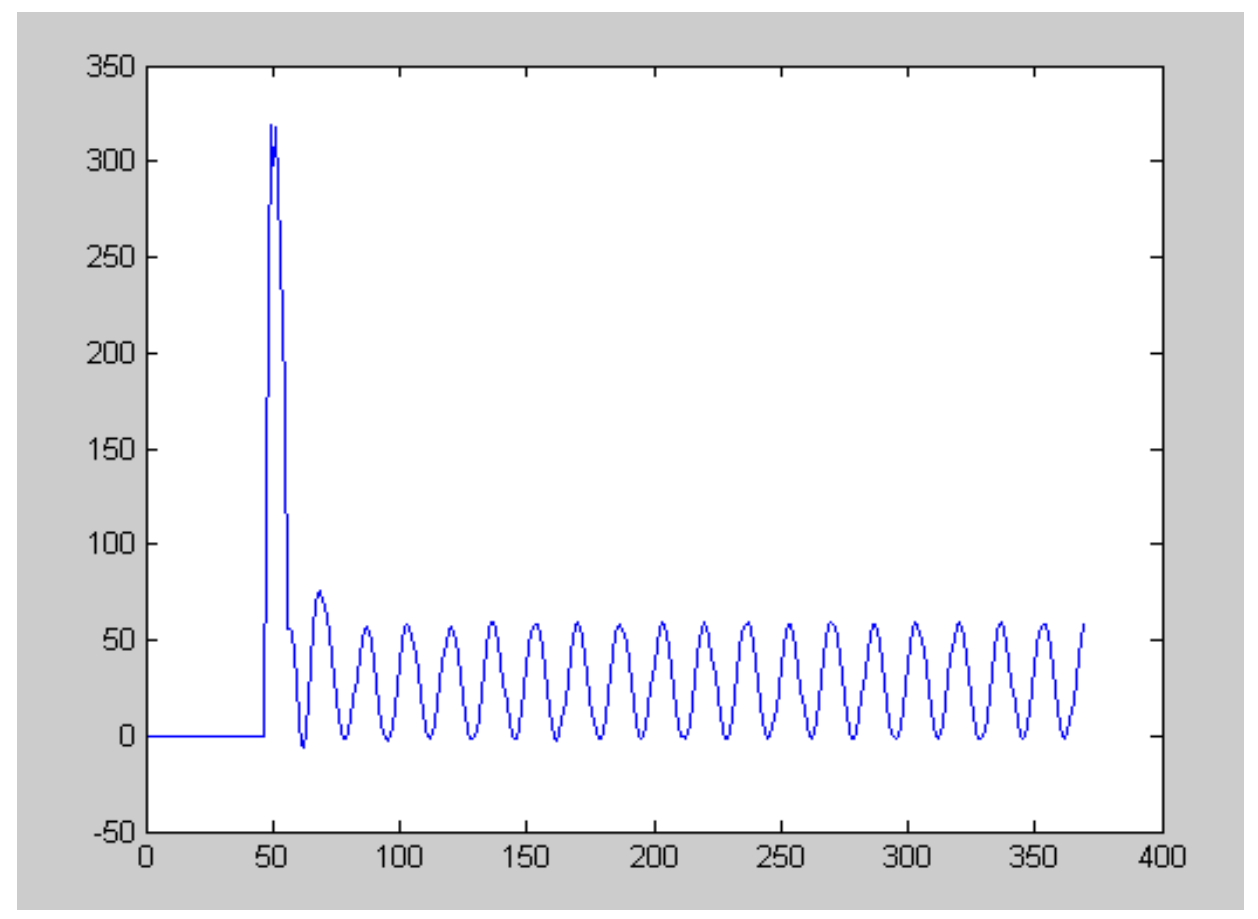

Figura 5.11 - Reatância relativa a um curto-circuito trifásico a $90 \mathrm{~km}$. Baseado no algoritmo de RAMAMOORTHY et all. 


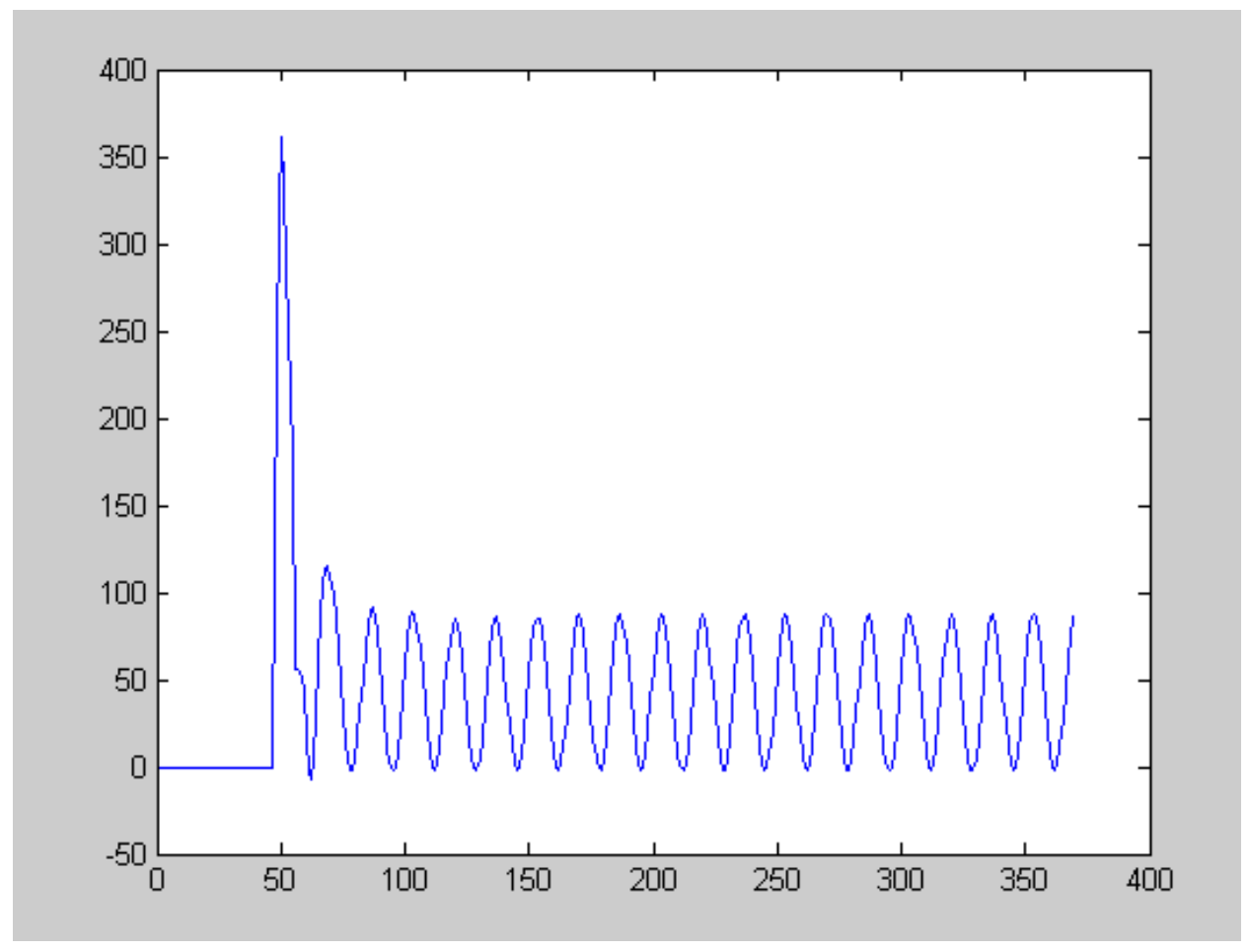

Figura 5.12 - Reatância relativa a um curto-circuito trifásico a $130 \mathrm{~km}$. Baseado no algoritmo de RAMAMOORTHY et all.

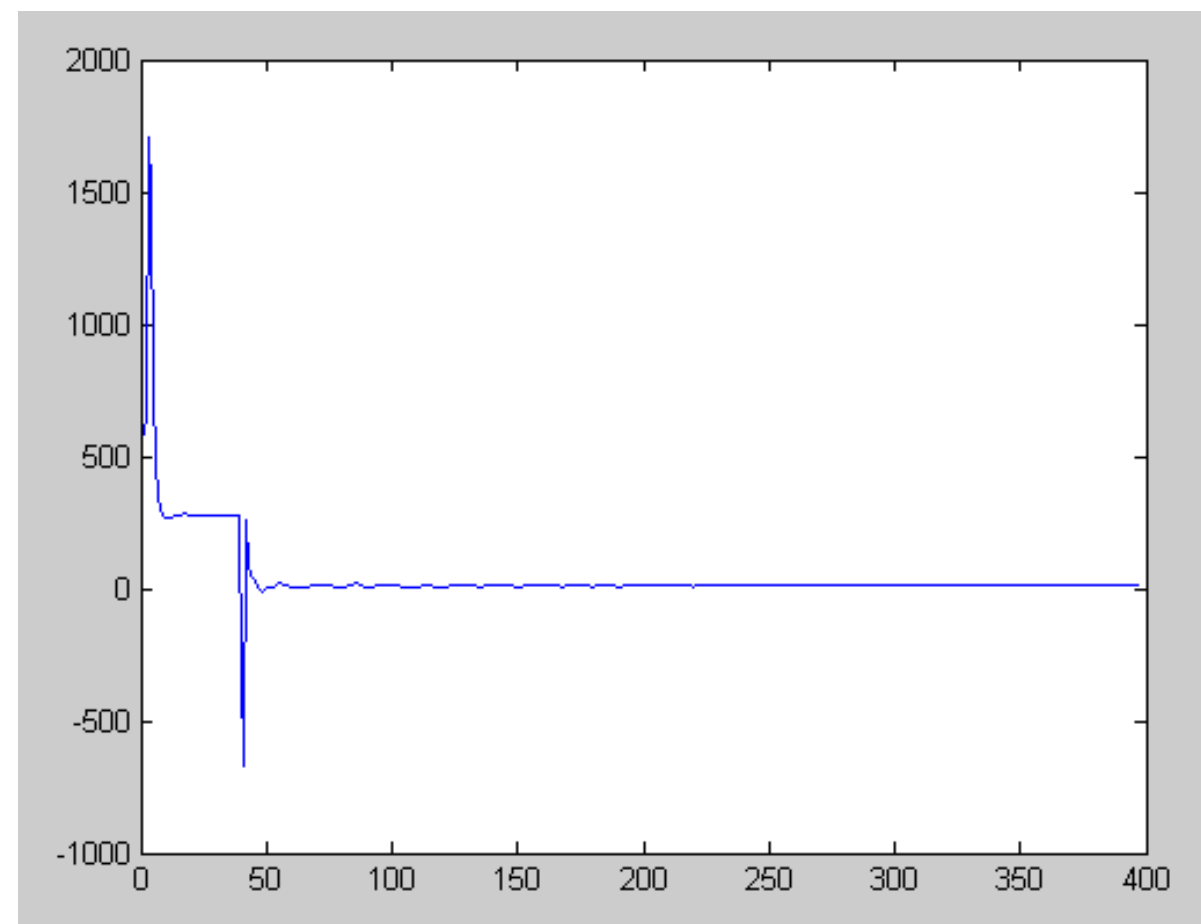

Figura 5.13 - Reatância relativa a um curto-circuito monofásico a $20 \mathrm{~km}$. Baseado no algoritmo de Mc-INNES \& MORRISON 


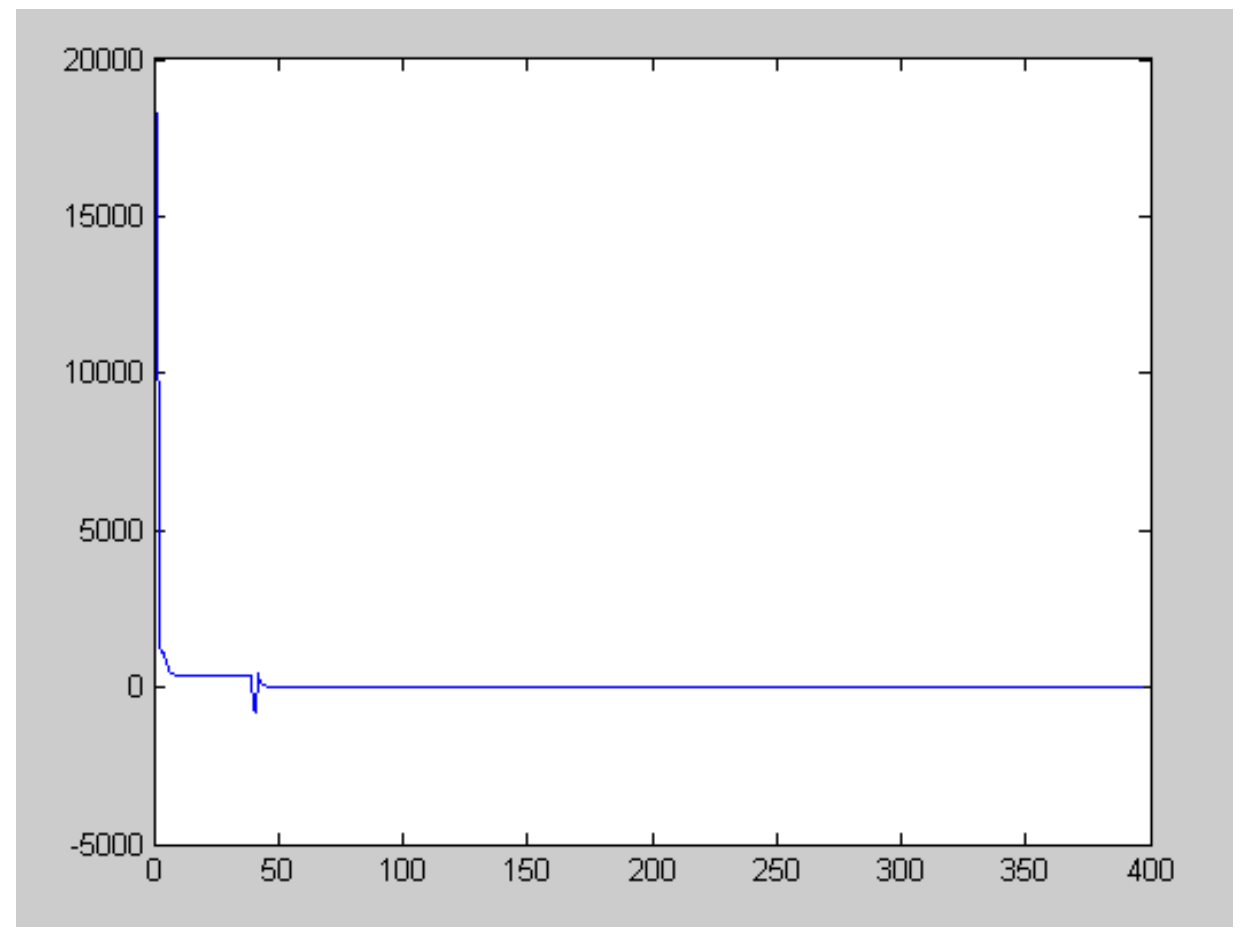

Figura 5.14 - Reatância relativa a um curto-circuito monofásico a $60 \mathrm{~km}$. Baseado no algoritmo de Mc-INNES \& MORRISON

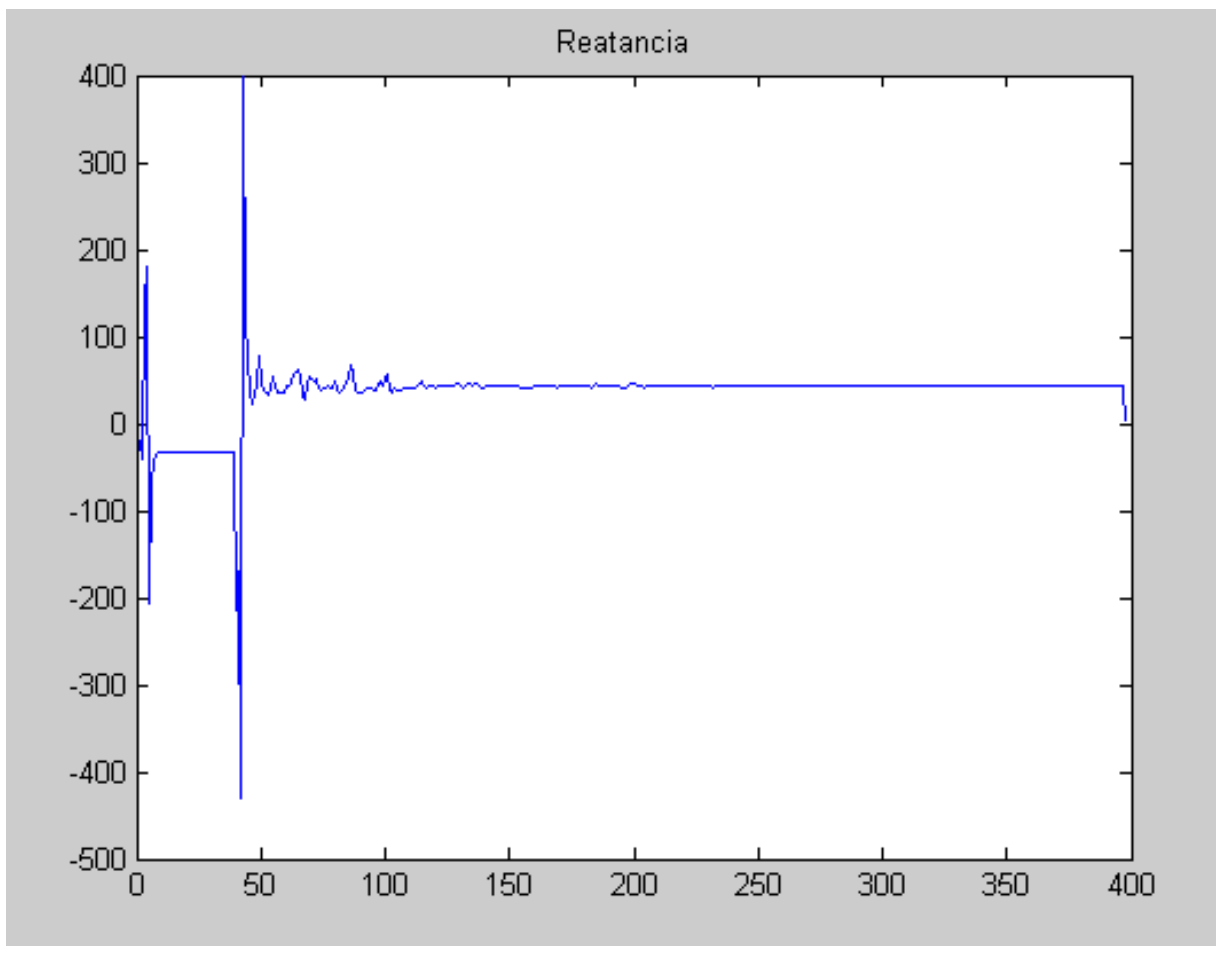

Figura 5.15 - Reatância relativa a um curto-circuito monofásico a $90 \mathrm{~km}$. Baseado no algoritmo de Mc-INNES \& MORRISON 


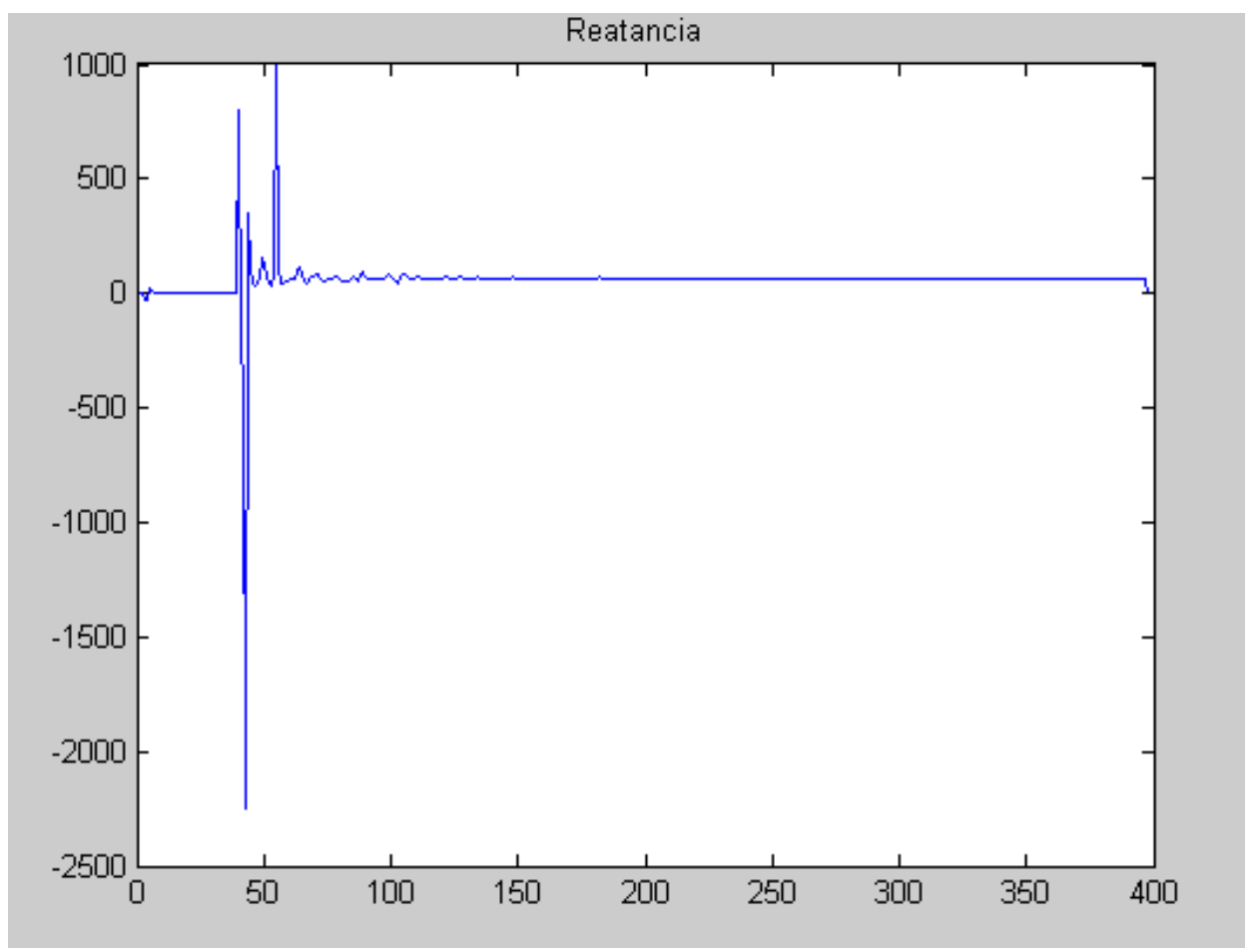

Figura 5.16 - Reatância relativa a um curto-circuito monofásico a $130 \mathrm{~km}$. Baseado no algoritmo de Mc-INNES \& MORRISON

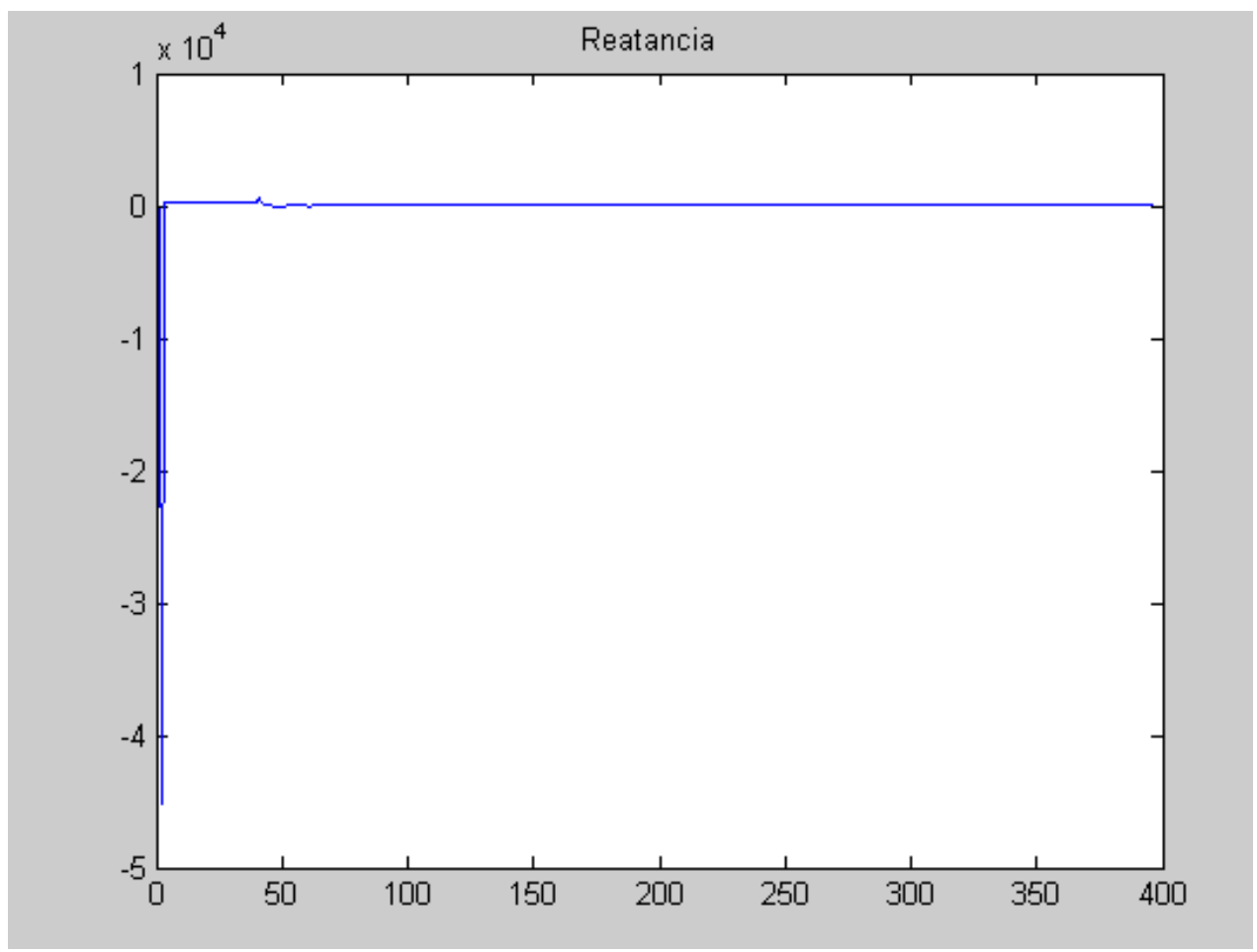

Figura 5.17 - Reatância relativa a um curto-circuito bifásico a $20 \mathrm{~km}$. Baseado no algoritmo de Mc-INNES \& MORRISON 


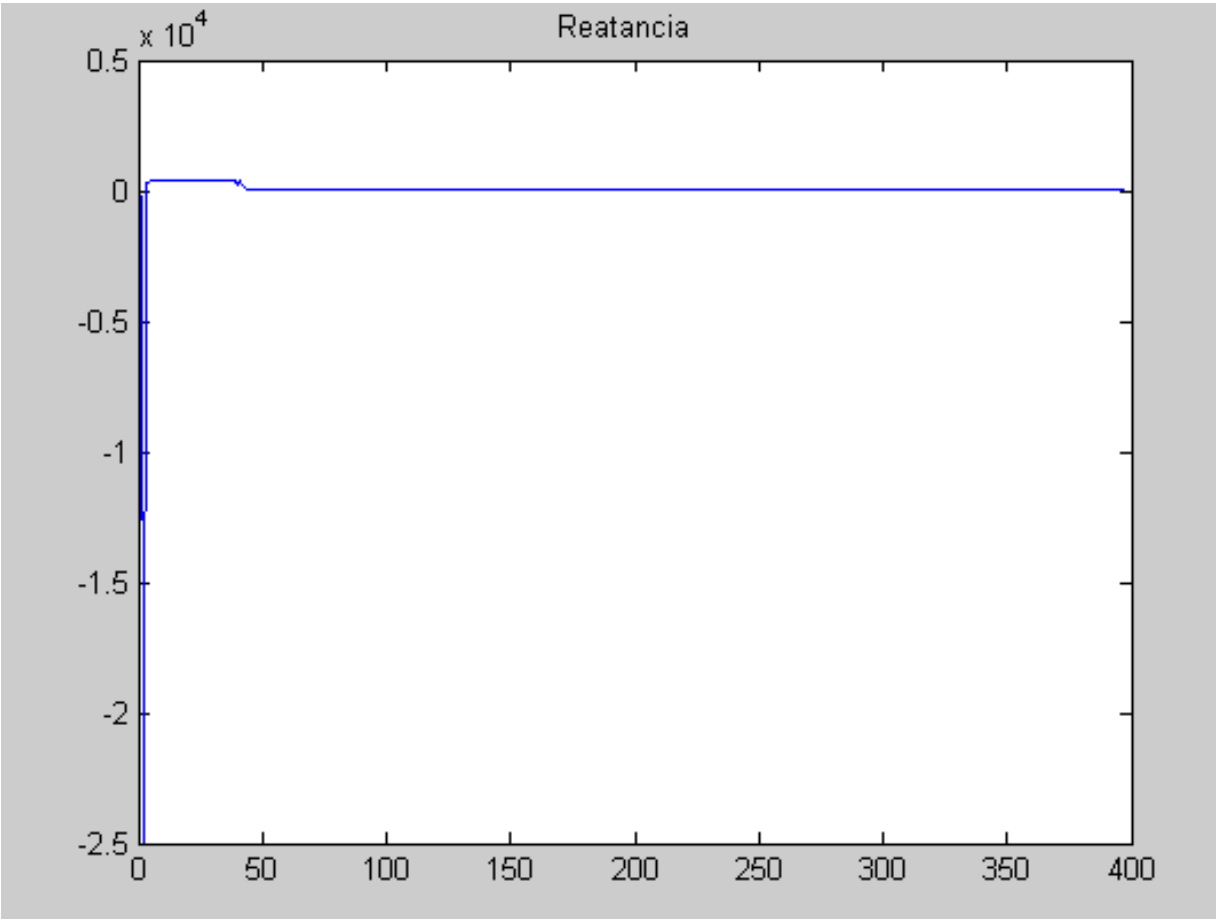

Figura 5.18 - Reatância relativa a um curto-circuito bifásico a $60 \mathrm{~km}$. Baseado no algoritmo de Mc-INNES \& MORRISON

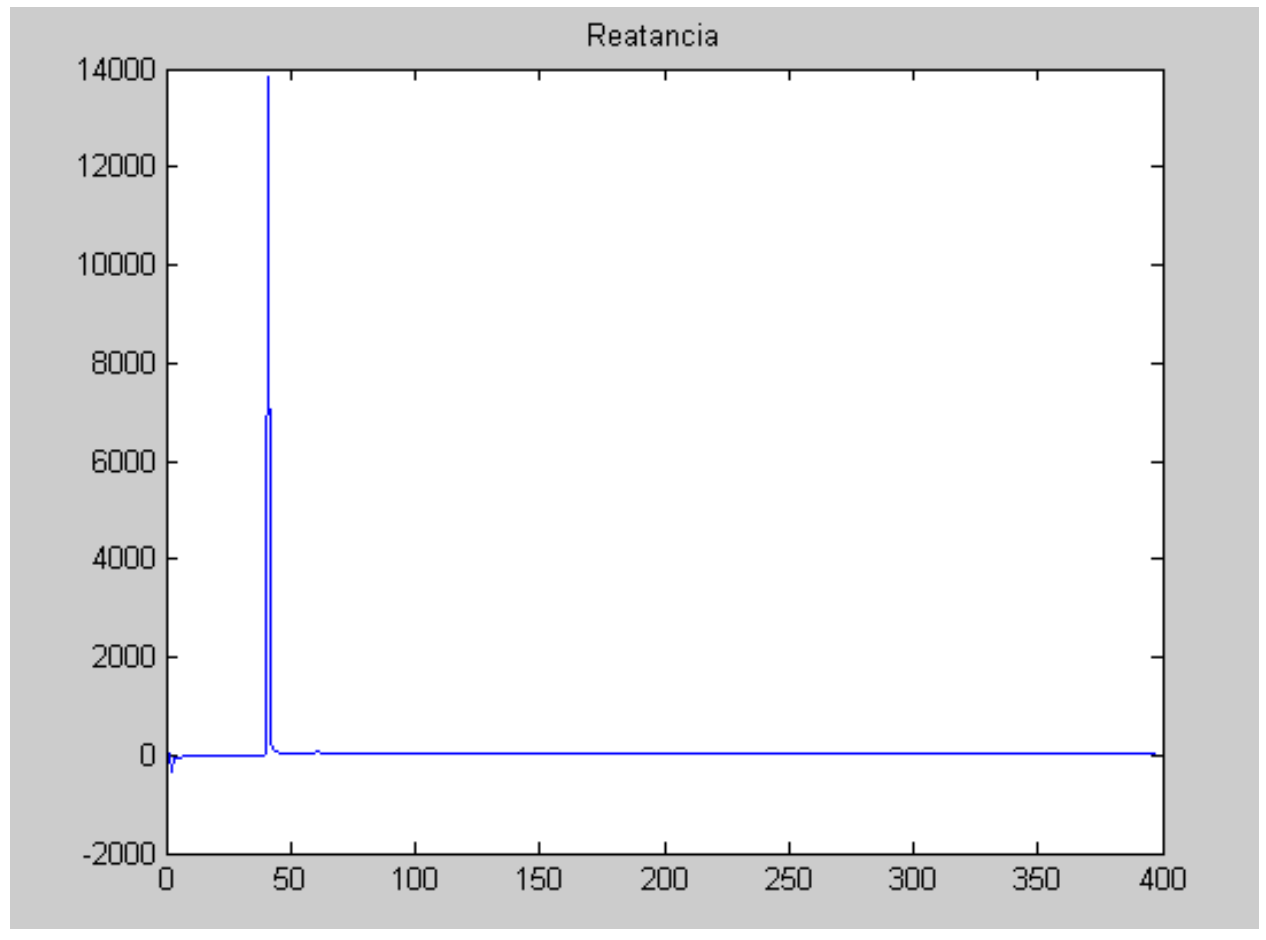

Figura 5.19 - Reatância relativa a um curto-circuito bifásico a $90 \mathrm{~km}$. Baseado no algoritmo de Mc-INNES \& MORRISON 


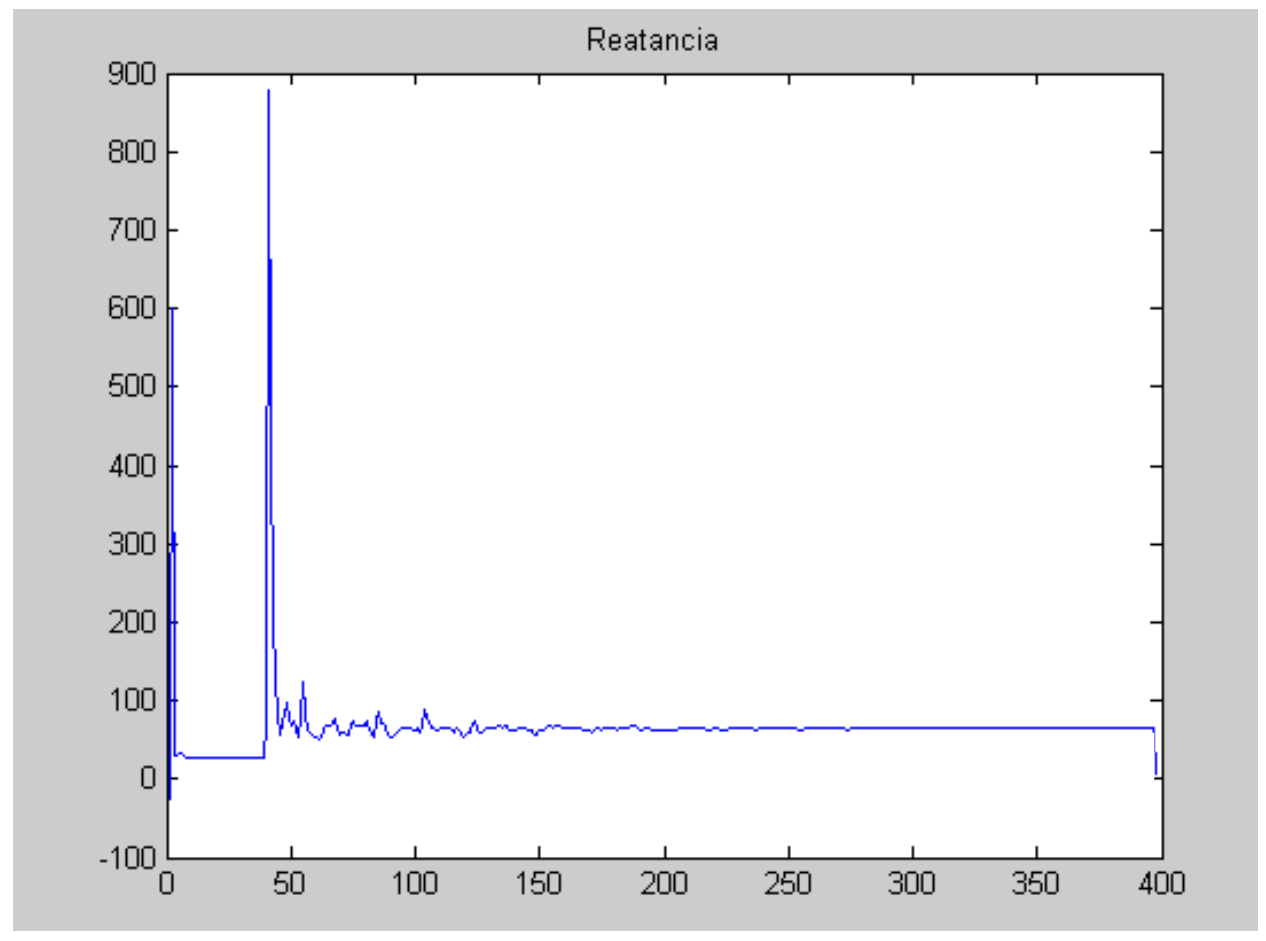

Figura 5.20 - Reatância relativa a um curto-circuito bifásico a $130 \mathrm{~km}$. Baseado no algoritmo de Mc-INNES \& MORRISON

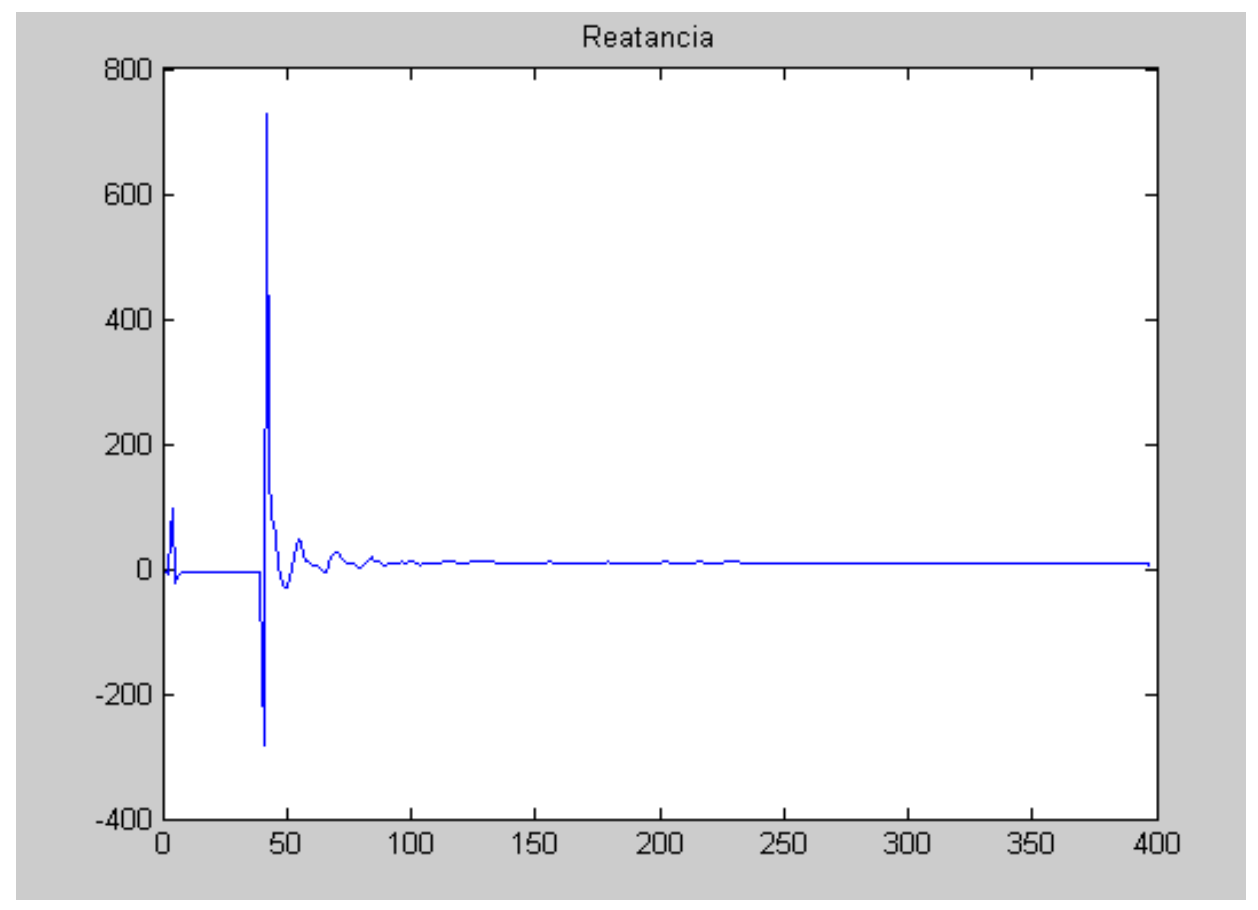

Figura 5.21 - Reatância relativa a um curto-circuito trifásico a $20 \mathrm{~km}$. Baseado no algoritmo de Mc-INNES \& MORRISON 


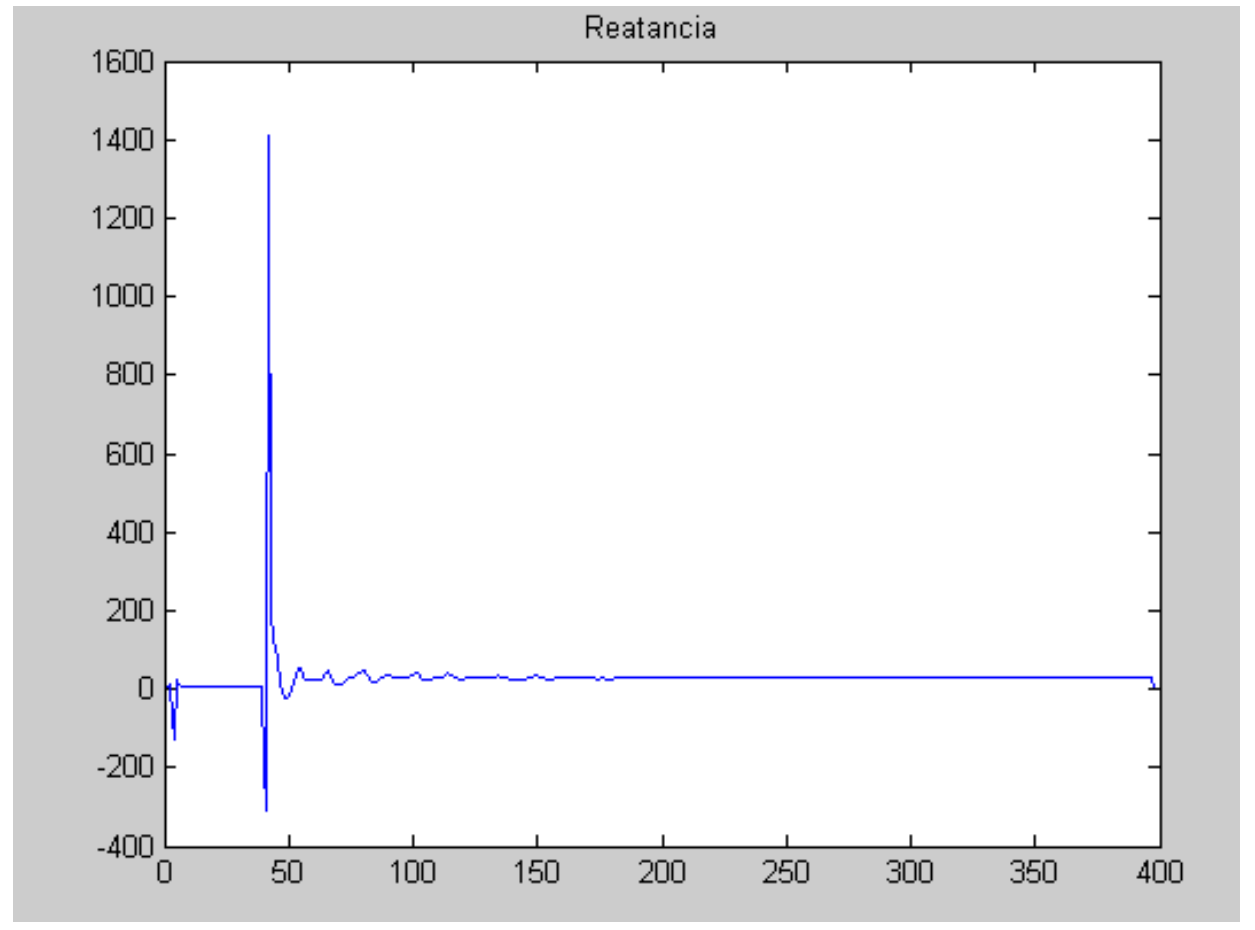

Figura 5.22 - Reatância relativa a um curto-circuito trifásico a $60 \mathrm{~km}$. Baseado no algoritmo de Mc-INNES \& MORRISON.

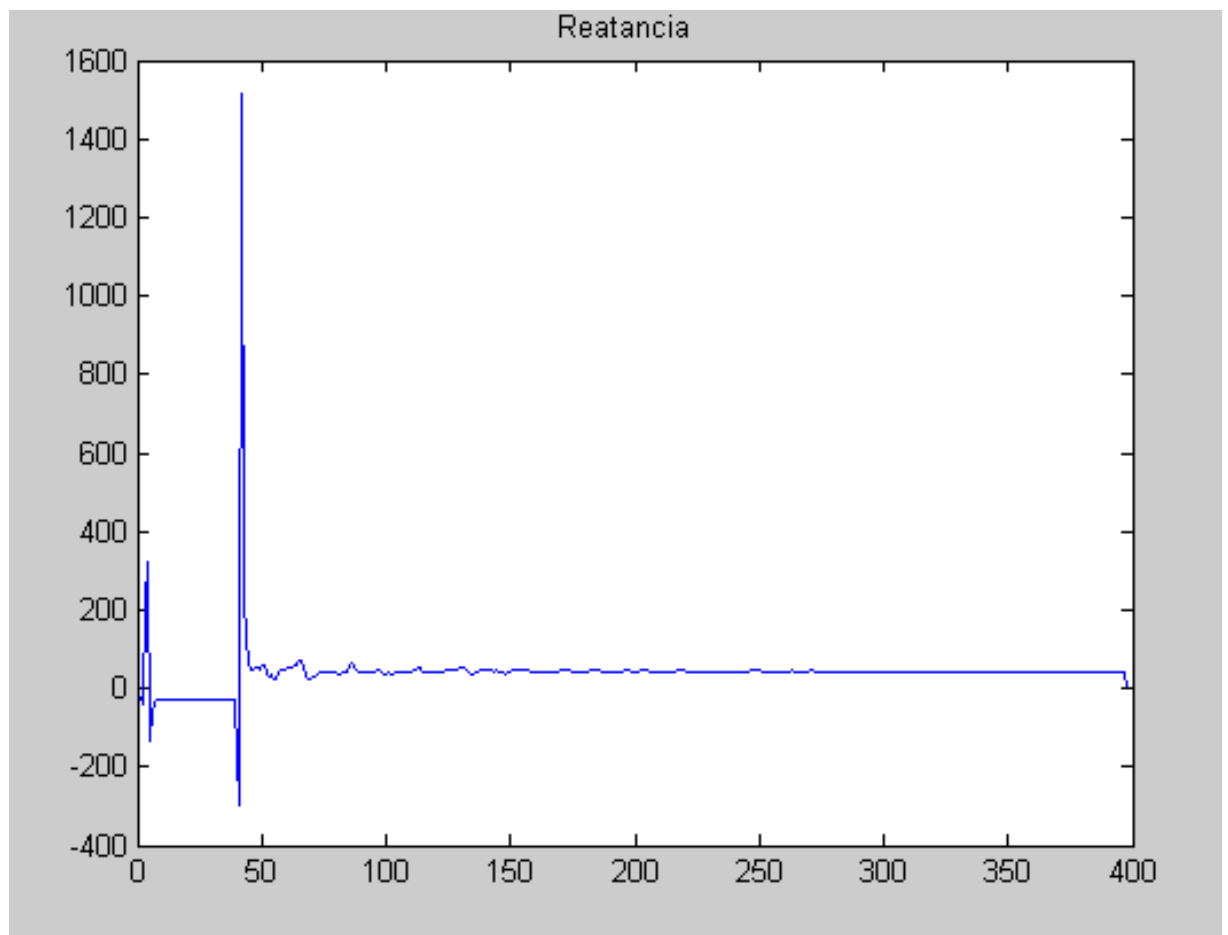

Figura 5.23 - Reatância relativa a um curto-circuito trifásico a $90 \mathrm{~km}$. Baseado no algoritmo de Mc-INNES \& MORRISON. 


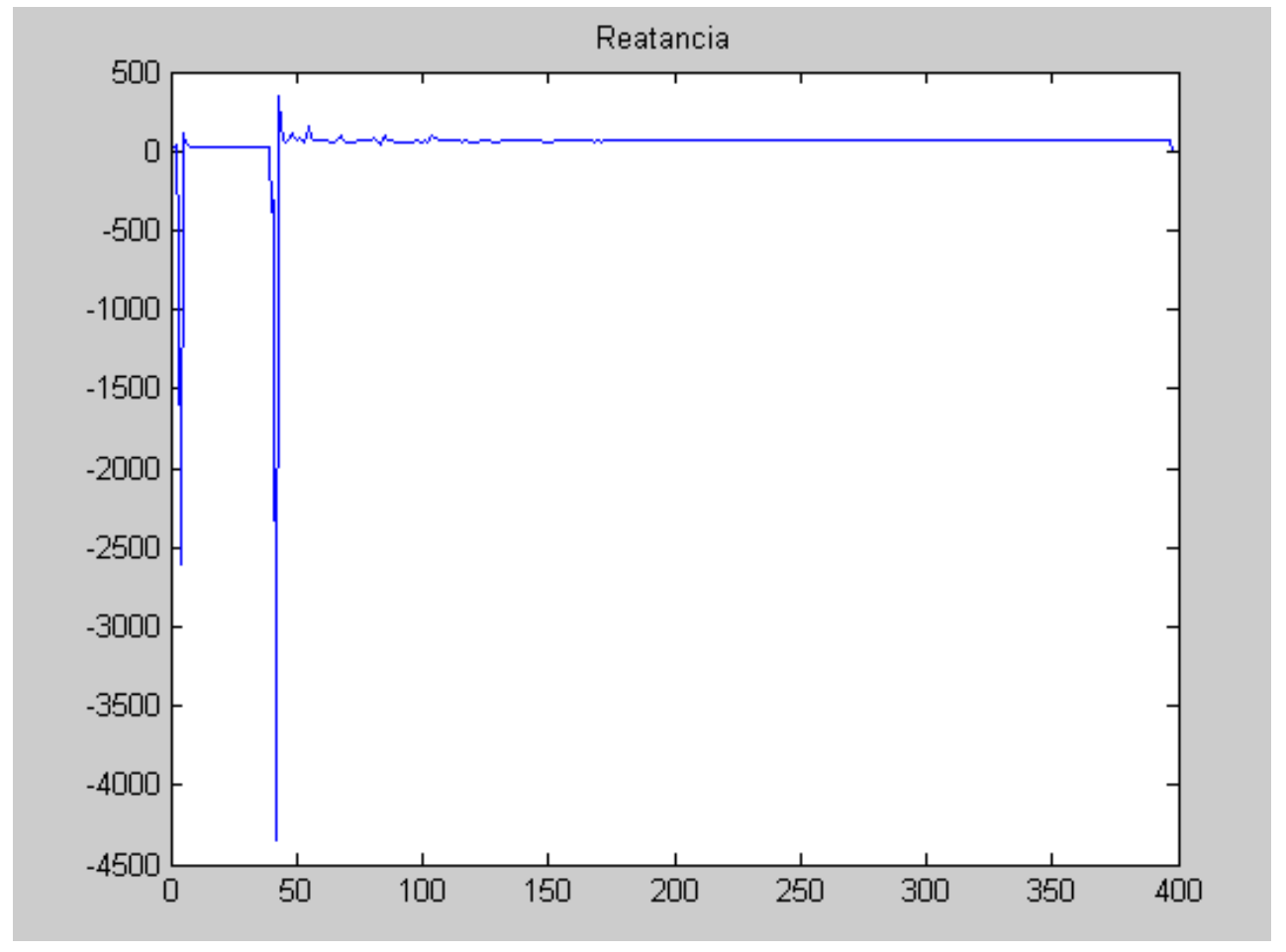

Figura 5.24 - Reatância relativa a um curto-circuito trifásico a $130 \mathrm{~km}$. Baseado no algoritmo de Mc-INNES \& MORRISON.

\section{1 - FILTRAGEM DOS SINAIS}

Utilizou-se um filtro digital passa-baixa do tipo Butterworth de segunda ordem com freqüência de corte de $200 \mathrm{~Hz}$ e freqüência de amostragem de $2000 \mathrm{~Hz}$ visando atenuar o aperiódico de corrente

Isto dá uma freqüência normalizada

$$
F c=\frac{200}{2000}=0,1
$$

Com as equações 3.2 e 3.4 faz-se a realização da transformação para o filtro digital e obtem-se

$$
K=\frac{1}{\operatorname{tg} \pi \cdot F_{c}}=399
$$




$$
s=399 \frac{1-z^{-1}}{1+z^{-1}}
$$

Com a função de transferência no plano-s para o filtro de Butterworth (5.4) obtem-se

$$
H(s)=\frac{1}{s^{2}+\sqrt{2} s+1}
$$

E a resposta final calculada para cada amostra fica:

$$
\mathrm{x}(\mathrm{k})=\mathrm{A} 1 \cdot(\mathrm{y}(\mathrm{k})+2 \cdot \mathrm{y}(\mathrm{k}-1)+\mathrm{y}(\mathrm{k}-2)-\mathrm{A} 2 \cdot \mathrm{x}(\mathrm{k}-1)-\mathrm{A} 3 \cdot \mathrm{x}(\mathrm{k}-2))
$$

onde $\mathrm{y}(\mathrm{k})$ representa o sinal de entrada na amostra $\mathrm{k}$ e $\mathrm{x}(\mathrm{k})$ o sinal de saída na amostra $\mathrm{k}$. As constantes são mostradas na Tabela 5.1

Tabela 5.1 - Coeficientes

\begin{tabular}{|c|c|c|}
\hline & Literal & Numérico \\
\hline A1 & $\frac{1}{1+\sqrt{2} k+k^{2}}$ & 0,0675 \\
\hline A2 & $2-2 k^{2}$ & $-16,944$ \\
\hline A3 & $1-\sqrt{2} k+k^{2}$ & 6,1196 \\
\hline
\end{tabular}

Para detecção da fase, ou fases faltosas, foi feito um cálculo para corrente antes do instante do curto, o valor base foi 293 A. Cada vez que o programa roda ele detecta se o valor da amostra é maior que essa média, porém como efeito de segurança, esse valor foi multiplicado por dois.

Para saber se o defeito teve contato com a terra, tomou-se a corrente de neutro como:

$$
\operatorname{In}(k)=i a(k)+i b(k)+i c(k)
$$

O algoritmo desenvolvido está mostrado na Figura 4.10. O programa desenvolvido em MATLAB está mostrado no Anexo. Este programa descreve todos os passos citados.

\section{2 - ZONAS DO RELÉ}


A cada amostra o programa faz um comparativo, se a corrente da amostra for maior que a de referência, os dados de falta são calculados. Para a primeira zona acusar um curto são necessárias 8 amostras consecutivas dentro da zona 1, para a segunda 20 e finalmente para a terceira necessita de 25 amostras. Lembrando que a segunda e terceira zonas funcionam também como retaguarda de segurança. Pois caso haja um defeito na detecção da primeira zona, a segunda atua como backup.

\section{3 - RESULTADOS ALCANÇADOS}

Utilizando os algoritmos enunciados calculou-se as distâncias das faltas. Os resultados encontrados utilizando o algoritmo de Mc-Innes \& Morrinson foram mais satisfatórios, entretanto, buscando uma melhor uma exatidão, fez-se uma modificação. Aplicou-se o principio da integração trapezoidal em doze intervalos consecutivos ao invés de apenas dois. E como esperado, obteve-se um erro menor. Os valores calculados estão mostrados na Tabela 5.2 .

Como esperado, as razões entre os sinais foram bastante satisfatória, indicando um erro médio menor que $1,13 \%$. Isso significa um erro de distância de aproximadamente 0,7 metros da detecção da falta para uma linha de $80 \mathrm{~km}$.

A margem de erro dos cálculos é expressa como um porcentagem do comprimento total da linha e é dado pela expressão:

$$
\text { \%erro }=\frac{\mid \text { distância.estimada }- \text { distância.real } \mid}{\text { comprimento.da.linha }} * 100
$$

E a faixa de busca é dada por:

$$
\mathrm{F}=\mid \text { distância estimada }- \text { distância real } \mid
$$

Tabela 5.2 - Distâncias Calculadas 


\begin{tabular}{|c|c|c|c|c|c|}
\hline Tipo & Distância (Km) & $k=2$ & $k=13$ & erro \% & $\begin{array}{c}\text { Faixade } \\
\text { Busca }\end{array}$ \\
\hline \multirow{4}{*}{ Monofásico } & 20 & 20,0926 & 20,0392 & 0,0490 & 0,0392 \\
\hline & 60 & 59,5882 & 59,6855 & 0,3931 & 0,3145 \\
\hline & 90 & 88,9826 & 89,9743 & 0,0214 & 0,0257 \\
\hline & 130 & 131.6796 & 131.3189 & 0.7327 & 1.3189 \\
\hline \multirow{4}{*}{ Bifásico } & 20 & 20,0776 & 19,9958 & 0,0053 & 0,0042 \\
\hline & 60 & 59,8424 & 60,8016 & 1,0020 & 0,8016 \\
\hline & 90 & 89,6853 & 91,2869 & 1,4299 & 1,2869 \\
\hline & 130 & 128,5267 & 129,0130 & 0,7592 & 0,9870 \\
\hline \multirow{4}{*}{ Trifásico } & 20 & 21,0018 & 20,8277 & 1,0346 & 0,8277 \\
\hline & 60 & 61,0692 & 60,9031 & 1,1289 & 0,9031 \\
\hline & 90 & 90,7851 & 92,5031 & 1,3906 & 0,7851 \\
\hline & 130 & 129,3370 & 129,0130 & 0.5483 & 0,9870 \\
\hline
\end{tabular}

O gráfico da Figura 5.25 mostra um comparativo de erro para cada tipo de falta (monofásica, bifásica e trifásica), com o objetivo de mostrar a pequena variância dos erros.

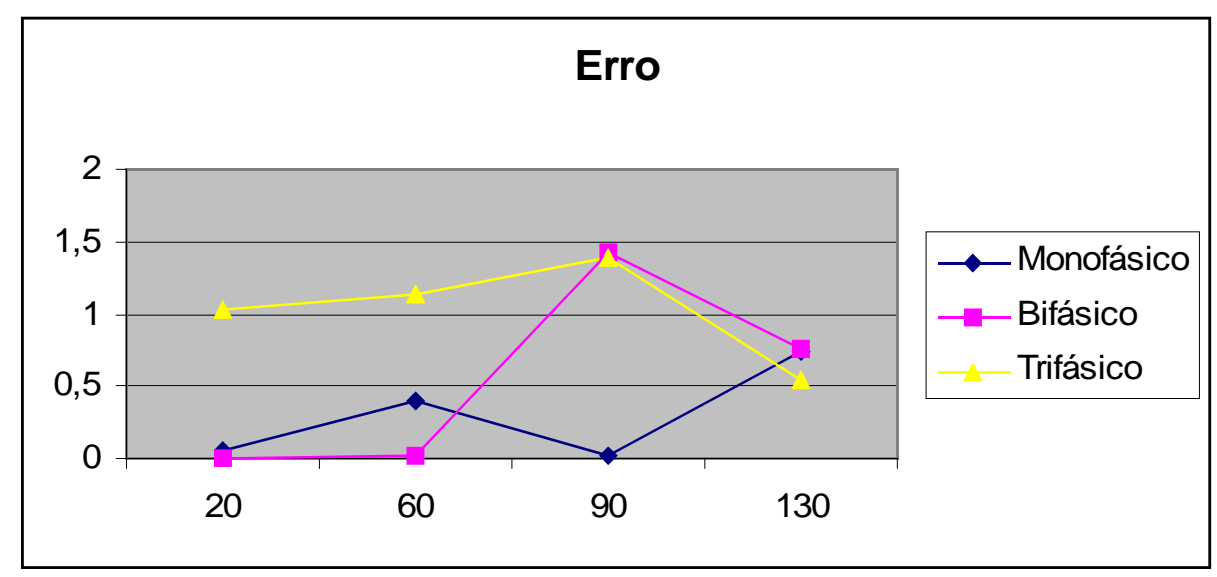

Figura 5.25 - Erro nas medidas

\section{6 - CONCLUSÃO}


O presente trabalho teve como objetivo o estudo da proteção de Distância Digital frente a dois algoritmos e localização das zonas de falta.

Através de simulações, dispondo-se do software ATPDraw, gerou-se um banco de dados que foi fonte para o algoritmo gerado.

Pelos resultados alcançados, pode-se observar uma precisão altamente satisfatória na localização das zonas de proteção. Além disso, pode-se afirmar que a aplicação é bastante adequada para uso em relés digitais de distância.

Com o algoritmo segundo Ramamoorthy, fez-se os gráficos observados. Os gráficos mostram as ondas que representam a reatância e que são base para calculo da distância de falta até o relé. Nota-se, no entanto a necessidade de um filtro adicional para tornar mais constante a reatância e conseqüentemente obter medidas mais exatas.

O algoritmo de McInnes e Morrison foi o que gerou melhor detecção da distância. O erro médio encontrado foi inferior ao patamar limite encontrado na bibliografia (5\%), não chegando a $1,13 \%$, com isso mostrando-se corretas as medidas.

As zonas aqui delimitadas foram construídas com retas verticais e horizontais por efeito de simplificação. E a detecção de zonas, devido a essa aproximação de limitação de zonas causou uma pequena incerteza. $\mathrm{O}$ ajuste pode não estar adequado.

Como sugestão para trabalhos futuros destaca-se a filtragem dos sinas de reatância como também o ajuste de zonas.

\section{REFERÊNCIAS BIBLIOGRÁFICAS}


[1] Caminha, A. C. (1978). Introdução à proteção dos sistemas elétricos. São Paulo: Edgard Blücher.

[2] Coury, D. V. (1987). Um Estimador ótimo aplicado à Proteção dos Sistemas Elétricos de Potência. Dissertação (Mestrado) - Escola de Engenharia de São Carlos, Universidade de São Paulo.

[3] MCINNES, A. D. , MORRISON, I.F. (1971).Real time Calculation of Resistance and Reactance for Transmission Line Protection by Digital Computer. IEE Transaction, Instituion of Engineers. Austrália, EE7,n.1,pp 16-23, jan.

[4] MANN, B.J., MORRISON, I. F. (1971) . Digital Calculation of Impedance for Transmition Line Protection. IEEE Trans. PAS vol. 90, pag 270 - 276 Jan /Fev (1971).

[5] PAVARD,M. La Numerization des Protections de Distance et des Fonctions connexes. Electricité de France, Direction des Études et Recherches. Journée d'etude SEE du 17 juin 1982.

[6] CLARK, H.K. Proteção de Sistemas Elétricos de Potência. 2a edição série PTI, edições UFSM,1983.

[7] HOROWITZ, S.; PHADEK, A. G. (1996). Power System Relaying. England: Research Studies Press Ltd.

[8] PHADKE, A. G. ; HORP, J. S. (1988). Computer Relaying forPpower System Systems. England : Research Studies Press Ltd.

[9] WARRINGTON, A. R. Van C.: Protective Relays: their theory and practice. Vols. 1 e 2. Chapmam and Hall, London, 1969.

[10] ATBEKOV, G. I.: The Relay Protection of high Voltage Networks. Pergamon Press Ltda.1960.

[11] TAKAGI, T. ET ALL. Digital Differential Relaying System for Transmission Line Primary Protection using Travelling Wave Theory - its Theory and Field Experience. IEEE Trans. Pas, dec.1978.

[12] TAKAGI, T. ET ALL. Feasibility Study for Current Differential Carrier Relay System Based onTtraveling Wave Theory. IEEE trans. PAS, nov . 1977

[13] MONTALVÃo, E. . Contribution Théorique à L'Etude d'une Protection Différentielle d'onde pour les Réseaux à três haute tension. Paris, 1983. 125 p./ Tese - Douctor Ingénieur - Université de Paris-Sud Centre d'Orsay. 
[14] FREITAS, Francisco Damasceno. Estudo de algoritmos de proteção de distância para implementação em tempo real. Tese de Mestrado Brasilia, 1987. $171 \mathrm{f}$

[15] P. M., Anderson e A. A., Fouad. (1986) "Power System Control and Stability.", The Iowa state University Press-USA.

[16] Central Electricity Generating Board

[17] ATP/RULE BOOK

APÊNDICES

APÊNDICE A 


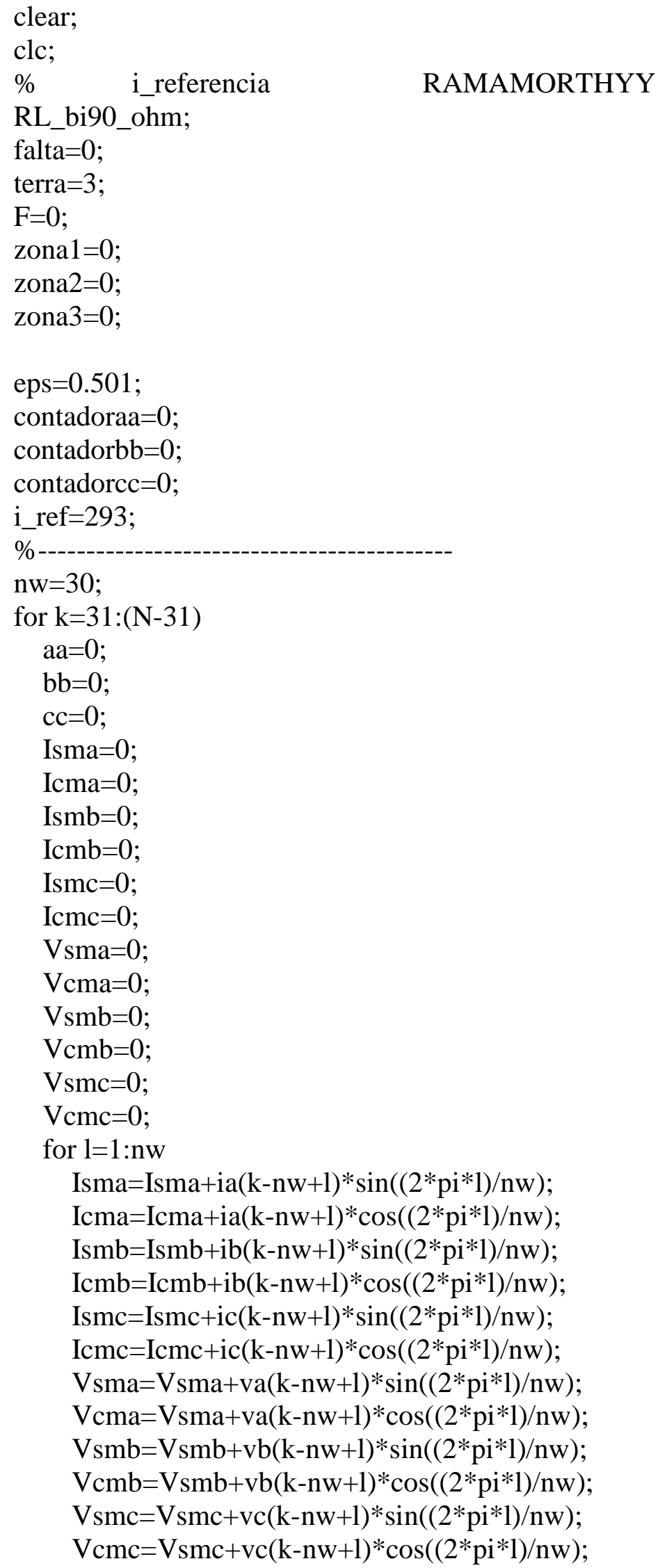




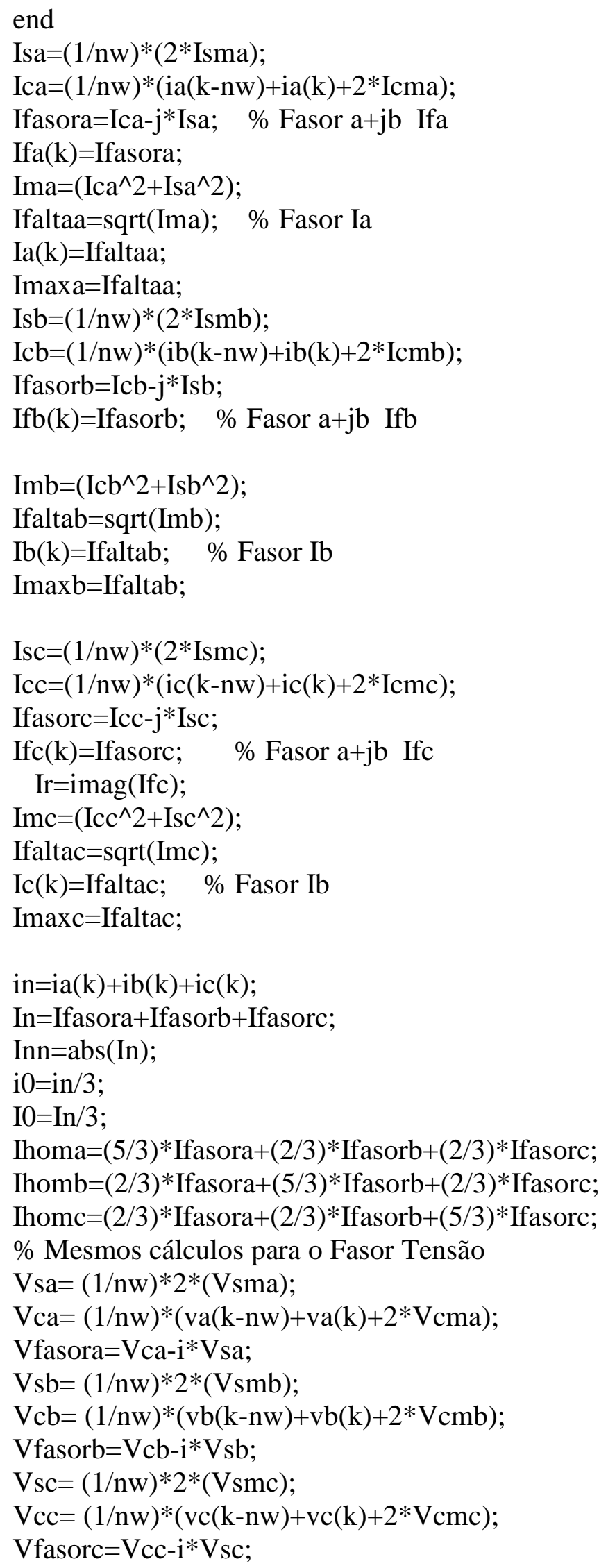




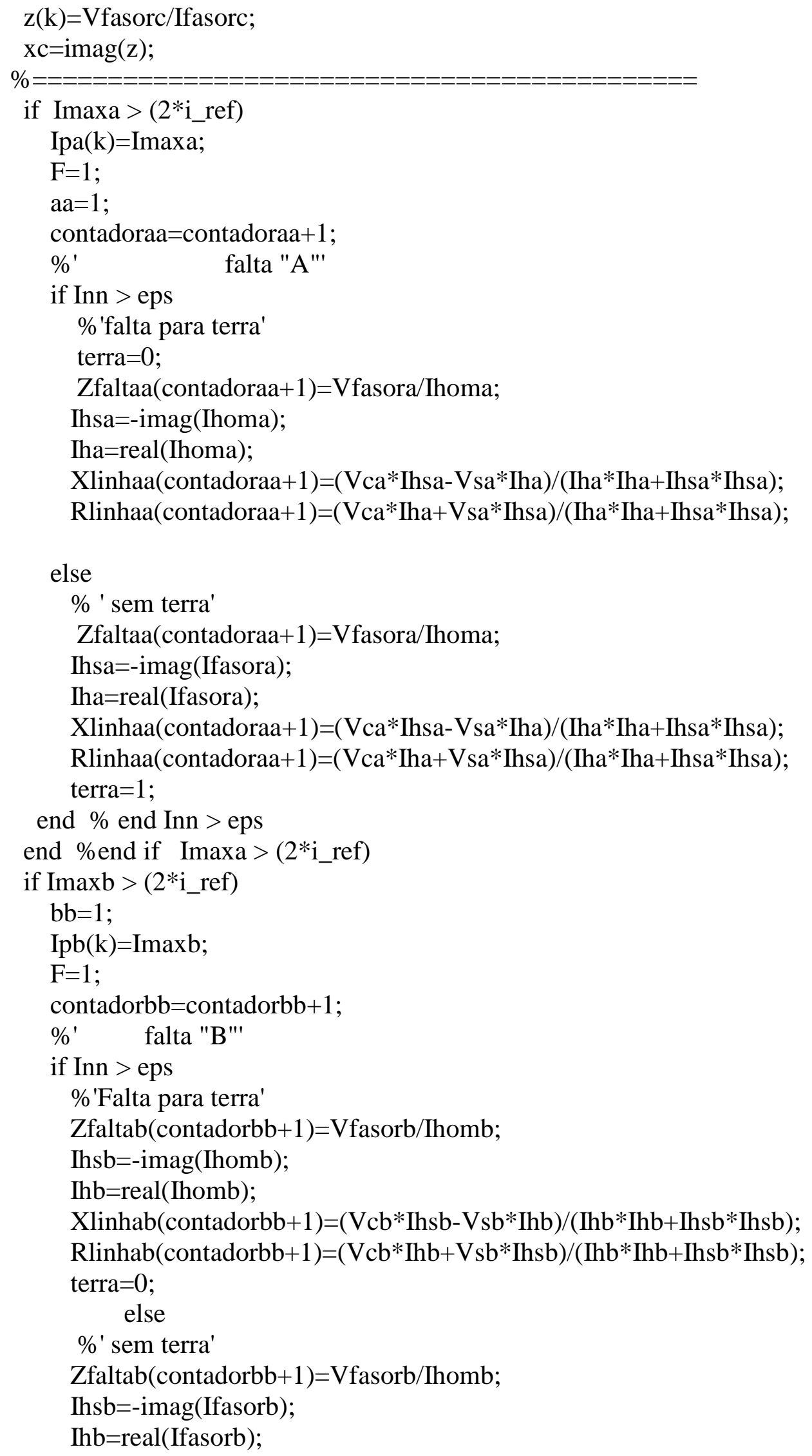




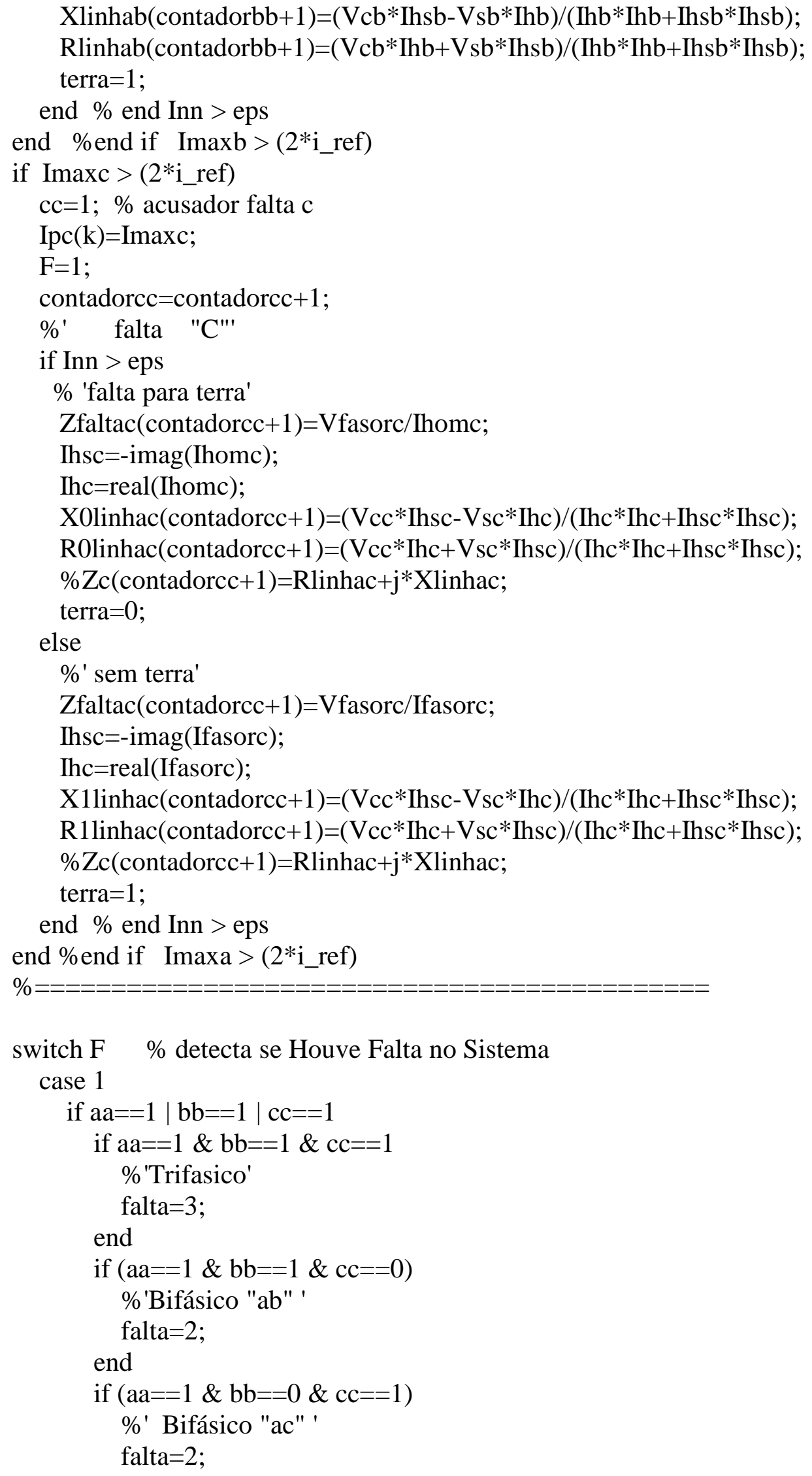




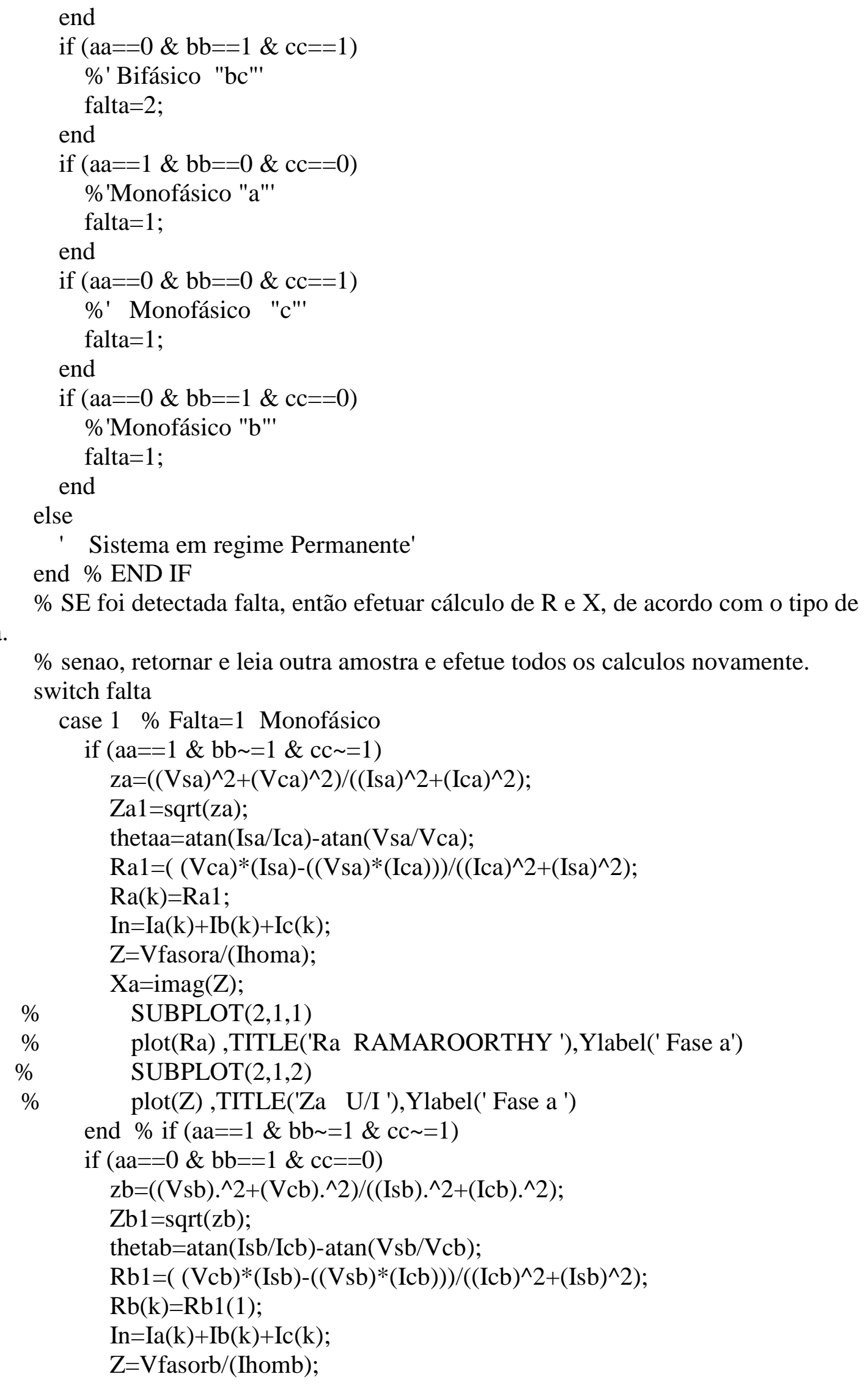




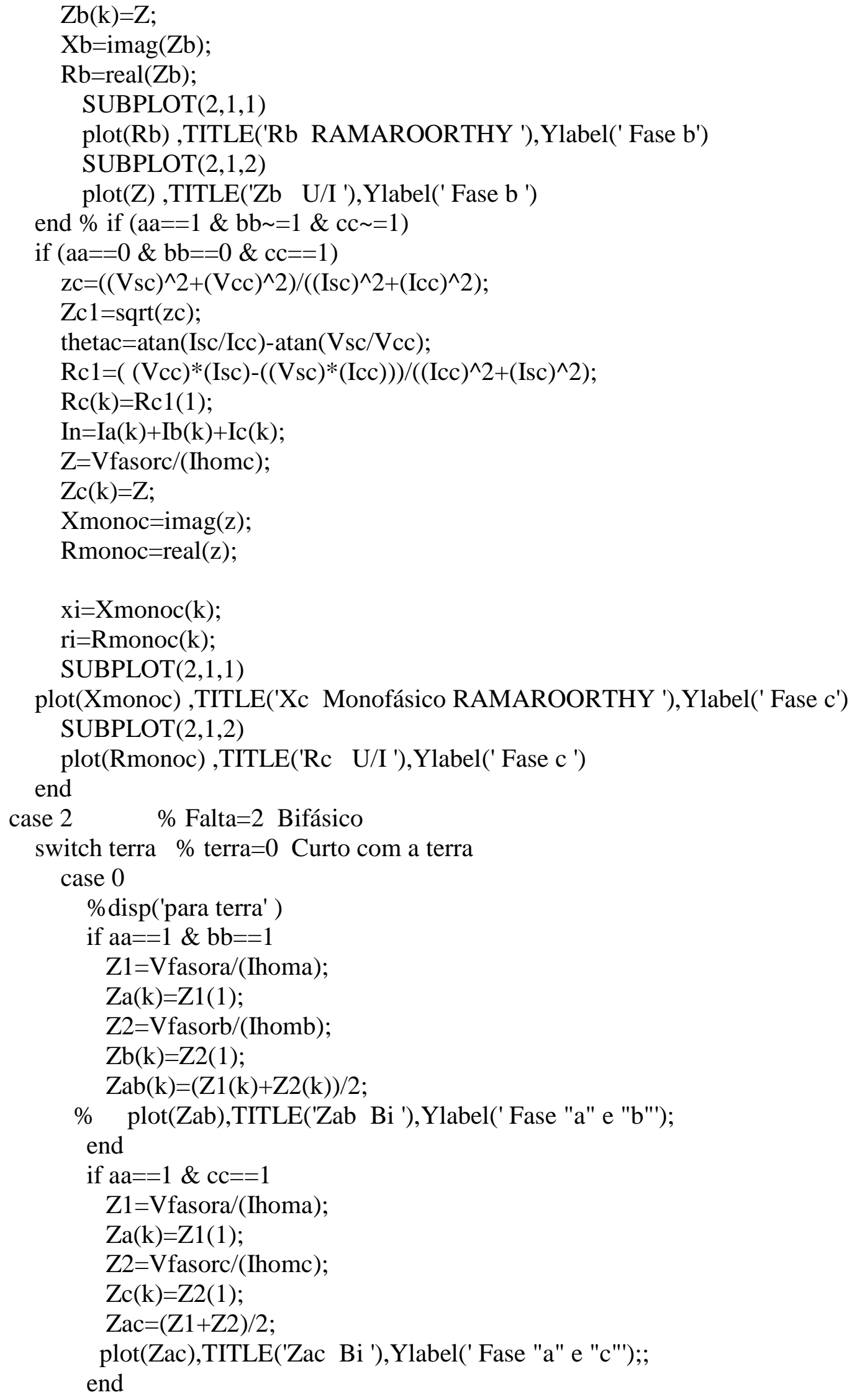




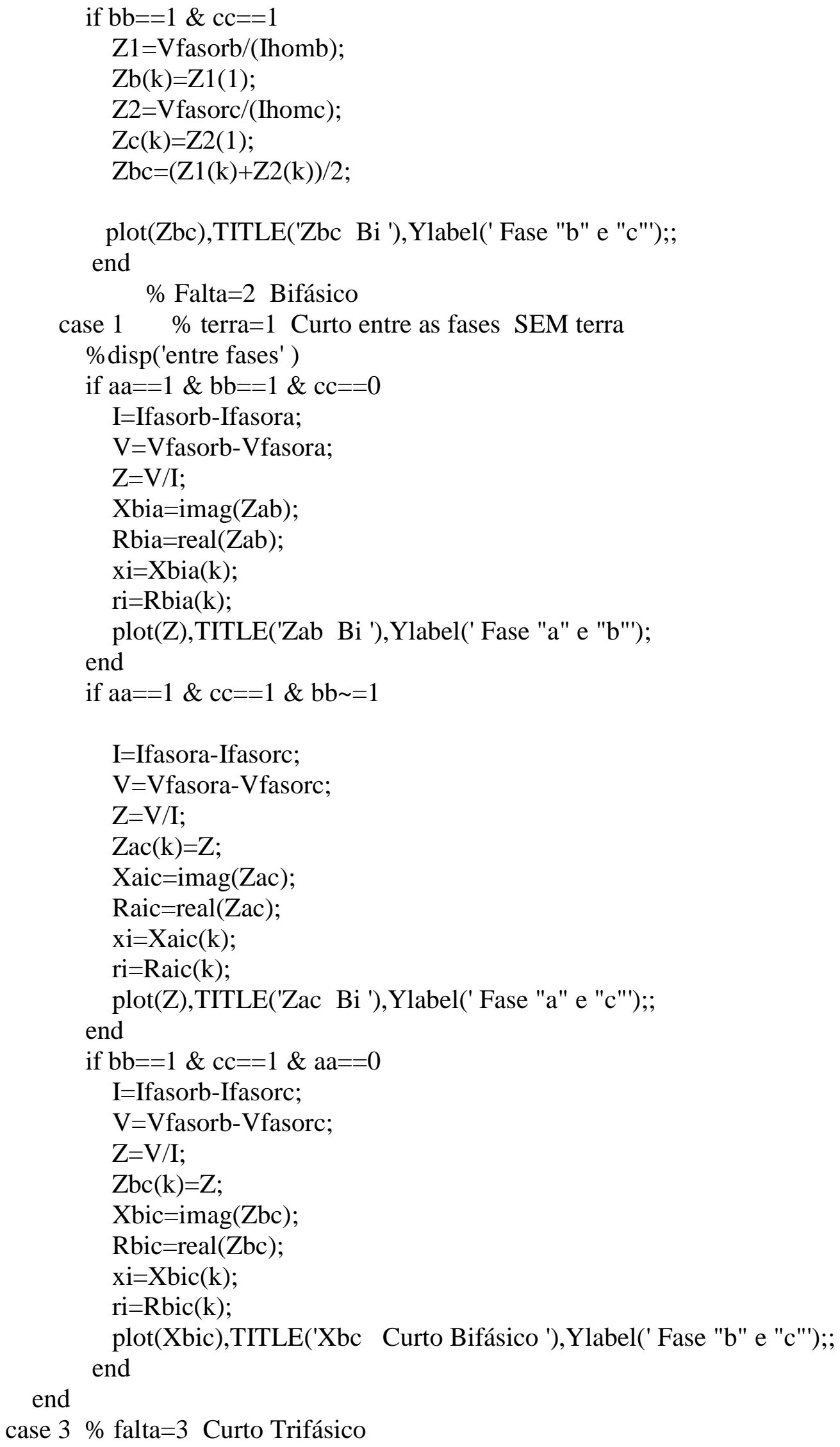




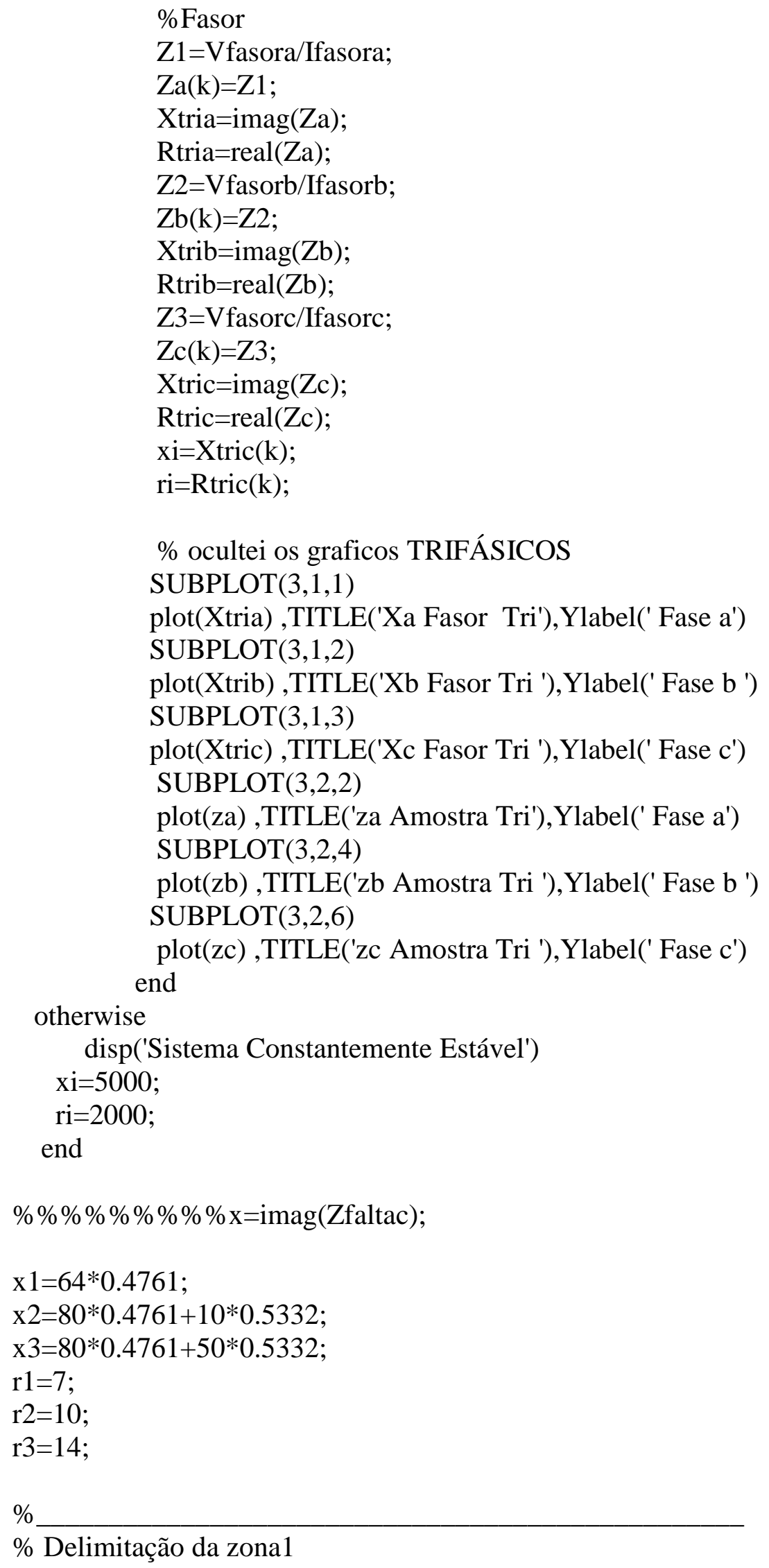




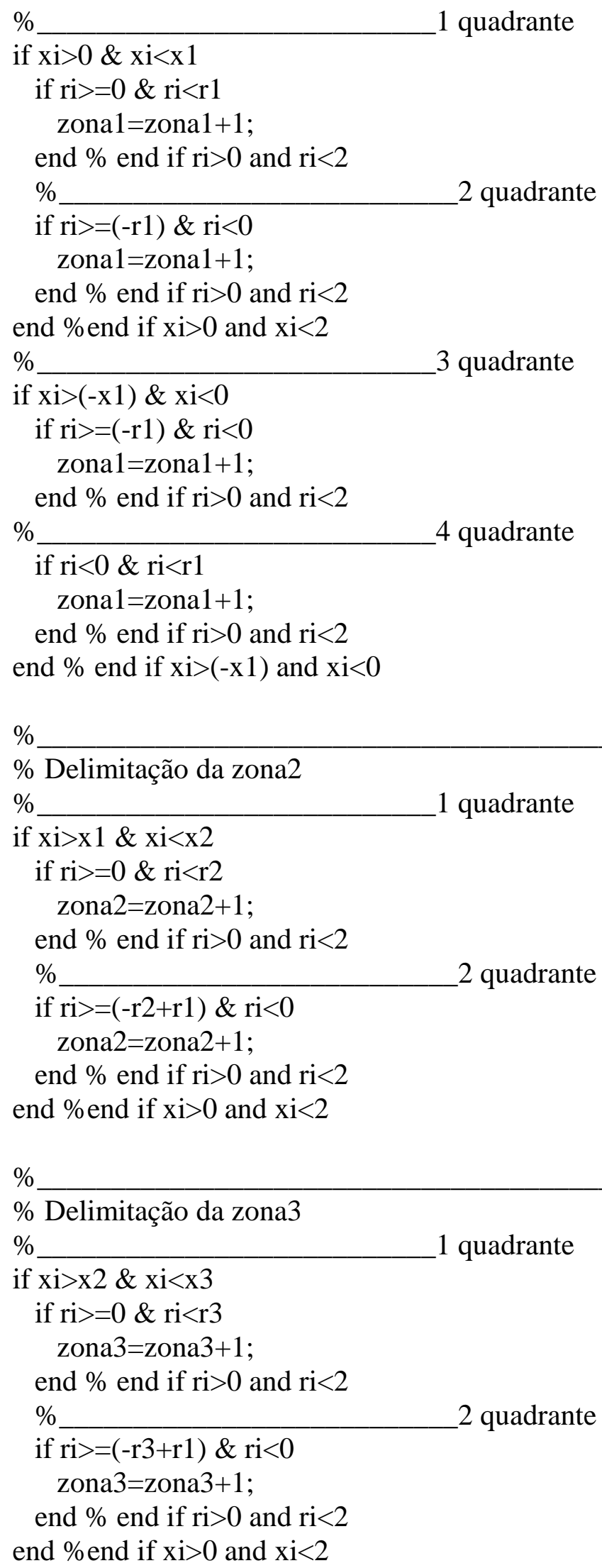




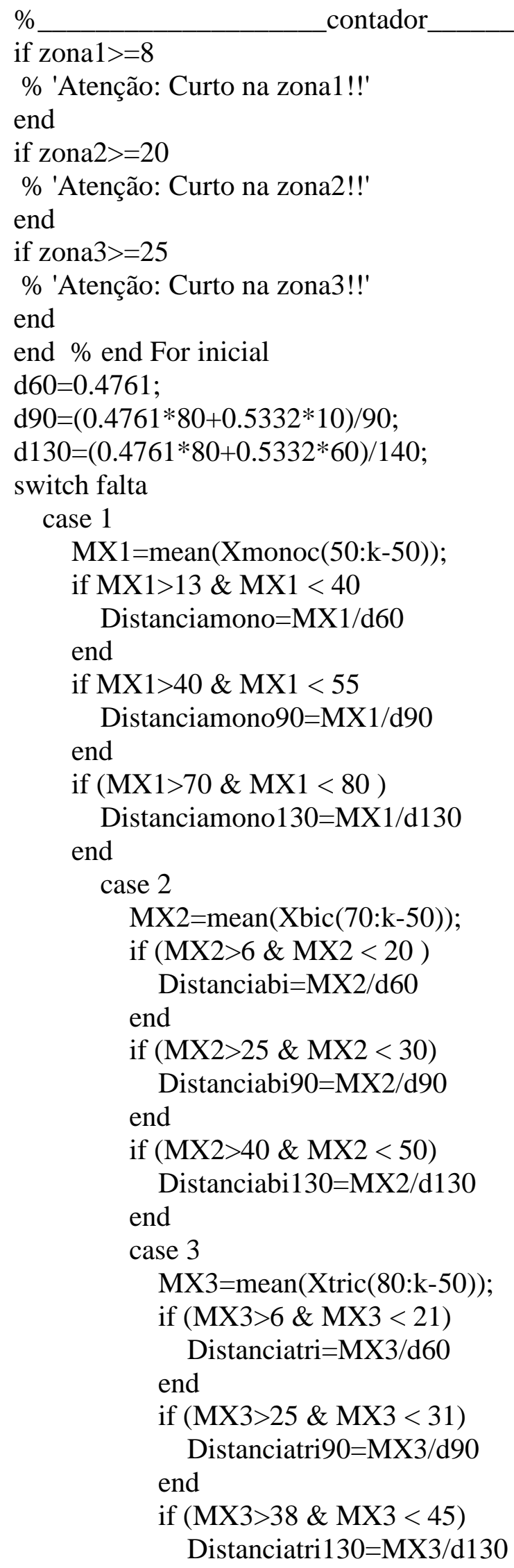




end end

zona1

zona2

zona3

\section{APêNDICE B}

$\%$ alg_filtran_FASE

\%Algoritmo Filtrante Passa Baixa $\%$ Mc-INNES \& MORRISON 


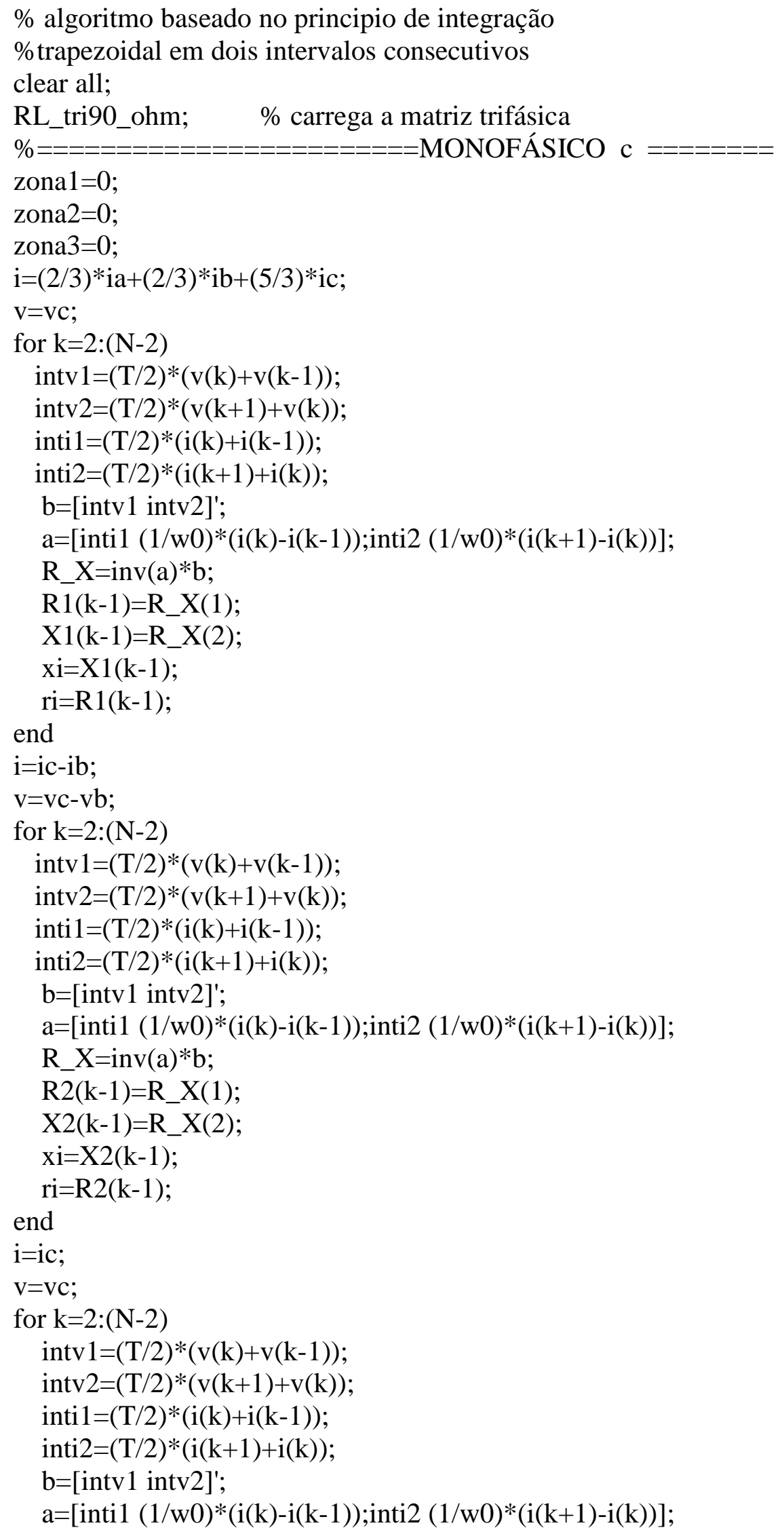




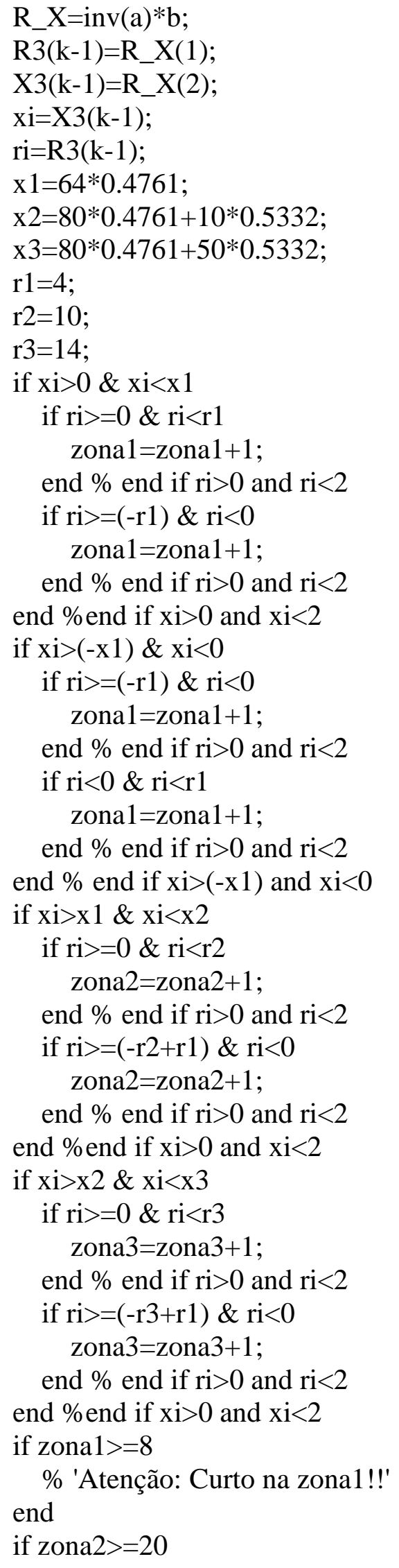




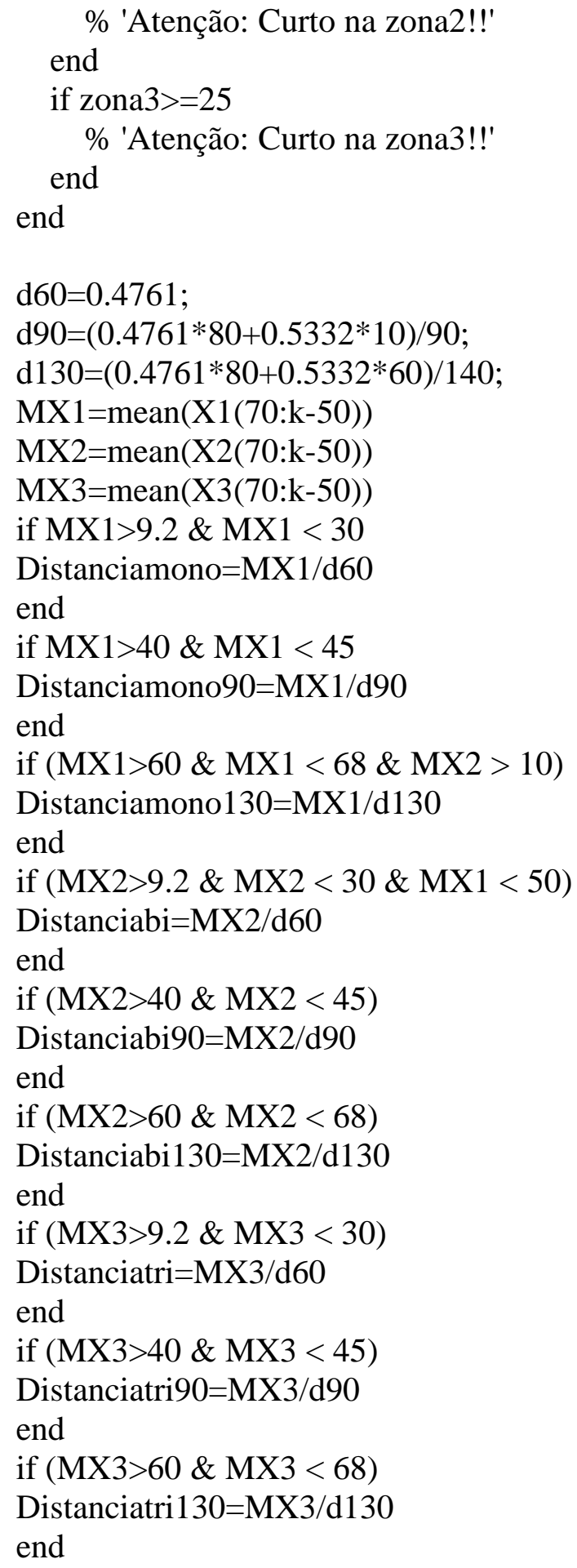

\section{APÊNDICE C}

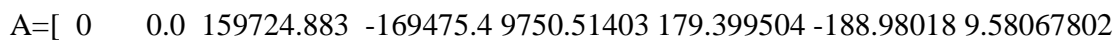

$500 \quad .5 \mathrm{E}-3 \quad 176285.209-150248.6-26036.612197 .703083-167.26103-30.44205$ 
$1000 \quad .1 \mathrm{E}-2 \quad 186600.542-125699.16-60901.378 \quad 209.00293-139.61658-69.386354$

$\begin{array}{llll}1500 & 0015 \quad 190305.46-96696.778-93608.682 & 212.898748-107.02614-105.87261\end{array}$

$2000 \quad 002187268.713-64268.86-122999.85209 .252525-70.644247-138.60828$

$2500 \quad 0025177597.878-29564.186-148033.69198 .193416-31.759737-166.43368$

$3000 \quad 003161635.5496187 .81457-167823.36180 .1132118 .24987203-188.36308$

$3500 \quad 0035139947.19941720 .6104-181667.81155 .65240647 .9672245-203.61963$

$4000 \quad$ 004 113301.151 75775.4316-189076.58 125.67753985.9853126-211.66285

$\begin{array}{lllll}4500 & 0045 \quad 82641.352 & 107145.872-189787.2291 .2504818 & 120.957328-212.20781\end{array}$

$5000 \quad$ 005 $49053.942134720 .615-183774.5653 .5908267151 .644374-205.2352$

$5500 \quad 005513728.7731157522 .812-171251.5914 .032696176 .959336-190.99203$

$6000 \quad$ 006 -22082.744 174744.684-152661.94-26.022553 196.005429-169.98288

$\begin{array}{lllll}6500 & 0065 & -57111.969 & 185776.14-128664.17-65.155941 & 208.107933-142.95199\end{array}$

$7000 \quad$ 007 -90117.976 190226.384-100108.41-101.98115 212.838108-110.85696

$7500 \quad 0075-119931.51187937 .765-68006.257-135.19362210 .028389-74.834769$

$8000 \quad .008-145496.41178991 .355-33494.949-163.61679199 .778306-36.161516$

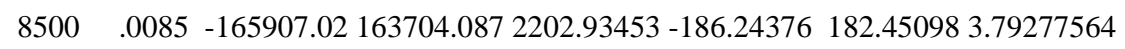

$9000 \quad 009-180440.3142617 .52137822 .7778-202.27294158 .66023643 .612707$

$9500 \quad 0095-188581.39116478 .65772102 .7305-211.13651129 .24887281 .8876369$

$10000 \quad$.01 - 190041.89 86213.4779 $103828.408-212.5204695 .258805117 .261655$

$10500 \quad$.0105-184770.06 52894.1451 131875.912-206.3757757.8941459 148.481622

$11000 \quad 011-172952.6617701 .0109155251 .646-192.9201118 .478559174 .441553$

$11500 \quad 0115-155008.32-18119.19173127 .513-172.63016-21.591641194 .221805$

$12000 \quad 012-131572.74-53297.512184870 .252-146.22471-60.896946207 .121653$

$12500 \quad 0125-103476.13-86587.742 \quad 190063.87-114.63917-98.044946212 .684113$

$13000 \quad 013-71713.825-116810.56 \quad 188524.38-78.992476-131.71966210 .712133$

$13500 \quad 0135-37411.021-142895.3180306 .321-40.547438-160.72813201 .275571$

$\begin{array}{lllllll}14000 \quad 014 & -1782.9135-163917.91 & 165700.82 & -66598701-184.04273 & 184.70872\end{array}$

$14500 \quad 014533908.3549-179133.64145225 .28539 .2390554-200.83753161 .598471$

$15000 \quad$ 015 68398.4025-188003.47 119605.072 $77.7540364-210.51755132 .763516$

$15500 \quad 0155100465.402-190213.1989747 .7896113 .514543-212.7398999 .2253478$

$16000 \quad 016128973.365-185684.5156711 .1469145 .253739-207.4258162 .1720717$

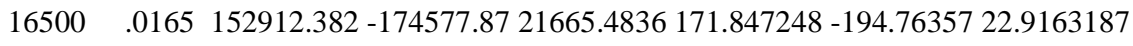

$17000 \quad 017 \quad 171434.401-157286.71-14147.69192 .352983-175.20173-17.151256$

$17500 \quad 0175183883.272-134423.6-49459.675206 .044519-149.43328-56.611238$

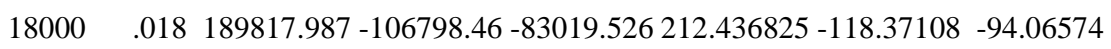

$\begin{array}{llll}18500 & 0185 & 189028.304-75389.935-113638.37 & 211.303448-83.115533-128.18792\end{array}$

$19000 \quad 019181542.199-41310.683-140231.52202 .684544-44.915573-157.76897$

$19500 \quad 0195167624.871-5767.9785-161856.89186 .885437-5.1244557-181.76098$

$20000 \quad$ 02 $147769.34929979 .0584-177748.41164 .46582234 .8481959-199.31402$

$20500 \quad 02059330.5873612027 .2282$-21357.816 661.622054 283.435429-945.05748

$21000 \quad$ 021 6209.38893 15030.7055-21240.094 770.656648 $537.870135-1308.5268$

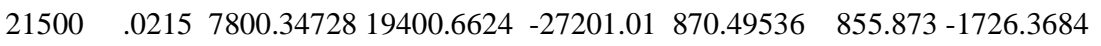


22000

22500

23000

23500

24000

24500

25000

25500

26000

26500

27000

27500

28000

28500

29000

29500

30000

30500

31000

31500

32000

32500

33000

33500

34000

34500

35000

35500

36000

36500

37000

37500

38000

38500

39000

39500

40000

40500

41000

41500

42000

42500
$.0228726 .4118423545 .4361-32271.848911 .6162531235 .84876-2147.465$ $\begin{array}{llllll}.0225 & -179890.03-9816.3049 & 189706.331774 .062422 & 1658.2197 & -2432.2821\end{array}$ $.0233907 .0429928950 .1351-32857.178774 .0376152095 .44288$-2869.4805 $.0235-10870.47228928 .8135-18058.342617 .4660972594 .67277-3212.1389$ $.024-14247.78827974 .0798-13726.292223 .8581843054 .44535-3278.3035$ $.0245-24840.4126399 .7848-1559.375-102.691763509 .59933-3406.9076$ $.02544448 .783439071 .1291-83519.913-478.696813921 .45318-3442.7564$ $.0255-29641.25219917 .95359723 .29803-1163.52414238 .06455-3074.5404$ $.026-15351.76719952 .8025-4601.0356-1591.64174485 .86666-2894.2249$ $\begin{array}{lllll}.0265 & -27710.35 & 16326.1378 & 11384.2122 & -1889.018 \\ 4720.24029 & -2831.2223\end{array}$ $.027-22932.3212548 .570910383 .7496-2391.31884842 .44321-2451.1244$ $.0275-124563.75-11953.138136516 .884-2860.81684875 .14451-2014.3277$ $.028-30789.417 \quad 1822.659128966 .7584-3163.43914812 .03676-1648.5977$ $.0285-27835.885-4663.086732498 .9719-3624.58664630 .73535-1006.1488$ $.029-6050.0099-6234.201812284 .2117-3899.78514356 .42087-456.63579$ $.0295-21195.925-12094.73533290 .6599-3921.18584063 .14204-141.95624$ $.0331368 .9771-6732.2872-24636.69-4018.30313672 .72741345 .575691$ $.03053582 .06545-17529.20313947 .1372-4115.62373210 .54362905 .080108$ $.0315723 .46874-18526.97112803 .5027-3872.84482754 .841981118 .00278$ $.0315-12768.594-24920.44537689 .0383-3721.72332262 .450411459 .27285$ $.03212732 .2014-22755.79310023 .5915-3525.03321722 .336691802 .69654$ $.0325-29625.649-29979.13759604 .7857-3060.91721243 .175811817 .74139$ $.0334805 .21614-21932.73817127 .5221-2577.6978796 .7225331780 .97526$ $.033514826 .2862-19977.5365151 .24936-2226.7582363 .1464121863 .61179$ $.03432719 .3766-13859.4-18859.977-1713.25196 .315952281706 .9359$ .0345 12927.0199-14348.136 1421.11651-1205.2109-264.34336 1469.55422 $.03548960 .3247-4400.3545-44559.97-763.68247-492.043121255 .72558$ .0355 36290.5943-2295.0225 -33995.572 -275.2628 -612.38877 887.651565 $.03623709 .41011199 .06798-24908.478237 .840364-611.7194373 .879039$ $.03655409 .374881845 .5544-7254.9293552 .706779-548.27634-4.4304374$ $.03720154 .572210452 .1762-30606.748918 .454257$-390.31532 -528.13894 $.03751096 .3668312502 .6668-13599.0341206 .9278-126.34961-1080.5782$

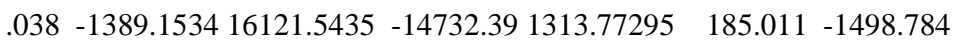
.0385 3359.23052 20780.6047-24139.835 1343.15773 547.694478 - 1890.8522 $.03910163 .625626348 .1156-36511.741 \quad 1358.1922982 .138712-2340.3309$ .0395 -3223.9218 26291.5214 -23067.6 1211.18534 1447.00461-2658.1899 $\begin{array}{lllllll}.04 & 4605.45016 & 30036.82 & -34642.27 & 1020.40001 & 1923.07894 & -2943.479\end{array}$ $.0405-13206.50127746 .5336-14540.032727 .8293312405 .01396-3132.8433$ $.041-14110.29427177 .0167-13066.723335 .8498492860 .66045-3196.5103$ $.0415-28654.82523385 .29765269 .52721-79.8714033277 .87227-3198.0009$ $\begin{array}{lllllll}.042 & -26307.9 & 23170.2687 & 3137.631 & -452.81184 & 3664.59281 & -3211.781\end{array}$ $.0425-17953.14621587 .8986-3634.7528-970.299083972 .7823-3002.4832$ 


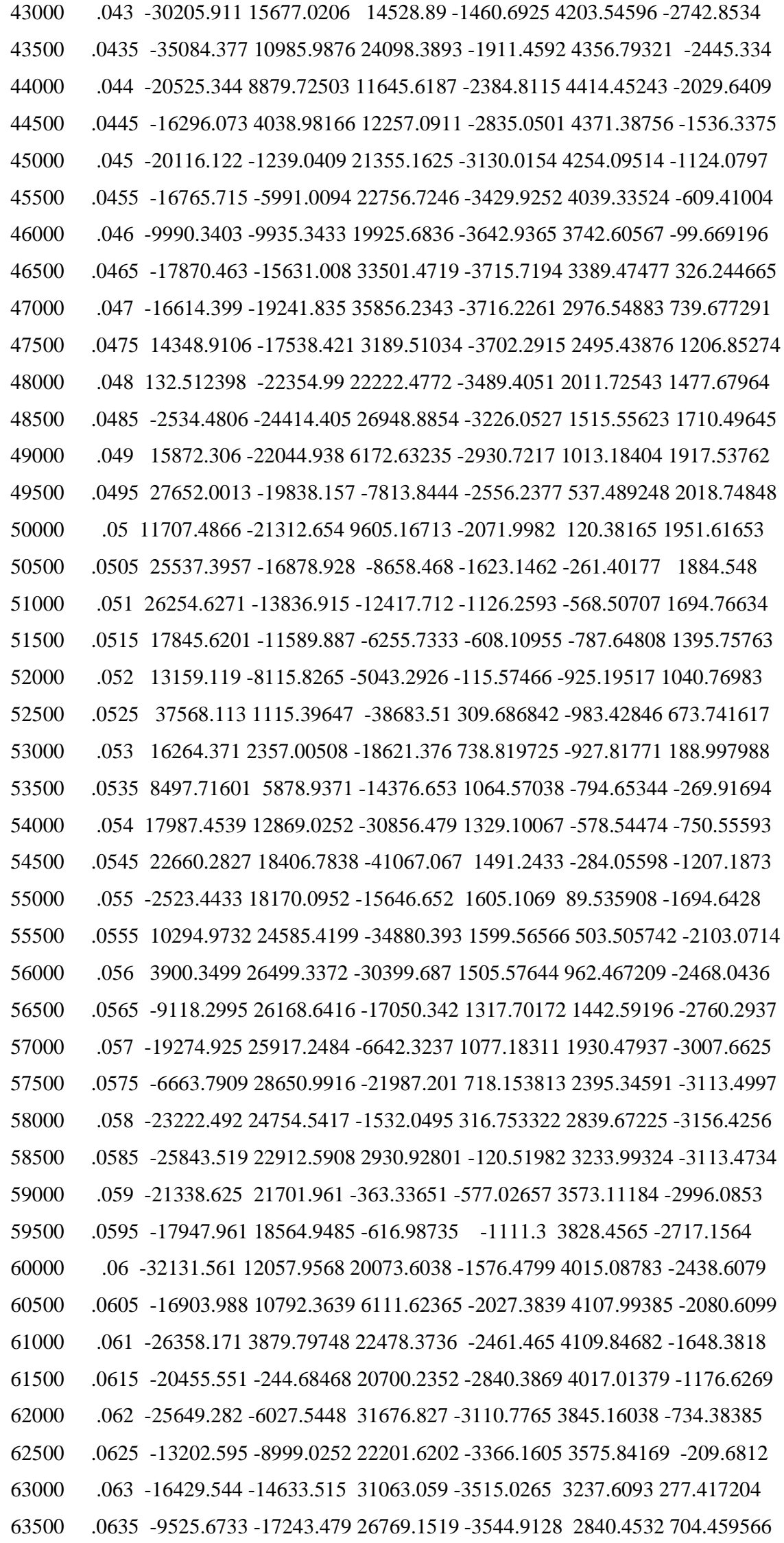


6400

64500

65000

65500

66000

66500

67000

67500

68000

68500

69000

69500

70000

70500

71000

71500

72000

72500

73000

73500

74000

74500

75000

75500

76000

76500

77000

77500

78000

78500

79000

79500

80000

80500

81000

81500

82000

82500

83000

83500

84000

84500
$.064-10088.624-20979.36631067 .9894-3499.1862394 .613351104 .57262$

$.0645 \quad 6237.8521-21240.24615002 .3935-3405.34191903 .202081502 .13977$ .0652039 .46553 -23763.864 21724.3983 -3154.69621412.60071 1742.09553 $.065516951 .2349-21846.864895 .62537-2849.6884917 .624911932 .06349$ .066 13206.9367-22948.748 9741.81108 -2492.277438.945884 2053.33107 .0665 18091.0355-21186.766 3095.7307-2066.7433-4.2554899 2070.99879 $.06716327 .2119-19438.9293111 .7172$-1574.2879-387.75474 1962.04268 $.067522810 .7657-15800.508-7010.2576-1105.4115-720.183831825 .59537$ $.068 \quad 19265.2-13119.103-6146.0972-605.59668-970.726671576 .32335$ $.068522793 .0575-8123.3423-14669.715-106.70291-1134.76221241 .46515$ $.06923184 .5206-3457.6223-19726.898351 .376147-1210.9811859 .604977$ $.069522698 .00631201 .63261-23899.639750 .500333-1201.4719450 .971577$ $.0716956 .27955485 .5039-22441.7831128 .19999-1088.0071-40.192858$ .0705 20741.6863 11339.0431-32080.729 1409.68158-894.03477-515.64681 $.07112435 .133314695 .1366-27130.271620 .4119-617.78704-1002.6249$ .0715 5949.86723 $18025.962-23975.8291739 .1469-271.52535$-1467.6216 .072 $2193.9007121570 .7558-23764.6571781 .56552138 .510713-1920.0762$ .0725 -975.86748 24256.0251-23280.158 1707.75132 583.835369-2291.5867 $.073-8953.437925321 .5674-16368.1291555 .001181061 .04221-2616.0434$ .0735 -9162.2775 26999.3993-17837.122 1311.32905 1546.79764-2858.1267 $.074-13809.06726945 .8674-13136.8999 .0199772027 .04419-3026.0642$ $.0745-18370.09525809 .6548-7439.5597 \quad 611.68062479 .74632-3091.4269$ .075 -20277.76124275.4699-3997.7091 177.8866812895.77612-3073.6628 $.0755-20733.24122032 .7059-1299.4653-297.268873252 .72443-2955.4556$ .076 -24624.694 18484.0125 6140.68118 -772.07568 3546.28709-2774.2114 $.0765-26537.3114273 .054412264 .2556-1271.66213756 .40264-2484.7405$ $.077-24818.41510398 .860314419 .5548-1737.12973884 .38368$-2147.254 .0775 -25677.5875460.44959 20217.1373-2175.3231 3918.64364-1743.3205 $.078-25774.765358 .36236925416 .4028-2566.87473861 .39497-1294.5203$ .0785 -18388.403 -3530.089 21918.4916-2906.1461 $3710.00872-803.8626$ $.079-16327.732-8144.185924471 .9178-3152.66563477 .73708-325.07149$ $.0795-15062.163-12825.91727888 .0793-3327.81643164 .64951163 .166889$ .08 -7340.6305-15892.987 23233.6177-3418.4574 2784.53844 633.918937 $.0805-4103.324-19180.28223283 .6065-3409.20742351 .95351057 .25393$ $\begin{array}{llllll}.081 & -746.85469 & -21563.322310 .1547 & -3294.9461884 .93477 & 1410.01126\end{array}$ .08155112 .37817 -22933.97 $17821.5921-3115.46471389 .998351725 .46639$ $.0828154 .13263-23749.11615594 .9835$-2837.9071 894.5808291943 .32628 .0825 $12262.5381-23349.42711086 .889-2482.9713413 .0669022069 .90437$ $.08315067 .3139-22266.1047198 .79022-2074.8737-40.281283 \quad 2115.155$ .0835 21972.2855-19585.664-2386.6216-1630.4016-450.66372 2081.06528 $.08420997 .946-17324.476-3673.4698-1139.4151-796.279851935 .69497$ .0845 18699.8635-14583.698-4116.1652-640.74141-1072.0976 1712.83899 
85000

85500

86000

86500

87000

87500

88000

88500

89000

89500

90000

90500

91000

91500

92000

92500

93000

93500

94000

94500

95000

95500

96000

96500

97000

97500

98000

98500

99000

99500

100000

100500

101000

101500

102000

102500

103000

103500

104000

104500

105000

105500
$.08526114 .2244-9270.6244 \quad-16843.6-156.22652-1267.98841424 .21494$

$.0855 \quad 22905.204-5473.1628-17432.041313 .628326-1373.19441059 .56609$ $.08620598 .5955-934.7136-19663.882753 .835741-1384.5424630 .706677$

$.086520620 .54074146 .36747-24766.9081127 .75033-1307.4034179 .653084$ $.08723434 .77749916 .7936-33351.5711440 .94196-1138.1834-302.75855$ $.087511940 .786812735 .0624-24675.8491681 .32439-884.66683-796.65755$ $.0889595 .578517147 .0466-26742.6251834 .40333-558.20986-1276.1935$ $.08857696 .7383220950 .6446-28647.3831884 .92495-171.35075-1713.5742$ $.089683 .3730423254 .6557-23938.0291852 .1691266 .839234-2119.0083$ $.0895-6787.986224740 .1745-17952.1881729 .84646737 .326066-2467.1725$ $.09-6299.754126882 .9425-20583.188 \quad 1509.66881222 .03594-2731.7047$ $.0905-12479.83826699 .7528-14219.9151213 .982481707 .00721-2920.9897$ $.091-17376.71125977 .0491-8600.3386857 .1855842174 .54332-3031.7289$ $.0915-19439.97224750 .3445-5310.3723 \quad 438.33912605 .27193-3043.611$ $.092-18761.80623044 .4847-4282.6784-25.8373592985 .34255-2959.5052$ .0925-27228.072 $18706.72238521 .34962-505.71323302 .69674-2796.9835$ $.093-25130.93415807 .49439323 .4395-991.770433544 .06681-2552.2964$ .0935-25100.216 $11567.153413533 .063-1480.41193699 .06164-2218.6497$ $.094-25145.5736885 .5419818260 .0306-1936.04773765 .20309-1829.1554$ $.0945-24929.7251998 .8774322930 .8481-2341.40733739 .96323-1398.5559$ .095 -19559.979-2143.6956 21703.6748 -2699.8713 3620.75219 -920.88091 $.0955-17902.009-7094.80624996 .8149-2983.91133415 .00571-431.09443$ $.096-14717.069-11383.67426100 .7435-3181.50733129 .7610351 .7462992$ $.0965-9993.4506-15085.43325078 .8834-3294.47882773 .35499521 .123776$ $.097-4410.9349-18203.65422614 .5893-3322.54312357 .46144965 .08165$ $.0975-3943.9496-21530.47725474 .4263-3245.19281900 .812381344 .38044$ $.0983375 .13921-22636.73119261 .5922-3080.32221415 .853741664 .46848$ .0985 $6728.50728-23837.1817108 .6728-2838.4919919 .0778251919 .4141$ $.09911292 .0583-23777.10112485 .0423-2517.4826429 .8215282087 .66108$ $.099515018 .8004-22794.7927775 .99186-2124.4731-33.3755822157 .8487$ $0.119059 .6049-20867.1061807 .50131-1689.6014-458.376662147 .97808$ $.100522549 .4576-18165.179-4384.2789-1214.9196-826.680332041 .59989$ $.10123380 .3329-15019.436-8360.8965-719.49839-1126.11671845 .6151$ $101524312.8872-11139.342-13173.545-222.30632-1346.67071568 .97701$ $.10224379 .9552-6895.2238-17484.731252 .714985-1482.17961229 .46462$ $102518982.8879-3154.9846-15827.903705 .341989-1523.7406818 .398629$ $.10320508 .17952262 .40448-22770.584 \quad 1103.3615-1474.4191371 .057586$ $103516662.20026668 .9703-23331.1711438 .22983-1334.4714-103.75842$ $.10413646 .141711178 .2429-24824.3851696 .9801-1109.2252-587.75486$ $104510603.3624 \quad 15527.86-26131.2221877 .85325-804.94696-1072.9063$ $.1059177 .1867719742 .4441-28919.6311962 .89979-435.95842-1526.9414$ $.10552566 .4396222300 .8217-24867.2611959 .76146-12.049661-1947.7118$ 


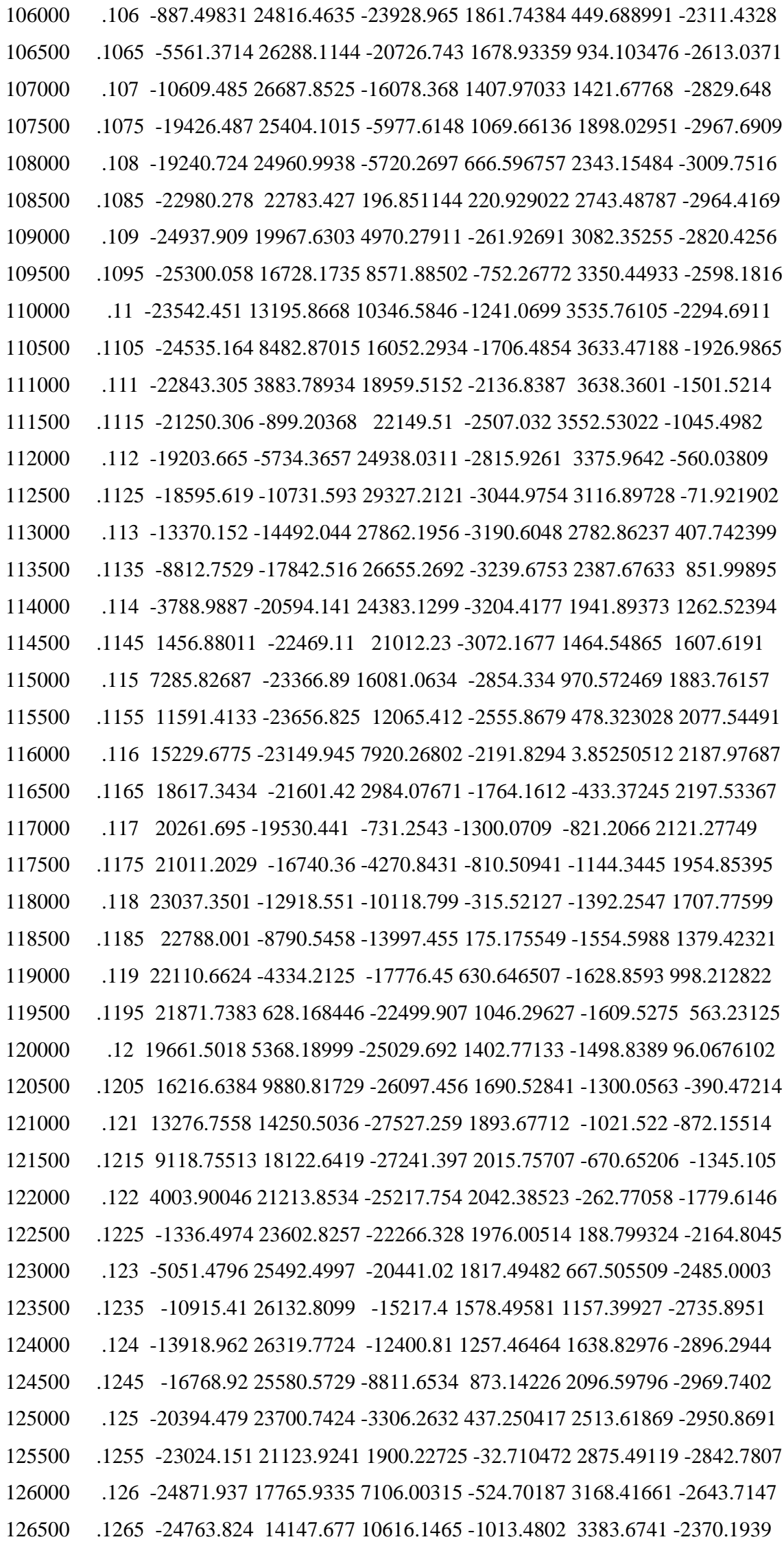




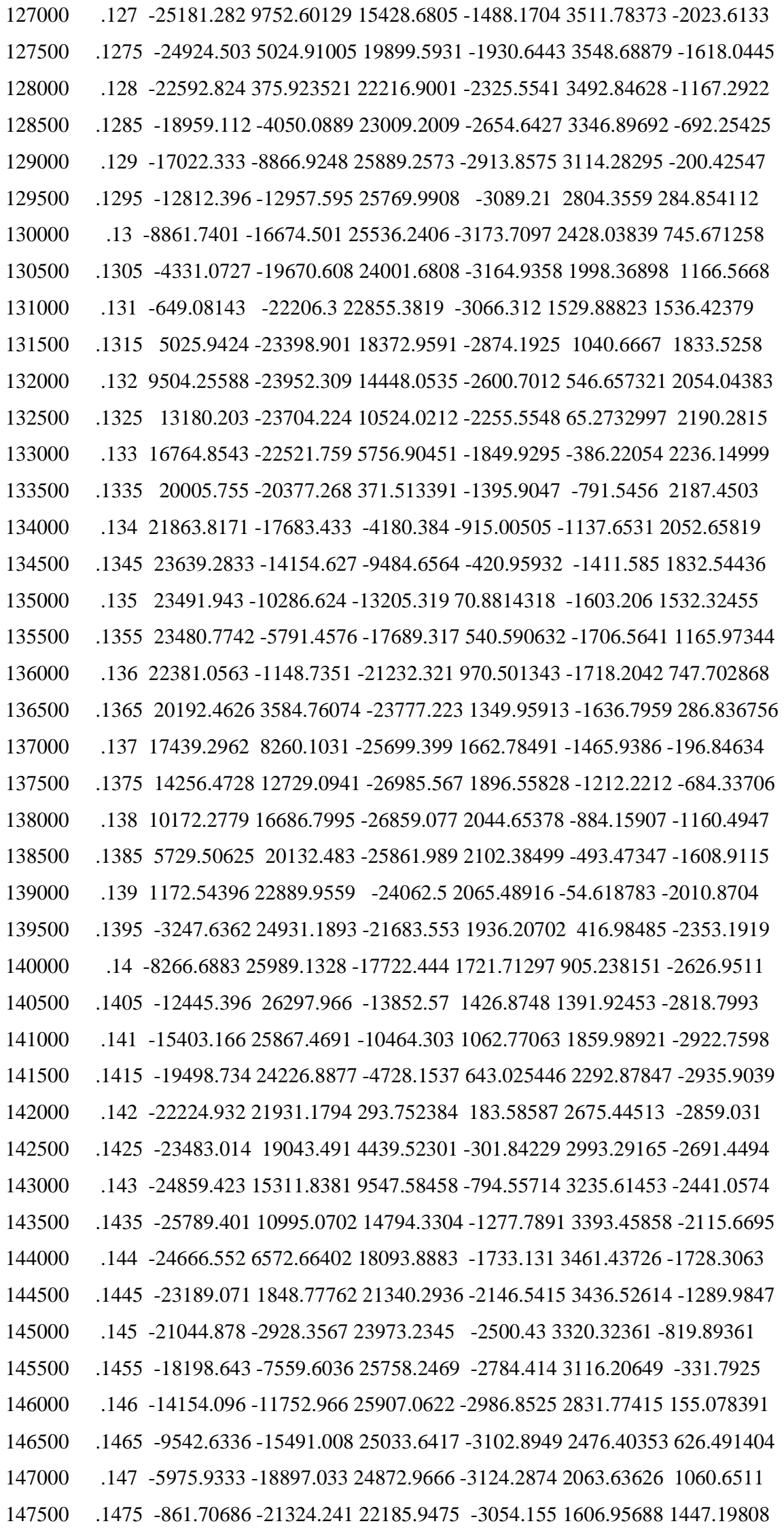




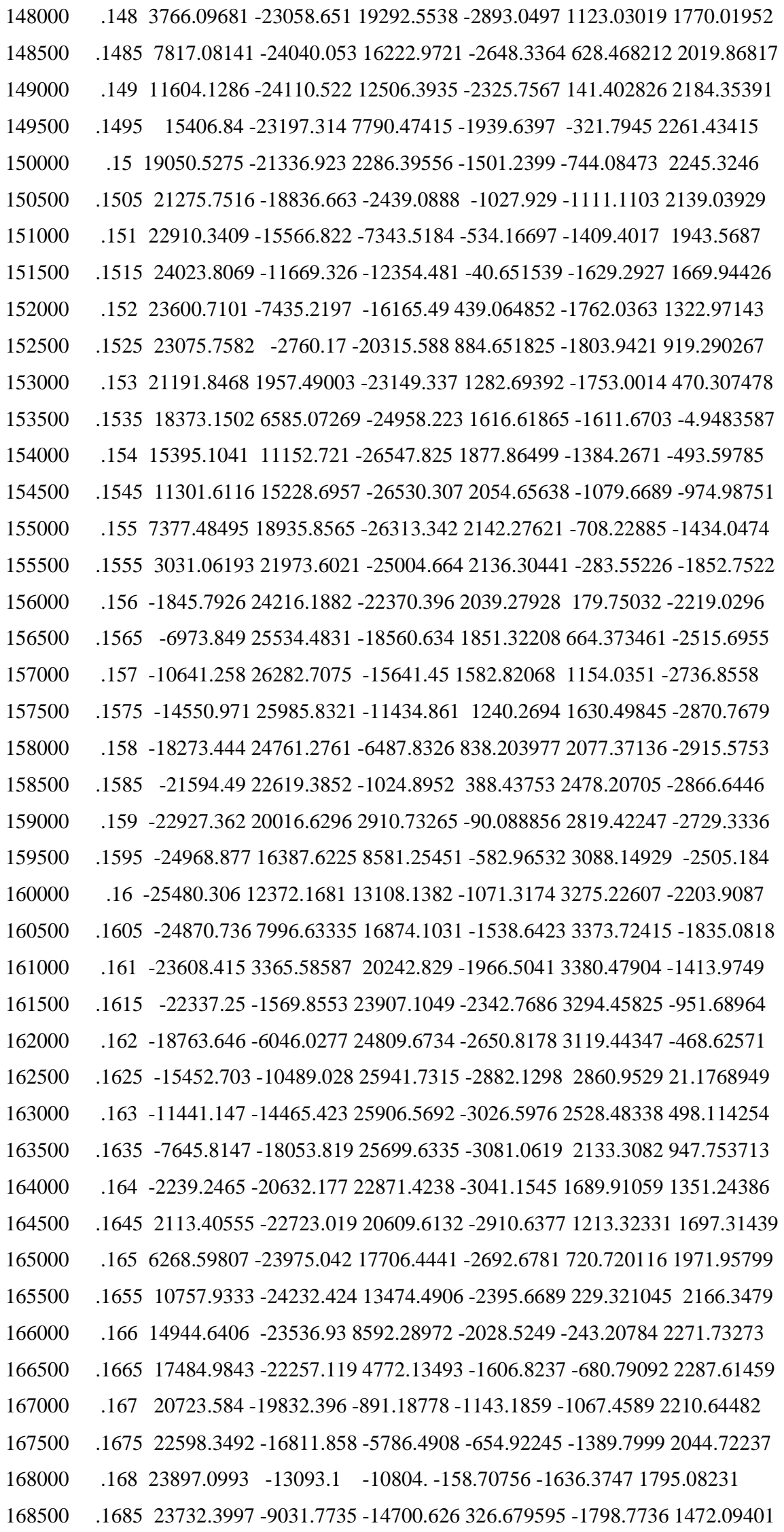




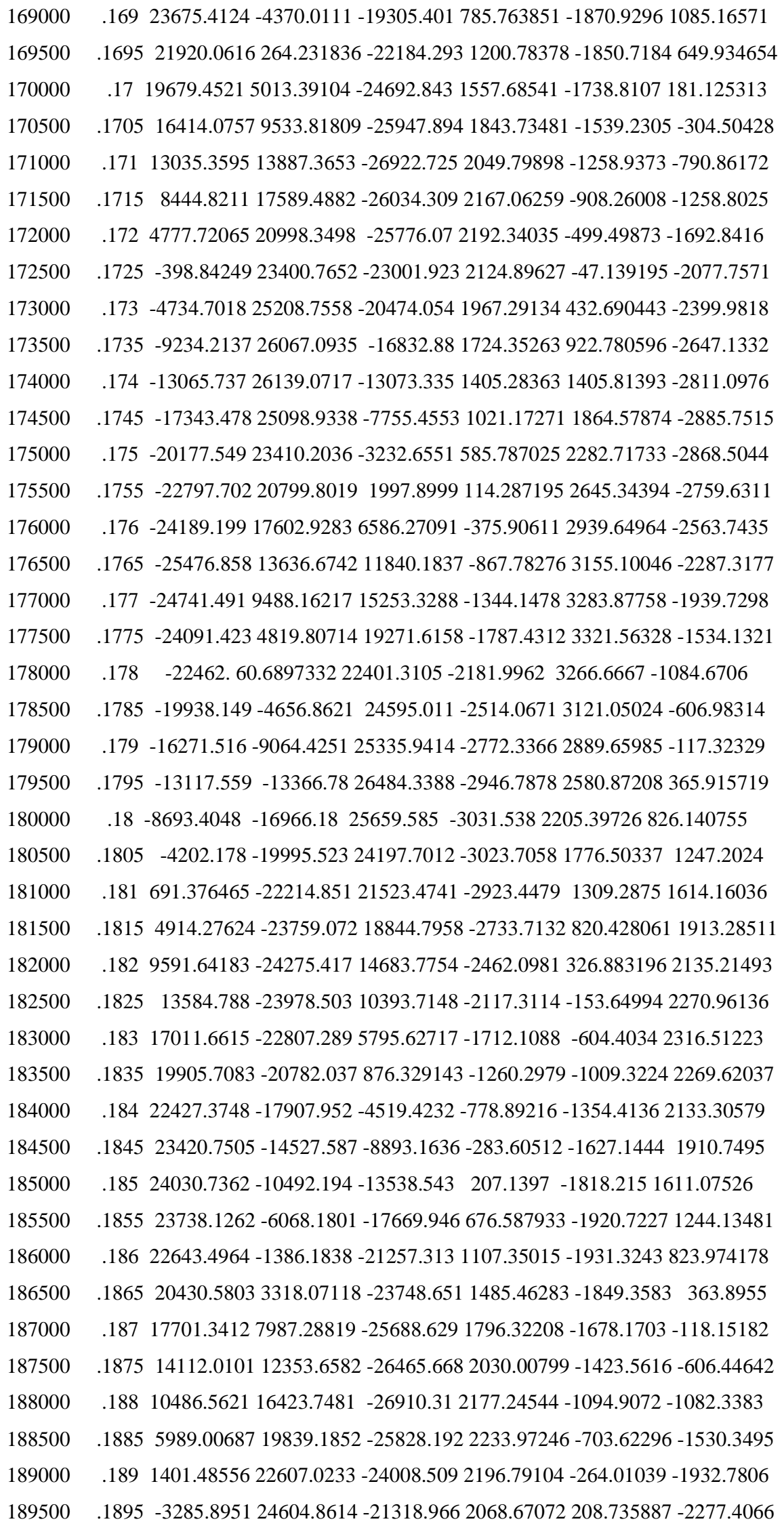




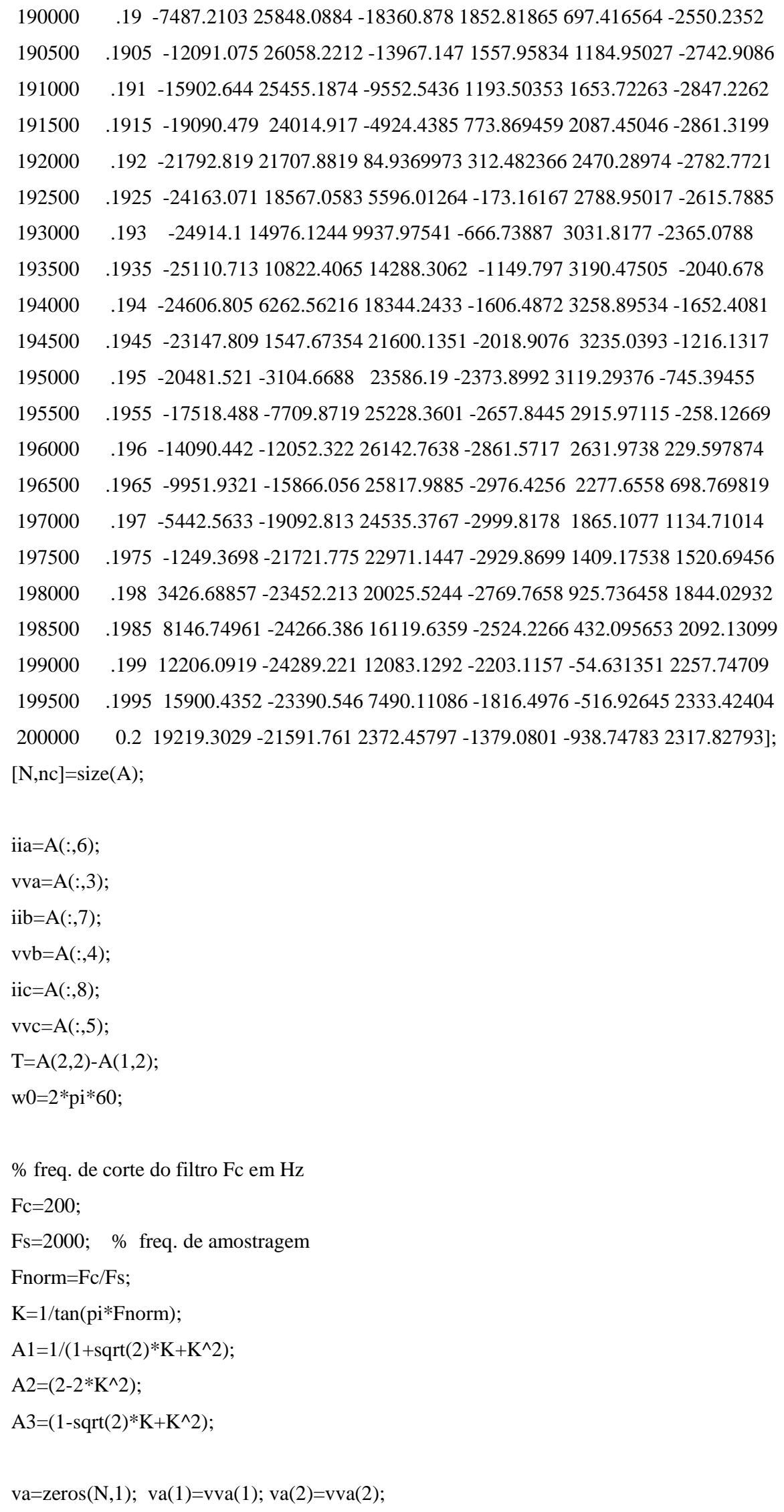




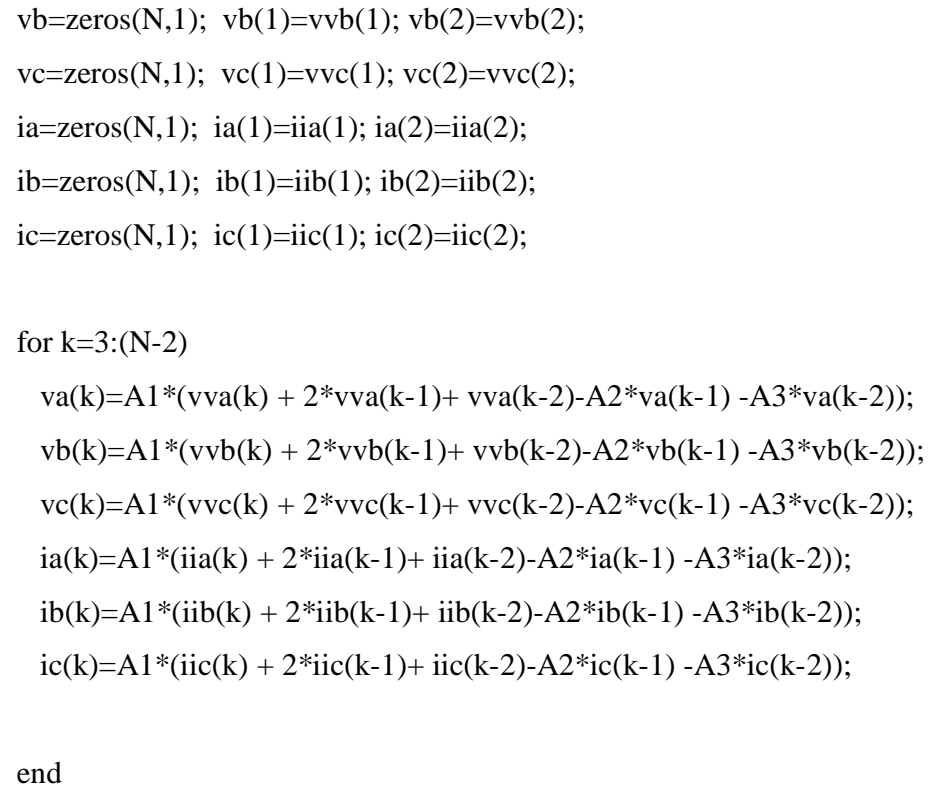

